\title{
Creep of Two-Phase Microstructures for Microelectronic Applications
}

\author{
Heidi Linch Reynolds \\ Ph.D. Dissertation \\ Department of Materials Science and Mineral Engineering \\ University of California, Berkeley \\ and \\ Center for Advanced Materials \\ Materials Science Division \\ Lawrence Berkeley National Laboratory \\ 1 Cyclotron Road \\ Berkeley, CA 94720
}

December 1998

This work was supported by the Director, Office of Energy Research, Office of

Basic Energy Sciences, Materials Science Division, of the U.S. Department of Energy, under Contract No. DE-AC03-76SF00098. 


\section{DISCLAIMER}

This report was prepared as an account of work sponsored by an agency of the United States Government. Neither the United States Government nor any agency thereof, nor any of their employees, make any warranty, express or implied, or assumes any legal liability or responsibility for the accuracy, completeness, or usefulness of any information, apparatus, product, or process disclosed, or represents that its use would not infringe privately owned rights. Reference herein to any specific commercial product, process, or service by trade name, trademark, manufacturer, or otherwise does not necessarily constitute or imply its endorsement, recommendation, or favoring by the United States Government or any agency thereof. The views and opinions of authors expressed herein do not necessarily state or reflect those of the United States Government or any agency thereof. 


\section{DISCLAIMER}

Portions of this document may be illegible in electronic image products. Images are produced from the best available original document. 
Creep of Two-Phase Microstructures for Microelectronic Applications

by

Heidi Linch Reynolds

B. S. (Colorado School of Mines) 1986

M.S. (University of California, Berkeley) 1993

A dissertation submitted in partial satisfaction of the requirements for the degree of

Doctor of Philosophy

in

Engineering-Materials Science

and Mineral Engineering

in the

GRADUATE DIVISION

of the

UNIVERSITY of CALIFORNIA at BERKELEY

Committe in charge:

Professor J. W. Morris, Jr., Chair

Professor R. O. Ritchie

Professor L. Pruitt

Fall 1998 
Creep of Two-Phase Microstructures for Microelectronic Applications

Copyright (C) 1998

by

Heidi Linch Reynolds

The U.S. Department of Energy has the right to use this document

for any purpose whatsoever including the right to reproduce all or any part thereof. 


\author{
ABSTRACT \\ Creep of Two-Phase Microstructures for Microelectronic Applications \\ by \\ Heidi Linch Reynolds \\ Doctor of Philosophy in Engineering-Materials Science and \\ Mineral Engineering \\ - University of California, Berkeley \\ Professor J. W. Morris, Jr., Chair
}

The mechanical properties of low-melting temperature alloys are highly influenced by their creep behavior. This study investigates the dominant mechanisms that control creep behavior of two-phase, low-melting temperature alloys as a function of microstructure. The alloy systems selected for study were $\mathrm{In}-\mathrm{Ag}$ and $\mathrm{Sn}-\mathrm{Bi}$ because their eutectic compositions represent distinctly different microstructures. 'The In-Ag eutectic contains a discontinuous phase while the Sn-Bi eutectic consists of two continuous phases. In addition, this work generates useful engineering data on $\mathrm{Pb}$-free alloys with a joint specimen geometry that simulates microstructures found in microelectronic applications. The use of joint test specimens allows for observations regarding the practical attainability of superplastic microstructures in real solder joints by varying the cooling rate. Steady-state creep properties of In-Ag eutectic, Sn-Bi eutectic, $\mathrm{Sn}-\mathrm{xBi}$ solid-solution and pure Bi joints have been measured using constant load tests at temperatures ranging from $0^{\circ} \mathrm{C}$ to $90^{\circ} \mathrm{C}$. Constitutive equations are 
derived to describe the steady-state creep behavior for In-Ag eutectic solder joints and $\mathrm{Sn}-\mathrm{xBi}$ solid-solution joints. The data are well represented by an equation of the form proposed by Dorn: a power-law equation applies to each independent creep mechanism. Rate-controlling creep mechanisms, as a function of applied shear stress, test temperature, and joint microstructure, are discussed. Literature data on the steady-state creep properties of Sn-Bi eutectic are reviewed and compared with the $\mathrm{Sn}-\mathrm{xBi}$ solid-solution and pure Bi joint data measured in the current study. The role of constituent phases in controlling eutectic creep behavior is discussed for both alloy systems. In general, for continuous, two-phase microstructures, where each phase exhibits significantly different creep behavior, the harder or more creep resistant phase will dominate the creep behavior in a lamellar microstructure. If a microstructure contains a hard, discontinuous phase, the creep behavior of this phase is not important.

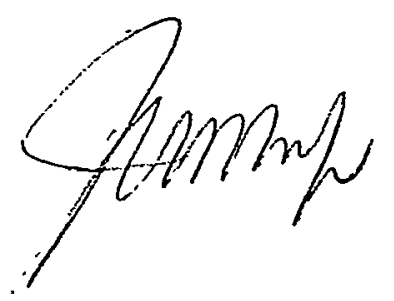




\section{Dedicated to}

the Master designer and builder, God, Almighty

and my Savior, Jesus Christ.

I am in awe of Your creation. 


\section{TABLE OF CONTENTS}

1. INTRODUCTION

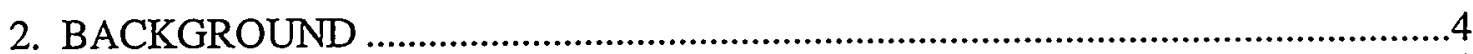

2.1. Eutectic Mierostructures .............................................................................

2.2. Phase Diagrams and Constituent Eutectic Phases .........................................5

2.2.1. In-Ag Eutectic ...................................................................................5

2.2.2. Sn-Bi Eutectic ............................................................................

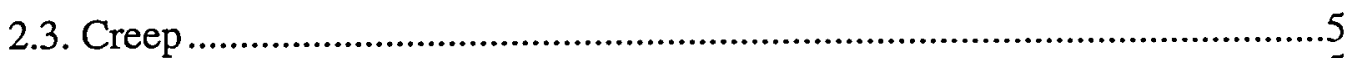

2.3.1. Creep Testing ................................................................................

2.3.2. Power-Law Creep …………............................................................

2.3.3. Power-Law Breakdown ...............................................................

2.3.4. Grain-Boundary Sliding / Superplasticity ....................................

2.3.5. Constitutive Creep Equations for Eutectic Materials ......................9

2.4. Literature Review ....................................................................................10

2.4.1. Two-Phase Creep Models .........................................................10

2.4.1.1. McDanels, Signorelli, and Weeton (1967) .....................10

2.4.1.2. Choi, Matlock, and Olsen (1990) .................................11

2.4.1.3. Ravichandran and Seetharaman (1993) .........................12

2.4.1.4. Tanaka, Sakaki, and lizuka (1991) .................................13

2.4.2. Creep of Sn-Bi Eutectic ...............................................................15

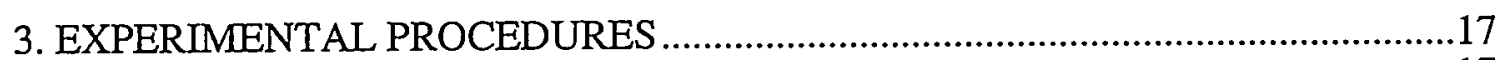

3.1 Specimen Preparation ...................................................................................17

3.1.1. General Procedures .........................................................................17

3.1.2. In-Ag Eutectic Specimens ......................................................18

3.1.3. Sn-Bi Solid Solution Specimens....................................................19

3.1.4. Pure Bi Specimens .......................................................................20

3.1.5. Sn-Bi Eutectic Specimens............................................................20

3.2 Creep Testing Procedures ..........................................................................21

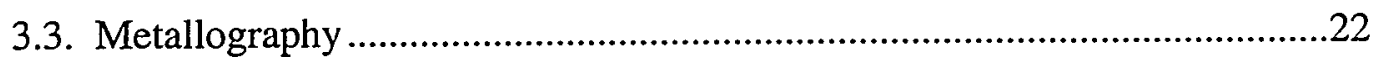

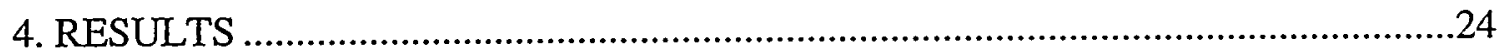

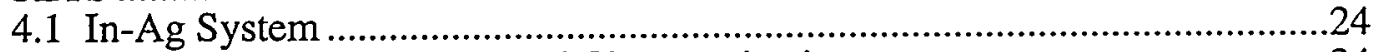

4.1.1. Metallography and Characterization .............................................24

4.1.2. Creep Behavior of In-Ag Eutectic Joints ......................................24

4.1.2.1. Stress Exponents .............................................................26

4.1.2.2. Activation Energies ........................................................26

4.1.2.3. Creep Mechanisms .......................................................2

4.1.2.4. Constitutive Equations ...................................................28 
4. RESULTS (continued)

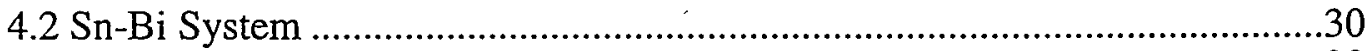

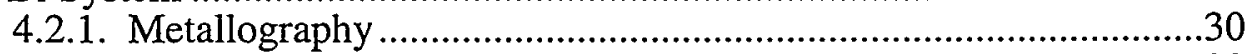

4.2.2. Creep Behavior of Sn-Bi Solid Solution Joints .............................30

4.2.2.1. Stress Exponents ...............................................................31

4.2.2.2. Activation Energies .......................................................32

4.2.2.3. Creep Mechanisms........................................................33

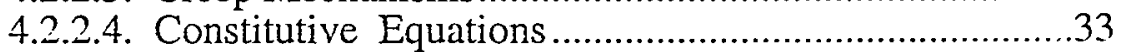

4.2.2.5. Role of Bi Precipitates ...................................................34

4.2.3. Creep Behavior of Pure Bi Joints ………………………............35

4.2.4. Creep Behavior of Sn-Bi Eutectic Joints ........................................36

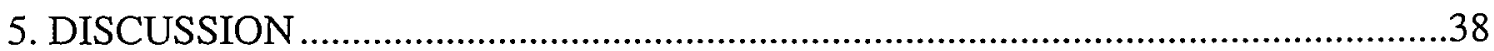

5.1. Role of Constituent Phases in Controlling Eutectic Creep Behavior ...........38

5.1.1. In-Ag System ...............................................................................38

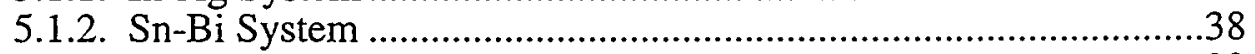

5.1.3. Continuous vs. Discontinuous Phases ...........................................39

5.2. Application of Two-Phase Creep Models from Literature ……...................40

5.3. Attainability of Superplastic Microstructures in Solder Joints .....................42

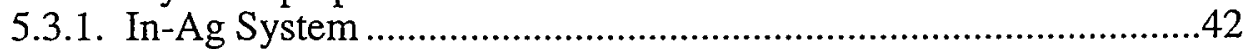

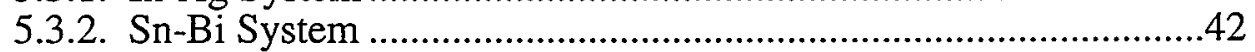

5.4. Alternative Constitutive Equations ...............................................................43

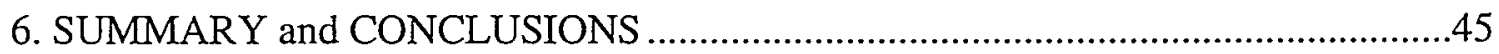

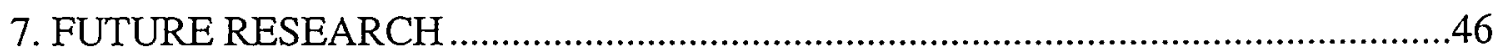

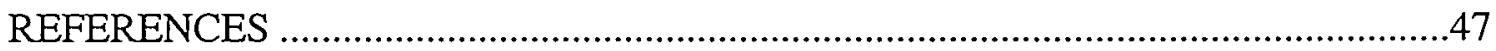

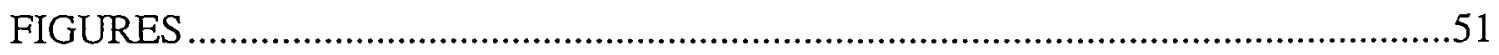

APPENDICES … -

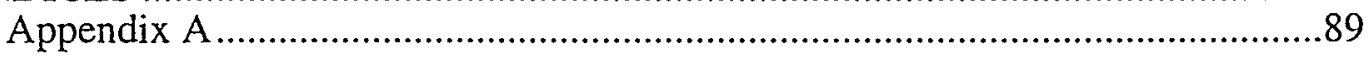

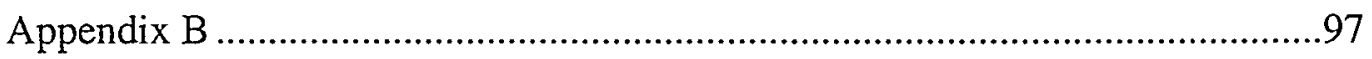




\section{LIST of FIGURES}

Figure 1.1. In-Ag phase diagram.[21]

Figure 2.2. Sn-Bi phase diagram.[21]

Figure 2.3. $\quad \mathrm{Pb}-\mathrm{Sn}$ phase diagram.[21]

Figure 2.4. Typical creep curve showing primary, steady-state, and tertiary creep regions.[6]

Figure 2.5. Schematic illustrating the behavior of multiple creep mechanisms.

Figure 2.6. Schematic illustrating the effect of grain (colony) size on the creep rate of a typical eutectic material.[30]

Figure 2.7. Creep behavior of Sn-Bi eutectic with "classic" (lamellar) microstructure. Different specimen geometries result in a range of cooling rates yet the microstructure and creep rate are nearly the same. (See Appendix B.)

Figure 3.1. Geometry of single shear joint specimen used for creep tests.[62] Solder Pad Dimensions: Area - 80mils x 45mils (2.03mm x 1.14mm) Thickness - 10 to $12 \mathrm{mils}(0.25$ to $0.30 \mathrm{~mm})$

Figure 3.2. Schematic of apparatus used for constant load creep testing:

Figure 3.3. Typical curves obtained for a sequential creep test.[6]

(a) strain vs. time, and (b) strain rate vs. time

Figure 4.1. Optical micrographs of In-Ag eutectic solder joint.[6] Etchant is $15 \% \mathrm{HNO}_{3}, 5 \% \mathrm{HCl}$, and $80 \% \mathrm{H}_{2} \mathrm{O}$.

The dark phase is In-rich matrix and the light phase is AgIn2 intermetallic. (a) Low Magnification (b) High Magnification

Figure 4.2. Creep behavior of In-Ag eutectic joints. Data shown are average values. [6]

Figure 4.3. Plot illustrating the determination of creep activation energy for In-Ag eutectic joints in the (a) high stress regime and (b) low stress regime.[6]

Figure 4.4. Plot showing the temperature-compensated creep rate as a function of reduced stress for In-Ag eutectic joints.[6] Assuming the following values for $\mathrm{Q}$, constitutive parameters $\mathrm{A}$ and $\mathrm{n}$ can be obtained.

(a) high stress regime, $\mathrm{Q}=0.84 \mathrm{eV}$ and

(b) low stress regime, $\mathrm{Q}=0.55 \mathrm{eV}$ 
Figure 4.5. Optical micrograph of Sn-Bi eutectic joint showing lamellar microstructure. Cooling Rate $-20^{\circ} \mathrm{C} / \mathrm{min}$.

(a) Low Magnification (b) High Magnification

Figure 4.6. Optical micrograph of Sn-Bi eutectic joint quenched in ice water, showing a finer, yet still lamellar microstructure.
(a) Low Magnification
(b) High Magnification

Figure 4.7. Optical micrograph of Sn-Bi eutectic bulk specimen after $50 \%$ reduction and annealing at $95^{\circ} \mathrm{C}$ for 1 hour. Microstructure is fine and equiaxed.

Figure 4.8. Creep behavior of Sn-2Bi solid solution joints.

Figure 4.9. Plot illustrating the determination of creep activation energy for Sn-2Bi solid solution joints in the(a)high stress regime and (b)low stress regime.

Figure 4.10. Plot showing the temperature-compensated creep rate as a function of reduced stress for $\mathrm{Sn}-2 \mathrm{Bi}$ solid solution joints. Assuming the following values for $\mathrm{Q}$, constitutive parameters $\mathrm{A}$ and $\mathrm{n}$ can be obtained.

(a) high stress regime, $Q=0.84 \mathrm{eV}$ and

(b) low stress regime, $\mathrm{Q}=1.0 \mathrm{eV}$

Figure 4.11. SEM micrograph of Sn-Bi eutectic. Bi precipitates can be seen within the Sn-rich phase.

Figure 4.12 Creep behavior of Sn-5Bi joints.

Figure 4.13 Comparison of creep behavior of $\mathrm{Sn}-2 \mathrm{Bi}$ and $\mathrm{Sn}-5 \mathrm{Bi}$ joints at $25^{\circ} \mathrm{C}$.

Figure 4.14. Comparison of creep behavior of $\mathrm{Sn}-2 \mathrm{Bi}, \mathrm{Sn}-5 \mathrm{Bi}, \mathrm{Sn}-10 \mathrm{Bi}$, and $\mathrm{Sn}-15 \mathrm{Bi}$ joints at $25^{\circ} \mathrm{C}$.

Figure 4.15. Creep behavior of quenched Sn-Bi eutectic joints compared with creep behavior of $\mathrm{Sn}-\mathrm{Bi}$ eutectic joints cooled at moderate rates.

Creep tests were conducted at room temperature.

Figure 5.1. Comparison of joint creep behavior for pure In and In-Ag, In-Sn, and Bi-Sn eutectics.[6] (See Appendix B.)

Figure 5.2. Comparison of joint creep behavior for $\mathrm{Sn}-2 \mathrm{Bi}$ solid solution and $\mathrm{Sn}-\mathrm{Bi}$ eutectic at $25^{\circ} \mathrm{C}$ and $75^{\circ} \mathrm{C}$.

Figure 5.3. Comparison of joint creep behavior for Sn-2Bi solid solution, $\mathrm{Sn}-\mathrm{Bi}$ eutectic and pure $\mathrm{Bi}$ at room temperature.

Figure 5.4. Steady-state creep rates of In-Ag eutectic joints compared with steady-state creep rates predicted from the continuum mechanics model proposed by Ravichandran and Seetharaman.

Figure 5.5. Steady-state creep rates of Sn-Bi eutectic joints compared with steady-state creep rates predicted from the continuum mechanics model proposed by Ravichandran and Seetharaman. 
Figure A.1. Schematics of the idealized microstructure of the composite (a) in two dimensions and (b) the unit cell.[37]

Figure A.2. Schematics of a bimaterial loaded in (a) parallel and (b) series.[37]

Figure A.3. Schematics of divisions of the unit cell into several elements, (a) and (b) representing the 3D model for particulate composites and (c) and (d) representing the $2 \mathrm{D}$ model for the transverse orientation of reinforced composites.[37]

Figure A.4. A schematic of a ductile layer between two rigid platens.[37]

Figure B.1. Double-lap shear specimen. $\left[9^{*}, 61^{*}\right]$ 


\section{LIST OF TABLES}

Table 4.1. List of Shear Moduli 


\section{ACKNOWLEDGMENTS}

I would like to express my appreciation to my research advisor, Professor J. W. Morris, Jr., for his support and guidance. Thanks also go to the members of my qualifying exam committee, Professor R. O. Ritchie, Dr. A. W. Thompson, Professor T. Sands, and Professor R. Jeanloz and to Professor R. O. Ritchie and Professor L. Pruitt for their time in reviewing this manuscript.

Thank you to Jane Fortado, who was always ready to lend a hand and kept me laughing. Jane, you added something special to the workplace. I would also like to express my appreciation to Jackie Gamble. Although the time has been brief, I am glad to have the opportunity to get to know you. It has been a pleasure. Thanks for everything. I must also express my gratitude to the many other Lawrence Berkeley National Lab employees who have assisted me through the years.

Thank you to all of my co-workers (past and present) in the Morris group. In particular, I would like to thank Dr. Ferdinand Bartels for his assistance and helpful discussions in initiating this research. Thanks to Robert Marks for his help in preparing test specimens and conducting creep tests. Special thanks also go to my office-mates . Pamela Kramer and Carlos Gonzalez and to Seung-Hyuk Kang for their suggestions and assistance.

Special thanks go to Ann Campbell and Judy Glazer, who have been both mentors and friends. To Mark, Steve, and others at Plan A Consulting - thanks for the many ways you have assisted me, including loaning me a computer when mine died just two weeks before the deadline!!!! 
I would like to say a very special thank you to my family and dear friends for their love and encouragement. I am continually blessed by those who believe not only in who I am, but more importantly, who I will become. (Phil. 1:6) Thank you. Words alone are not enough to thank my husband Michael, who truly knows what it means to share my dreams. Thank you for encouraging me and supporting me in the work that I enjoy. Finally, I would like to thank my son, Garrett, who has shown me that there is nothing more magical than one of his hugs.

This work was supported by the Director, Office of Energy Research, Office of Basic Energy Sciences, Materials Sciences Division of the U.S. Department of Energy under Contract No. DE-AC03-76SF00098. 


\section{INTRODUCTION}

Low melting temperature alloys (solders) are used extensively in the assembly of microelectronic components. These alloys often have eutectic compositions and exhibit classic two-phase microstructures. Approximately 20 years ago, the primary role of a solder joint was to provide an electrical connection. Current assembly technologies (surface mount) and finer pitch designs for electronic circuit boards now, however, require that solder joints support higher mechanical stresses as well as provide electrical connections. The primary failure mode of solder joints in service is thermal fatigue. The mechanical properties of eutectic solders, however, are highly influenced by their creep behavior due to their low melting points. Even at room temperature these alloys operate at temperatures greater than $0.5 \mathrm{~T} \mathrm{~m}$. Knowledge regarding the creep mechanisms of eutectic solders is critical in determining the creep-fatigue interaction leading to joint failure.

The most commonly used alloy is $\mathrm{Sn}-\mathrm{Pb}$ eutectic $(62 \mathrm{Sn}-38 \mathrm{~Pb}$ by wt.) which melts at $183^{\circ} \mathrm{C}$. The failure mechanism in thermal fatigue, creep, and isothermal fatigue in Sn$\mathrm{Pb}$ eutectic has been studied extensively.[1-5] In the past decade, however, there has been increasing interest in $\mathrm{Pb}$-free solders. This interest stems from several factors: 1) pending legislation on the regulation of $\mathrm{Pb}, 2)$ step soldering processes which require the use of solders with successively lower melting points and 3) the use of thermally sensitive components. The failure mechanisms of $\mathrm{Pb}$-free solders, unfortunately, have only recently come under investigation. In order for $\mathrm{Pb}$-free solders to be used reliably for electronic assembly, it is important to build an understanding of their creep mechanisms. 
The objective of this study is twofold: 1) to determine the dominant mechanisms that control creep behavior of two-phase, low-melting temperature alloys as a function of microstructure (phase continuity) and 2) to generate useful engineering data with a joint specimen geometry, simulating microstructures found in microelectronic applications. The alloy systems chosen for this study were In-Ag and Sn-Bi. These alloy systems were selected because of their $\mathrm{Pb}$-free compositions and the difference in their eutectic microstructures. The Sn-Bi eutectic microstructure consists of approximately equal volume fractions of each phase, so that each phase is continuous. The In-Ag eutectic microstructure contains a much larger volume fraction of the In-rich phase, such that the AgIn2 intermetallic phase is discontinuous. In addition, both phases within these two-phase alloys have significantly different creep properties. For the purposes of this study, only creep behavior will be considered.

To the author's knowledge, this is the first research study to measure and report the creep behavior of In-Ag eutectic.[6] While pure In $\left(T_{m}=156.6^{\circ} \mathrm{C}\right)$ is a soft solder which is used for electrical interconnections and die attachment, the addition of $3 \mathrm{wt} . \%$ Ag to In results in a eutectic composition with improved mechanical properties, yet an only slightly lower melting point $\left(141^{\circ} \mathrm{C}\right)$. In-Ag eutectic solder may replace pure In in certain applications, enhancing the mechanical performance without significantly changing the processing parameters. This study reports the steady-state creep properties of In-Ag eutectic solder joints and provides constitutive equations to describe this behavior.

$\mathrm{Sn}-\mathrm{Bi}$ eutectic has been considered a promising alternative to $\mathrm{Sn}-\mathrm{Pb}$ eutectic, therefore the literature contains a significant amount of information about this alloy.[7-12] A comprehensive review of this information has been published by Glazer.[13] The current work focuses on the creep behavior of the constituent phases; Sn-rich solid 
solution and pure $\mathrm{Bi}$. Although the literature contains some data on the creep behavior of bulk Sn-xBi solid solutions $[14,15,16]$, the present study is the first research to measure and report the creep behavior of $\mathrm{Sn}-\mathrm{xBi}$ joints. Constitutive equations are derived to describe this behavior and comparisons are made with $\mathrm{Sn}-\mathrm{Bi}$ eutectic (joint) creep data.

Preparing joint specimens is a fairly laborious task, especially in the case of In- $\mathrm{Ag}$ eutectic. In addition, small changes in microstructure and geometry can influence the creep rate, therefore, it is necessary to test a sufficiently large number of samples to obtain reliable and accurate data. Constitutive equations generated from creep tests of joint specimens are particularly useful, however, because the creep properties are measured from microstructures that simulate "real" solder joints. Furthermore, working with joint specimens allows for observations regarding the practical attainability of superplastic microstructures by varying the cooling rate. 


\section{BACKGROUND}

\subsection{Eutectic Microstructures}

The mechanical properties of a material depend not only on its composition, but also on its microstructure. For this reason, it is useful to review the various microstructures which can be obtained for a material with a eutectic composition. Eutectic microstructures can vary depending on the cooling rate and the volume fraction of the phases. If a material with a eutectic composition is solidified by cooling relatively slowly it forms a "classic eutectic microstructure" consisting of alternating lamellae of the two constituent phases. These two phases grow simultaneously and parallel to each other in grain-like colonies. The solute of one phase is rejected into the liquid ahead of the solidification front and is incorporated into the second phase as a solvent. If the two constituent phases are present in roughly equal volume fraction, they grow as parallel plates within each colony. If one phase predominates, the second ordinarily forms discrete rods in the matrix of the other.[17]

If a material with a eutectic composition is solidified by cooling at a much faster rate, however, the microstructure can change significantly.[18,19,20] Mei [18] compares the microstructures of eutectic $\mathrm{Pb}-\mathrm{Sn}$ at three cooling rates. Slow cooling produces a lamellar microstructure while quenching produces a fine-grained, equiaxed microstructure. An intermediate cooling rate produces a microstructure which is between these two extremes. Earlier research $[19,20]$ also used $\mathrm{Pb}-\mathrm{Sn}$ eutectic material to observe this effect. Unlike the slow-cooled, lamellar microstructure, the quenched microstructure exhibits no apparent crystallographic relationship between the two constituent phases. 


\subsection{Phase Diagrams and Constituent Eutectic Phases}

\subsubsection{In-Ag Eutectic}

The In-Ag phase diagram is shown in Figure 2.1. The eutectic composition is 97In-3Ag by weight with a melting temperature of $141^{\circ} \mathrm{C}$. The In-rich phase has minimal solubility for Ag. The two constituent eutectic phases are pure In and AgIn2 intermetallic. The volume fraction of In phase to intermetallic phase is approximately 92:8. Indium has a face-centered tetragonal crystal structure. The AgIn2 intermetallic has the $\mathrm{C} 16\left(\mathrm{Al}_{2} \mathrm{Cu}\right)$ crystal structure.

\subsubsection{Sn-Bi Eutectic}

The Sn-Bi binary system is a simple eutectic. The phase diagram is shown in Figure 2.2 and bears a striking resemblance to the $\mathrm{Pb}-\mathrm{Sn}$ phase diagram (Figure 2.3). The eutectic composition is $57 \mathrm{Bi}-43 \mathrm{Sn}$ by weight with a melting temperature of $139^{\circ} \mathrm{C}$. At the eutectic temperature the solubility of $\mathrm{Bi}$ in $\mathrm{Sn}$ is about $21 \mathrm{wt}-\%$ while $\mathrm{Bi}$ has essentially no solubility for $\mathrm{Sn}$. At room temperature the Sn-rich phase contains approximately $2 \mathrm{wt}-\% \mathrm{Bi}$. The two constituent phases are, therefore, a Sn-rich Bi solid solution and pure Bi. The volume fraction of the $\mathrm{Sn}$-rich phase to Bi phase is 51:49. Tin has a body-centered tetragonal crystal structure. Bismuth has a rhombohedral crystal structure.

\subsection{Creep}

Creep is time-dependent plastic deformation which becomes more significant in materials at high temperatures $\left(T \geq 0.5 \mathrm{~T}_{\mathrm{m}}\right)$.

\subsubsection{Creep Testing}

A creep test is conducted at a constant temperature and stress. For samples tested in shear, a constant load test is equivalent to a constant stress test since necking does not 
occur. The displacement of the material is recorded with respect to time. The displacement is converted to strain. An example of this type of data is shown in Figure 2.4. The creep curve is conveniently divided into three regions: primary (transient) creep, secondary creep, and tertiary creep. The secondary creep region is also known as the steady state region and is the region of interest in this study. This region is linear and represents a balance between strain-hardening and recovery processes in the material. The slope of the creep curve in the steady state region is the minimum strain rate for a given stress value. The following semi-empirical equation has been shown to represent the steady state creep behavior of a number of materials[22]:

$$
\dot{\gamma}=\mathrm{A}\left[\frac{\tau}{\mathrm{G}}\right]^{\mathrm{n}} \exp \left[-\frac{\mathrm{Q}}{\mathrm{kT}}\right]
$$

where $\dot{\gamma}$ is the shear strain rate, $\tau$ is the shear stress, $\mathrm{G}$ is the shear modulus, $\mathrm{Q}$ is the activation energy, $\mathrm{T}$ is the absolute temperature, $\mathrm{k}$ is Boltzmann's constant, and $\mathrm{n}$ and $\mathrm{A}$ are constants.

In order to obtain a precise constitutive equation, the creep mechanisms must be understood. Values of $\mathrm{n}$ and $\mathrm{Q}$ can be related to rate-controlling processes in steady state creep. Separate creep mechanisms may be distinguished from each other by different values of $\mathrm{n}$ and $\mathrm{Q}$. The stress exponent $(\mathrm{n})$ can be determined by plotting the steady state strain rate versus the applied shear stress on a log-log plot and measuring the slope. Similarly, the apparent activation energy (Q) can be determined by plotting the steady state strain rate versus the reciprocal of the test temperature. If multiple mechanisms are operating in series, the slowest mechanism will dominate the creep behavior. Conversely, if multiple mechanisms are operating in parallel, the fastest 
mechanism will dominate the creep behavior. These multiple mechanisms are illustrated schematically in Figure 2.5 .

\subsubsection{Power-Law Creep}

At intermediate to high stresses and temperatures $>0.5 \mathrm{~T}_{\mathrm{m}}$, the creep process is thermally activated and dominated by the activation energy for self diffusion ( $\mathrm{Q}_{\text {creep }} \approx$

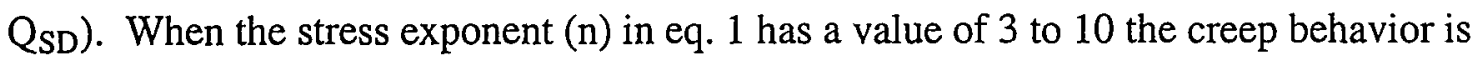
referred to as power-law creep (PLC).[23] In general, power-law creep is controlled by dislocation motion. A stress exponent value of $n \approx 3$ may indicate a creep mechanism controlled by the velocity of dislocations. This glide-controlled creep mechanism, however, lacks a satisfactory description of a balance between hardening and recovery processes.

At high temperatures dislocations can climb, as well as glide. Creep processes are then controlled by dislocation climb plus glide. Dislocation glide is responsible for most of the strain, but the strain rate is determined by the climb step, therefore, mechanisms based on a climb-plus-glide sequence are referred to as climb-controlled creep processes. The rate-controlling process is the diffusion of single vacancies to or from the climbing dislocation. Glide-controlled and climb-controlled creep mechanisms are not dependent on grain size.

\subsubsection{Power-Law Breakdown}

At high stresses, dislocation glide contributes increasingly to the overall strain-rate.

The measured creep rates are greater than those predicted by a simple power law. This phenomenon is referred to as power-law breakdown (PLB). It is believed that the ratecontrolling process is the generation of dislocations rather than the velocity of

dislocations in the lattice. Deformation in the power-law breakdown regime is similar 
to low temperature deformations mechanisms. Power-law breakdown has often been described empirically using an exponential rate equation. Representation of the PLB regime is discussed further in section 5.4.

\subsubsection{Grain-Boundary Sliding / Superplasticity}

Grain-boundary sliding (GBS) represents the response of high angle grain boundaries to shear stresses. Grains slide past one another along the plane of common boundary. Dislocation motion within the grains must accompany deformation by GBS in order to prevent large voids from opening up in the material structure. Deformation associated with GBS can produce large strains at low stresses resulting in an effect known as superplasticity. Superplastic creep behavior is associated with a fine grain size ( 1 to 10 $\mu \mathrm{m})$, deformation temperatures $>0.5 \mathrm{~T}_{\mathrm{m}}, \mathrm{n}$ values $<3$, and activation energies on the order of those for grain boundary diffusion. Reviews of superplastic literature are provided by several authors.[24,25,26] Superplasticity of extruded $\mathrm{Sn}-\mathrm{Pb}$ eutectic and Sn-Bi eutectic material was first reported by Pearson.[27] He discovered that these extruded, eutectic alloys could be elongated up to $2000 \%$ when loaded at a constant stress. Extruded solid solution alloys of Sn-1Bi and Sn-5Bi (wt.\%) demonstrated superplastic behavior for grain sizes $<10 \mu \mathrm{m}$. [14,15] Alden [14] reports that a Sn-5Bi extruded specimen with a grain size of $16 \mu \mathrm{m}$ shows superplastic characteristics only at low strain rates. Cline and Alden [28] report that an extruded specimen of pure Sn with a large grain size $(45 \mu \mathrm{m})$ did not exhibit superplastic characteristics even at low strain rates. 


\subsubsection{Constitutive Creep Equations for Eutectic Materials}

In the Dorn representation, an equation of the form (1) applies to each independent creep mechanism. A typical eutectic material that is tested at high homologous temperatures $\left(\mathrm{T} / \mathrm{T}_{\mathrm{m}}\right)$ shows at least two independent creep mechanisms: a low-stress region with a stress exponent, $\mathrm{n} \approx 3$, joined to a high-stress region with a significantly larger stress exponent. The two mechanisms operate in parallel; the dominant mechanism is that which produces the higher strain rate. While the mechanistic details of these mechanisms are not fully known, both are dominated by dislocation motion in the bulk, and are governed by an activation energy, Q, that is associated with lattice diffusion.

In addition, eutectic materials that are sufficiently fine-grained show a low-stress creep mechanism that is dominated by grain boundary sliding. This is the mechanism that is responsible for "superplastic creep" in fine-grained materials, and is well-documented in fine-grained eutectic $\mathrm{Pb}-\mathrm{Sn}$ and other fine-grained solder joints.[29] As mentioned previously, in its purest form, this mechanism is characterized by a stress exponent $\mathrm{n} \approx$ 2 , and an activation energy that is the activation energy for grain boundary diffusion, and is roughly half of the activation energy for bulk diffusion: $\mathrm{Q}_{\mathrm{GB}} \approx 0.5 \mathrm{QB}_{\mathrm{B}}$. It is also characterized by an extensive region of steady-state creep (the behavior that leads to superplastic deformation). The grain boundary mechanism is, however, made complicated by the fact that the pre-exponential factor (the factor $A$ in eq. 1) depends on the grain size, and decreases as the grains grow.

Since grain boundary creep and bulk creep operate in parallel, the overall creep rate is governed by the faster of the two mechanisms. Since the grain boundary creep rate 
decreases with grain size, it is only observed when the material is very fine-grained, and dominates over a range of stresses that decreases with increasing grain size. This grainsize (or colony-size in a lamellar microstructure) effect is illustrated schematically in Figure 2.6.[30]

\subsection{Literature Review}

\subsubsection{Two-Phase Creep Models}

The literature reports numerous studies of high temperature mechanical properties of two phase systems. Much of this literature deals with composite materials. The steady-state creep behavior of continuous fiber and laminate composites have been predicted using a rule-of-mixtures approximation of the creep behavior of the component materials.[31-36] Several studies [33, 35] simplify their analyses by assuming that the stress dependence of the components is approximately equal.

\subsubsection{McDanels, Signorelli, and Weeton (1967)}

McDanels et al. [33] predicts the steady-state creep behavior of tungsten-fiberreinforced copper composites under conditions of constant tensile loading. The following assumptions are made:

(1) Strains in the fiber and the matrix are equal to each other.

(2) The fiber area, $A_{f}$, plus the matrix area, $A_{m}$, are equal to the area of the composite $A_{c}$, which is taken as unity.

(3) Composites are reinforced with longitudinally oriented fibers and are tested in the direction parallel to the reinforcement.

(4) Components of the composites are insoluble.

(5) Tensile failure of both the fiber and the matrix occurs. 
The constitutive relationship between the applied stress and steady-state creep rate of the composite, based on the component properties is given as:

$$
\sigma_{c}=\left(\sigma_{f}\right)_{o}\left(\dot{\varepsilon}_{f}\right)^{\psi_{f}} A_{f}+\left(\sigma_{m}\right)_{o}\left(\dot{\varepsilon}_{m}\right)^{\psi_{m}} A_{m}
$$

where $\sigma$ is the stress on each component, $\mathrm{A}$ is the relative area of each component, is the steady-state creep rate and $c, f$, and $m$ represent the composite, fiber, and matrix components, respectively. The subscript, o, denotes the stress required to give a creep rate of $1 \% /$ hour, and $\psi$ represents the strain rate sensitivity. Since the creep rates are equal, eq. (2) becomes:

$$
\sigma_{c}=\left(\sigma_{f}\right)_{o}(\dot{\varepsilon})^{\psi_{I}} A_{f}+\left(\sigma_{m}\right)_{o}(\dot{\varepsilon})^{\psi_{m}} A_{m}
$$

When the strain rate sensitivity $(\psi)$ of the fiber and matrix are approximately equal, eq. (3) may be simplified to the following form:

$$
\sigma_{c}=\left[\left(\sigma_{f}\right)_{0} A_{f}+\left(\sigma_{m}\right)_{o} A_{m}\right](\dot{\varepsilon})^{\psi}
$$

Steady-state creep rates were measured on tungsten-fiber-reinforced copper composites at $650^{\circ} \mathrm{C}$ and $815^{\circ} \mathrm{C}$. Experimental results were in good agreement with those predicted by eq. (4).

\subsubsection{Choi, Matlock, and Olsen (1990)}

Choi et al. [35] investigate the creep behavior of $\mathrm{Ni}$-Cu laminate composites with controlled composition gradients. Experimental results are compared with predications 
based on the following composite model, with the continuous composition gradients being approximated as a series of discrete compositional zones.

$$
\sigma_{c}=V_{A} K_{A} \dot{\varepsilon}^{\frac{1}{3}}+V_{B} K_{B} \dot{\varepsilon}^{\frac{1}{b}}
$$

where $\sigma_{\mathrm{C}}$ is the stress in the composite, $\mathrm{V}_{\mathrm{A}}$ and $\mathrm{V}_{\mathrm{B}}$ are volume fractions of the respective layers, and $\mathrm{K}_{\mathrm{A}}, \mathrm{K}_{\mathrm{B}}$, $\mathrm{a}$, and $\mathrm{b}$ are constants at a given temperature.

If the materials have similar deformation behavior, the strain rate exponents are assumed to be equal and eq. (5) becomes:

$$
\dot{\varepsilon}=\frac{\sigma_{\mathrm{c}}{ }^{\mathrm{n}}}{\left[\mathrm{V}_{\mathrm{A}} \mathrm{K}_{\mathrm{A}}+\mathrm{V}_{\mathrm{B}} \mathrm{K}_{\mathrm{B}}\right]^{\mathrm{n}}}
$$

\subsubsection{Ravichandran and Seetharaman (1993)}

Ravichandran and Seetharaman [37] use a continuum mechanics-based model to predict the steady-state behavior of particulate composites containing coarse, rigid reinforcements based on the creep behavior of the matrix and volume fraction of the constituents. This model derives expressions for the steady-state creep behavior of two phase systems, using a unit cell representative of the microstructure. The details of this model are described in Appendix A. The resulting equations are given here. If the steady-state creep behavior of the matrix is expressed as:

$$
\dot{\varepsilon}_{\mathrm{m}}=\mathrm{K}_{\mathrm{m}} \sigma^{\mathrm{n}_{\mathrm{m}}}
$$

then the steady-state creep rate of the composite is given as: 


$$
\dot{\varepsilon}_{\mathrm{c}}=\mathrm{K}_{\mathrm{m}}\left[\frac{\sigma_{c}(1+c)^{2}}{\left(1+\frac{0.3}{c}\right)\left(\frac{(1+c)}{c}\right)^{\frac{1}{n_{\mathrm{m}}}}+(1+c)^{2}-1}\right]^{\mathrm{n}_{\mathrm{m}}}
$$

where $\mathrm{c}$ incorporates the volume fraction of the second phase $\left(\mathrm{V}_{\mathrm{p}}\right)$ by:

$$
c=\left[\frac{1}{V_{p}}\right]^{\frac{1}{3}}-1 \quad \text { where } V_{p}+V_{m}=1
$$

Therefore, for a given volume fraction of the second phase, knowing the constants in the matrix creep equation, the steady-state creep behavior of the composite can be calculated as a function of the applied stress.

The predicted steady-state creep rates are consistent with experimental values for WCCo systems and dual $\alpha+\beta$ brass at all volume fractions of second phase particles. At intermediate volume fractions, however, the predicted creep rates are slightly higher than the measured creep rates. In addition, although the model proposed by Ravichandran et al. is a simple one, the calculations are in good agreement with more rigorous calculations from self-consistent and finite element models (FEM).[36] Other finite element models have been used to predict the creep behavior of metal matrix composites.[38-41]

\subsubsection{Tanaka, Sakaki, and Iizuka (1991)}

Another continuum mechanics model predicts the creep deformation of ductile twophase alloys including both the transient and steady-state behavior.[42] The steadystate creep behavior is of interest with regard to the current study, therefore, predictions 
of transient creep behavior will not be discussed here. If the creep deformation in both second phase and matrix exhibit power-law creep, the creep rates can be given by:

$$
\begin{aligned}
& \dot{\varepsilon}_{33}^{\mathrm{I}}=\mathrm{K}_{\mathrm{I}}\left(\sigma_{\mathrm{e}}^{\mathrm{I}}\right)^{\mathrm{m}}=\mathrm{K}_{\mathrm{I}}\left(\sigma_{33}^{\mathrm{A}}-\mathrm{fKEx}\right)^{\mathrm{m}} \\
& \dot{\varepsilon}_{33}^{\mathrm{II}}=\mathrm{K}_{\mathrm{II}}\left(\sigma_{\mathrm{e}}^{\mathrm{II}}\right)^{\mathrm{n}}=\mathrm{K}_{\mathrm{II}}\left\{\sigma_{33}^{\mathrm{A}}+(1-\mathrm{f}) \mathrm{KEx}\right\}^{\mathrm{n}}
\end{aligned}
$$

where $\sigma_{\mathrm{e}}$ represents the equivalent stress (actual stress acting on each phase), $\mathrm{K}_{\mathrm{I}}, \mathrm{KII}$, $\mathrm{m}$, and $\mathrm{n}$ are materials constants, $\mathrm{K}$ is a shape factor, and $\mathrm{f}$ is the volume fraction.

The internal stresses in both the second phase and matrix are considered to be constant in the steady-state creep regime, therefore:

$$
\dot{\varepsilon}_{33}^{\text {I }}=\dot{\varepsilon}_{33}^{\text {II }}=\dot{\varepsilon}_{s}
$$

The applied stress is related to the steady-state creep rate by:

$$
\sigma_{33}^{A}=(1-f)\left(\frac{\dot{\varepsilon}_{s}}{K_{I}}\right)^{\frac{1}{m}}+f\left(\frac{\dot{\varepsilon}_{s}}{K_{\text {II }}}\right)^{\frac{1}{n}}
$$

Tanaka's [42] continuum mechanics model and McDanel's [33] constant creep rate model give the same values in the steady-state regime. The creep strains predicted by Tanaka and McDanels are larger than the measured creep strains for ferrite-pearlite steels[42], yet smaller than the measured creep strains for bulk Sn-Bi eutectic[43], while those predicted for tungsten fiber reinforced copper[42] are consistent with experimental results. The equations used by McDanels[33], Choi[35], and Tanaka[42] are similar. 


\subsubsection{Creep of Sn-Bi Eutectic}

As previously mentioned, $\mathrm{Sn}-\mathrm{Bi}$ eutectic has been considered a promising alternative to $\mathrm{Sn}-\mathrm{Pb}$ eutectic, therefore the literature contains a significant amount of information about this alloy. A comprehensive review of this information was published by Glazer.[13] Unlike $\mathrm{Pb}-\mathrm{Sn}$ eutectic, Bi-Sn eutectic appears to preserve a lamellar microstructure over a wide range of cooling rates. This fact is illustrated in the creep data shown in Figure 2.7. Different specimen geometries result in a range of cooling rates yet the microstructure (not shown here) and creep rate are nearly the same. ${ }^{*}$ (See Appendix B.) It appears that two creep mechanisms operate in parallel: The low stress regime has a stress exponent of $n=3$ and the high stress regime has a stress exponent of $\mathrm{n}=6$. (See Discussion section 5.4) The study by Mei and Morris [7] discusses the data in terms of only one creep mechanism and reports an $n$ value of approximately 4 and an activation energy of $0.73 \mathrm{eV}$. A review of this paper shows that only limited data was measured in the high stress regime. It is clear from Figure 2.7, that the data from Mei and Morris [7], when included with the data from other references, is consistent with the later interpretation that two parallel mechanisms exist. When data from all three references $\left[7,8,9^{*}\right]$ at temperatures of $25^{\circ} \mathrm{C}, 75^{\circ} \mathrm{C}$, and $90^{\circ} \mathrm{C}$, are considered, the activation energies are calculated to be $\mathrm{Q}=0.88 \pm 0.02 \mathrm{eV}$ for the low stress regime and $\mathrm{Q}=0.95 \pm 0.11 \mathrm{eV}$ for the high stress regime. These $\mathrm{Q}$ values are in agreement with values reported in the literature for the activation energy of creep in polycrystalline Sn. Frenkel[44] reports $\mathrm{Q}=0.91 \mathrm{eV}$ and Mohamed et al.[45] reports $\mathrm{Q}=1.0 \mathrm{eV}$. The room temperature data in Figure 2.7, along with additional temperature data from Mei and Morris [7], Bartels et al.[8] and Freer Goldstein et al.[9*] support the generalizations discussed in Section 2.3.5. on the steady-state creep behavior of a typical lamellar eutectic: Two mechanisms operate in parallel, both are dominated by dislocation 
motion in the bulk, and are governed by an activation energy, $Q$, that is associated with lattice diffusion.

Raeder et al.[10] report a stress exponent of $n=3$ and an activation energy of $Q=0.63$ $\mathrm{eV}$ for creep of $\mathrm{Sn}-\mathrm{Bi}$ eutectic, which is similar to $\mathrm{Q}$ values reported in the literature for the activation energy of creep in pure Bi. These literature values for creep of pure Bi (bulk) include $0.49 \mathrm{eV}[46], 0.52 \mathrm{eV}$ [47] and $0.6 \mathrm{eV}[43]$, which are in agreement with the activation energy for self-diffusion in $\mathrm{Bi}\left(\mathrm{QSD}_{\mathrm{SD}} \approx 0.6 \mathrm{eV}\right) \cdot[48,49]$

Tomlinson and Collier [11] report a significantly lower activation energy of $Q=0.31 \mathrm{eV}$ for creep of $\mathrm{Bi}-\mathrm{Sn}$ eutectic in the temperature range of $60^{\circ} \mathrm{C}-100^{\circ} \mathrm{C}$. This value is lower than the literature values for creep activation energy of either pure $\mathrm{Sn}$ or pure Bi.

Pattanaik and Raman [12] report data for rolled Sn-Bi eutectic specimen tested in tension. At strain rates $<2 \times 10^{-3} \mathrm{~s}^{-1}$, the strain rate sensitivity $(\mathrm{m})$ was 0.5 and at strain rates $>2 \times 10^{-3} \mathrm{~s}^{-1}$, the strain rate sensitivity was 0.1 . These $\mathrm{m}$ values correspond to stress exponents of $n \approx 2$ at low strain rates and $n \approx 10$ at high strain rates. The mechanical behavior at low strain rates is more closely related to the creep properties of $\mathrm{Sn}-\mathrm{Bi}$ eutectic and is of interest to the current study. 


\section{EXPERIMENTAL PROCEDURES}

\subsection{Specimen Preparation}

\subsubsection{General Procedures}

The sample geometry used for this study is illustrated in Figure 3.1. This single-shear joint specimen was chosen because this geometry provided a material microstructure on the order of an actual solder joint microstructure, while still being large enough to avoid complications from intermetallic reactions at the solder-substrate interface. The substrate material and processing parameters varied depending on the material to be tested. The specific materials and procedures are described in more detail below. In general, however, the substrate materials consisted of $\mathrm{Cu}$, electroplated $\mathrm{Cu}$, or FR-4 epoxy with patterned $\mathrm{Cu}$ pads. The $\mathrm{Cu}$ plate had an initial thickness of 0.125 inches $(3.18 \mathrm{~mm})$. These plates were masked and etched to produce the nine raised pads which were approximately 10 mils $(250 \mu \mathrm{m})$ above the plane of the plate. Due to slight variations in the thickness of the initial $\mathrm{Cu}$ plate, and uncontrollable variations in the etching process, the pad height had a deviation of \pm 1 mil. Therefore, it was necessary to measure the pad height on each individual substrate in order to determine the correct spacer needed to obtain the desired joint thickness. Each substrate contained nine raised pads. The dimensions of each pad were 80 mils $x 45$ mils $(2.03 \mathrm{~mm} \times 1.14 \mathrm{~mm})$ for a cross-sectional area of $0.0036 \mathrm{in}^{2}\left(2.314 \mathrm{~mm}^{2}\right)$ or a total cross-sectional area of 0.0324 in $2\left(20.83 \mathrm{~mm}^{2}\right)$. The substrates were cleaned with a $\mathrm{HCl}-\mathrm{ZnCl}_{2}$ flux, then rinsed with de-ionized water and alcohol. The solder materials were in the form of foils or solder paste. The material to be tested was placed between opposite lands on the two substrates, and reflowed in a nitrogen gas environment. In most cases (except as noted below), the samples were cooled using liquid nitrogen at a computer-controlled rate. The cooling rate was also measured using a thermocouple (directly attached to the specimen) and a strip chart recorder. The samples were clamped during reflow with 
appropriate spacers, resulting in a reasonably consistent joint thickness among the specimen. It was important to insure that the solder wet the substrate surface on the raised pads only. Wetting off of the raised pads would change the joint geometry and affect the stress state in the tested material. To prevent wetting "off-the-pad", a colloidal silica solution was used to mask the area around each pad. This step was not necessary in the case of the FR-4 epoxy samples.

\subsubsection{In-Ag Eutectic Specimens}

Solder is intended to wet the metal surfaces it joins and form a strong bond between them. Both wetting and bonding are enhanced if there is a chemical reaction between the solder and the substrate. The substrate material for the In-Ag specimens was chosen to be $\mathrm{Cu}$ coated with $\mathrm{Ni}$ and $\mathrm{Au}$. The $\mathrm{Cu}$ plates were prepared as indicated above and then coated with a thin layer of electroless $\mathrm{Ni}(<2 \mu \mathrm{m})$, and electroplated with 2-3 $\mu \mathrm{m}$ Au. The Ni layer acted as a barrier to prevent diffusion of $\mathrm{Cu}$ into the joint during reflow. Approximately one-half of the Au coating was dissolved into the solder during reflow, forming an Au-In intermetallic layer, consisting of a mixture of AuIn2 and AuIn compounds.

The material that was used for the creep tests was taken from In- $\mathrm{Ag}$ foils, 4 mils $(0.1 \mathrm{~mm})$ in thickness. These foils were produced by Indium Corporation of America. The composition of the foils was certified by the producer and reported to be the eutectic composition: 97In-3Ag, by weight. The composition was confirmed in this laboratory using energy dispersive $\mathrm{X}$-ray analysis prior to sample preparation.

The In-Ag solder joints were made from rectangular sections that were punched from the $4 \mathrm{mil}(0.1 \mathrm{~mm}) \mathrm{In}-\mathrm{Ag}$ eutectic foils. Initial attempts were made to prepare the joints using only one thickness ( 4 mil) of foil. Due to the deviation in pad height discussed 
above, these foils proved too thin for reliable wetting of the substrates with standard sample preparation procedures. For this reason, the test joints were created by stacking three punched rectangles. The stack was placed between opposite lands on the two substrates, fluxed with an $\mathrm{HCl}-\mathrm{ZnCl}_{2}$ flux and melted to form joints by heating at either $170^{\circ} \mathrm{C}$ (the first few specimens) or $185^{\circ} \mathrm{C}$ (the remainder of the specimens), using a typical reflow profile. The cooling rate was approximately $35^{\circ} \mathrm{C} / \mathrm{min}$. Appropriate spacers were used to obtain a final joint thickness of $300 \mu \mathrm{m}$. The reflow temperature was changed during the course of the work because the higher reflow temperature reduced the incidence of poorly bonded or defective joints. It did not appear to affect the creep rates. The samples were held at room temperature for at least 24 hours after reflow, prior to testing, in order to relieve any residual stress in the joints due to processing.

Making the In-Ag eutectic joints was a very detailed, labor-intensive process. The softness of the In-Ag eutectic foil made it particularly difficult to work with. The equipment used to punch the rectangular sections required repeated cleaning, as the material would "gum" up the apparatus.

\subsubsection{Sn-Bi Solid Solution Specimens}

Due to the melting point of $\mathrm{Sn}-2 \mathrm{Bi}(\mathrm{wt} \%$ ) and $\mathrm{Sn}-5 \mathrm{Bi}$ (wt\%) solid solution alloys, higher reflow temperatures were required and, the FR-4 epoxy substrates could not be used. (Reflow temperatures are generally $40^{\circ} \mathrm{C}-50^{\circ} \mathrm{C}$ above the melting point of the alloy. The epoxy resin begins to break down at temperatures $>250^{\circ} \mathrm{C}$.) Cu plates, etched to produce nine raised pads, were used. The solid solution alloys were produced in this laboratory and rolled into foils with a thickness of 10 mils. The material compositions were verified using energy dispersive $\mathrm{X}$-ray analysis. Cu substrates were cleaned as described above. Rectangular sections were punched from the rolled foils. 
The material was placed between opposite lands of the two substrates, fluxed with an $\mathrm{HCl}-\mathrm{ZnCl}_{2}$ flux, reflowed in nitrogen at a temperature of $270^{\circ} \mathrm{C}$, and cooled at approximately $20^{\circ} \mathrm{C} / \mathrm{min}$. Appropriate spacers were used to obtain a final joint thickness of $250 \mu \mathrm{m}$.

\subsubsection{Pure Bi Specimens}

The melting point of pure $\mathrm{Bi}$ was also too high to allow use of the FR-4 epoxy substrates. The substrate material for the pure $\mathrm{Bi}$ specimens was $\mathrm{Cu}$ coated with $\mathrm{Ni}$. The $\mathrm{Cu}$ plates were masked and etched to produce nine raised pads and were then coated with a layer of $\mathrm{Ni}$. In this case, the Ni layer not only acted as a barrier to prevent diffusion of $\mathrm{Cu}$ into the joint during reflow, but also allowed for the formation of a $\mathrm{NiBi} 3$ intermetallic to form at the solder-substrate interface. The material to be tested was in the form of solder paste containing $87 \mathrm{wt} . \%$ metallic powder and $13 \mathrm{wt} . \%$ "no clean" flux (NCSMQ51SC). A pneumatic dispenser was used to place the solder paste on the pads. Pure Bi samples were reflowed in a nitrogen gas environment, at a temperature of $300^{\circ} \mathrm{C}$ and cooled at approximately $20^{\circ} \mathrm{C} / \mathrm{min}$. The final joint thickness was $250 \mu \mathrm{m}$.

\subsubsection{Sn-Bi Eutectic Specimens}

The substrate material for the Sn-Bi eutectic specimens was an FR-4 epoxy patterned. with a pure $\mathrm{Cu}$ film. No additional metallization was required. $\mathrm{A} \mathrm{Cu}_{6} \mathrm{Sn}_{5}$ intermetallic phase formed at the interface. The Sn-Bi eutectic material was supplied in ingot form by Indium Corporation of America. The composition of the material was certified by the producer. The material was hot-pressed into foils with a thickness of 10 mil. The eutectic composition ( $43 \% \mathrm{Sn}-57 \% \mathrm{Bi}$ ) of these foils was confirmed in this laboratory using energy dispersive $\mathrm{X}$-ray analysis prior to sample preparation. 
The epoxy substrates with $\mathrm{Cu}$ pads were cleaned as described above. Rectangular sections were punched from the pressed foils. The material was placed between opposite lands of the two substrates, fluxed with an $\mathrm{HCl}-\mathrm{ZnCl}_{2}$ flux and reflowed in nitrogen at a temperature of $170^{\circ} \mathrm{C}$. The $\mathrm{Sn}-\mathrm{Bi}$ eutectic specimen were cooled at two different cooling rates. One set of specimens was cooled at a rate of $20^{\circ} \mathrm{C} / \mathrm{min}$. The second set of $\mathrm{Sn-Bi}$ eutectic joint specimens was cooled rapidly by quenching in ice water. The exact cooling rate could not be recorded therefore, for the purposes of this study, these specimen will be referred to as "quenched". Appropriate spacers were used to obtain a final joint thickness of $250 \mu \mathrm{m}$.

\subsection{Creep Testing Procedures}

A schematic drawing of the machine used for creep testing is shown in Figure 3.2. The specimens were gripped on the two ends, using spacers to provide appropriate alignment. Pins held the grips in place. The lower grip was fixed while the upper grip was attached to a pull-rod and was free to move in response to the applied load. Because the specimens were loaded in shear, necking of the solder did not occur. (*Note when the single-shear specimen is pulled from each end, a rotational moment occurs, because the loading is not on the same axis. This moment results in a non-shear component. This non-shear component has been calculated elsewhere [50] and determined to be negligible.) The constant applied load resulted in a constant shear stress $(\tau)$, which was calculated as the applied load $(\mathrm{P})$ divided by the total area of the nine pads (A).

$$
\tau=\mathrm{P} / \mathrm{A}
$$

The relative displacement $(\Delta \mathrm{x})$ of the plates was measured as a function of time using a linear variable differential transformer (LVDT), and converted into shear strain $(\gamma)$. The 
shear strain $(\gamma)$ was calculated as the measured displacement $(\Delta x)$ divided by the joint thickness (h):

$$
\gamma=\Delta \mathrm{x} / \mathrm{h}
$$

A typical creep curve has already been shown in Figure 2.3. After the initial transient (primary creep) the sample relaxed into steady-state creep and the strain increased linearly with time. Each test was continued until this steady-state creep rate was reached (strain rate remained constant with time). The steady-state strain rate $(\dot{\gamma})$ was determined by calculating the slope in this linear region. To conserve material, where appropriate, several sequential tests were done with a single sample; after the sample had reached steady state at one stress, the load was increased to measure the strain rate at higher load. To insure that a steady-state strain rate was, in fact, reached before increasing the load in the sequential tests, the strain rate was computed and plotted as a

function of time. Results from single and multiple load tests were compared to insure that the steady-state creep rates were not effected by microstructural evolution during testing. A typical creep curve for a sequential test is shown in Figure 3.3. Figure 3.3(a) shows the shear strain as a function of time, Figure 3.3(b) shows the computed shear strain rate as a function of time. Increasing the load during sequential tests resulted in initial increases in strain, causing "jumps" in the strain rate which are observed in Figure 3.3(b). Steady-state creep behavior is represented on a log-log plot of steadystate strain rate versus applied shear stress (or normalized shear stress).

\subsection{Metallography}

The legs of the creep specimen were cut off using a diamond blade cutting wheel and the section containing the solder joints was mounted in epoxy. The mounted samples were ground on coarse silicon carbide paper until enough $\mathrm{Cu}$ was removed and crosssections of three out of nine solder joints were flush with the surface. All samples were 
then ground on successively finer silicon carbide paper down to 600 grit and polished sequentially with $6 \mu \mathrm{m}$ and $1 \mu \mathrm{m}$ diamond paste and oil on nylon polishing pads. A solution of $0.05 \mu \mathrm{m}$ alumina and water was used for the final polishing step. Polishing of the solder joints presented a problem due to the difference in hardness of the solder and substrate materials. The solder had a tendency to be polished away at a faster rate, creating a "scooped" or "dished" effect at the interface. The effect was increased for longer polishing times. For this reason, it was important to keep the grinding and polishing times at each grit level to a minimum. The In-Ag eutectic samples were etched with a solution of $15 \% \mathrm{HNO}_{3}, 5 \% \mathrm{HCl}$, and $80 \% \mathrm{H}_{2} \mathrm{O}$. The $\mathrm{Sn}$-Bi samples were etched with a solution of $5 \% \mathrm{HNO}_{3}, 2 \% \mathrm{HCl}$, and $93 \%$ methanol. Etching times ranged from 2 to 10 seconds. 


\section{RESULTS}

\subsection{In-Ag System}

\subsubsection{Metallography and Characterization}

Metallographic examination of the solder joint reveals a microstructure that appears to be fine-grained. Although the exact grain size is difficult to determine, it seems to be $\sim 5 \mu \mathrm{m}$. Addition of Ag stabilizes the In grain size. The microstructure is shown in Figure 4.1 where the dark phase is the In-rich matrix and the light phase is the $\mathrm{AgIn}_{2}$ intermetallic. The In-rich phase has minimal solubility for $\mathrm{Ag}$, thus, the two constituent eutectic phases are (essentially) pure In and $\mathrm{AgIn} 2$ intermetallic. The volume fraction of In phase to intermetallic phase is approximately 92:8, therefore the AgIn2 intermetallic phase is discontinuous within the microstructure.

Approximately one-half of the Au coating was dissolved into the solder during reflow, forming an Au-In intermetallic layer, consisting of a mixture of AuIn 2 and AuIn compounds. Creep deformation and subsequent failure of the joints occurred in the solder rather than at the solder/intermetallic interface. It is probable that a small amount of $\mathrm{Au}$ was dissolved into the interior of the In- $\mathrm{Ag}$ joint, although this amount was too small to be measured quantitatively. The steady-state creep properties measured in this study are essentially those of unalloyed In-Ag eutectic.

\subsubsection{Creep Behavior of In-Ag Eutectic Joints}

Steady-state creep rates were measured at four temperatures: $0^{\circ} \mathrm{C}, 30^{\circ} \mathrm{C}, 60^{\circ} \mathrm{C}$ and $90^{\circ} \mathrm{C}$. The loads used covered the range of shear stress between 0.6 and $3.0 \mathrm{MPa}$, producing shear strain rates that ranged from $\approx 10^{-8}$ to $\approx 10^{-2} / \mathrm{sec}$. The low-stress limit 
of the tests was fixed by the characteristics of the machine; the dead-weight load must significantly exceed the gravitational load from the machine itself. After testing, the specimens were inspected for bonding flaws. While the geometry of the test specimens made it difficult to verify joint integrity prior to testing, poor joint quality was revealed during the test by anomalously high creep rates and by noticeable flaws in the fracture surfaces of the broken specimens. Fracture surfaces of the flawed joints contained evidence of non-wetting and/or an excessive amount of voids ( $>10 \%$ of the crosssectional area). While the substantial majority of the samples tested were sound, a few contained flawed joints and were rejected.

The average steady state strain rates are plotted as a function of reduced stress $(\tau / G$, where $G$ is the shear modulus) in Figure 4.2. Since the temperature dependence of the shear modulus of In-Ag eutectic is unknown, an approximation was made using the published shear modulus for pure In [51]:

$$
\mathrm{G} \approx \mathrm{G}_{\mathrm{In}}=4.4-0.0135(\mathrm{~T}-298) \quad[\mathrm{GPa}]
$$

The measured creep rates vary by an order of magnitude or more. This result is typical of creep measurements taken on joint specimens, and shows the influence of small changes in microstructure and joint geometry which are difficult to measure. As shown in Figure 4.2, however, the average values of the steady-state creep rate are reasonably well-behaved.

The data are well represented by the Dorn equation[22] discussed in section 2.3.1. In the Dorn representation, an equation of the form (1) applies to each independent creep mechanism. 


\subsubsection{Stress Exponents}

As shown in Figure 4.2, the In-Ag eutectic samples tested show two mechanisms. Only the high-stress mechanism appears in the $60^{\circ} \mathrm{C}$ and $90^{\circ} \mathrm{C}$ data,. The low stress mechanism is first observed in the $30^{\circ} \mathrm{C}$ data, and dominates over an increasing stress range at $0^{\circ} \mathrm{C}$. The best fit to the data gives the stress exponents:

$$
\begin{array}{ll}
\mathrm{n} \approx 6.2 & \text { (high stress) } \\
\mathrm{n} \approx 2.5 & \text { (low stress) }
\end{array}
$$

The low-stress creep exponent is, hence, midway between that expected for a low-stress bulk mechanism and a grain boundary mechanism.

\subsubsection{Activation Energies}

The activation energies for the two creep mechanisms can be obtained from the dependence of $\dot{\gamma}$ on $\mathrm{T}$ at a constant value of the normalized stress. The best fits are illustrated in Figure 4.3a (high stress mechanism) and Figure 4.3b (low stress mechanism). In constructing this plot, the temperature dependence of the shear modulus is assumed to be that of pure In [51], since that of In-Ag eutectic is unknown. However, the weak T-dependence of G has a very small affect on the results. The measured activation energies are:

$$
\begin{aligned}
& \mathrm{Q} \approx 0.84 \mathrm{eV} \quad \text { (high stress) } \\
& \mathrm{Q} \approx 0.55 \mathrm{eV} \quad \text { (low stress) }
\end{aligned}
$$


These $Q$ values were confirmed by applying a multivariable linear regression analysis of the measured data fit to the Dorn equation (1). This confirmation is particularly important for the low-stress regime, since the value of the low-stress $Q$ is based on data at only two temperatures. The precise value of the low-stress Q must still be taken with some caution. However, it is clear that the activation energy for the low-stress mechanism is significantly below that for the high-stress mechanism, since the range of the low-stress mechanism increases significantly as the temperature drops.

\subsubsection{Creep Mechanisms}

Taking the stress exponent and activation energy together, along with the microstructural observations, it is reasonable to conclude that the low-stress mechanism is the grain boundary mechanism that is commonly observed in fine-grained eutectic solders. This expectation is consistent with observations on the creep tests themselves; tests conducted in the low-stress regime show steady-state creep over an extensive range, as expected from superplastic deformation. The low stress regime exhibits a steady-state strain of $\approx 15 \%$ while the steady-state strain exhibited by the high stress regime is only about $8 \%$.

The activation energy for the high-stress mechanism is in agreement with numerous values published in the literature for the activation energy of creep in bulk In. Dorn [44,52] and Weertman [53] report values of QIn ranging from $0.72 \mathrm{eV}$ to $0.78 \mathrm{eV}$ for pure In. Note, however, that Darveaux [54] reports a somewhat lower value of QIn $(\approx 0.5 \mathrm{eV})$ for the same high stress regime. The reason for this discrepancy is not clear. Based on the value of $\mathrm{Q}$ measured in the present study, and reasonable agreement with the work of Dorn and Weertman, it is concluded that the thermal dependence of the 
creep rate of In-Ag eutectic is dominated by the thermal dependence of creep in the Inrich matrix, which is believed to be dominated by self-diffusion of In.

\subsubsection{Constitutive Equations}

In the Dorn representation, as previously stated, an equation of the form (1) applies to each independent creep mechanism. The remaining value to be determined is the preexponential factor, $\mathrm{A}$, which is measured from a plot of the temperature-compensated strain rate $(j \exp [\mathrm{Q} / \mathrm{kT}])$ against the shear $(\tau / \mathrm{G})$. The results are shown in Figures $4.4 \mathrm{a}$ and $4.4 \mathrm{~b}$. The best fit equations are shown in the figures. Truncating to two significant figures, behavior in the two creep regimes is well fit by the constitutive equations:

$$
\begin{aligned}
& \dot{\gamma}=\left(1.3 \times 10^{30}\right)\left[\frac{\tau}{G}\right]^{6.2} \exp \left[-\frac{0.84}{\mathrm{kT}}\right] \\
& \dot{\gamma}=\left(1.0 \times 10^{12}\right)\left[\frac{\tau}{\mathrm{G}}\right]^{2.5} \exp \left[-\frac{0.55}{\mathrm{kT}}\right]
\end{aligned}
$$

where $\mathrm{T}$ is measured in degrees Kelvin, $\mathrm{k}$ is Boltzmann's constant and the $\mathrm{Q}$ values are given in $\mathrm{eV}$. The creep rate at given $\tau$ and $\mathrm{T}$ is the larger of these two creep rates (strictly speaking, it is the sum of the two, but difference is irrelevant except in the very narrow range of $\tau$ where the two creep rates are nearly the same.)

In using these constitutive relations (eqs. 20 and 21), one must recognize that they are affected by the microstructure of the solder.[29,55,56] The microstructure dependence of the bulk (high-stress) creep mechanism is relatively weak, and experience with other eutectic solders suggests that eq. 20 can be used with some confidence. The grain boundary mechanism, on the other hand, is affected both by the grain size and by the uniformity of the grain size. Research on $\mathrm{Pb}-\mathrm{Sn}$ eutectic solders shows that the preexponential factor, A, varies inversely with the grain size (researchers disagree on the 
precise power of the inverse dependence). The stress exponent also changes, approaching the value 2.0 as the grain size becomes finer, more uniform and more equiaxed. It is, unfortunately, a difficult task to incorporate the microstructure dependence into eq. 21 , and was not possible within the scope of this work. (This problem is not completely solved for eutectic $\mathrm{Pb}-\mathrm{Sn}$, after many years of research.) Eq. 21 should give a reasonable approximation to the creep rate for small In-Ag eutectic joints that are solidified at naturally rapid cooling rates, resulting in fine-grained microstructures $(<10 \mu \mathrm{m})$. 


\subsection{Sn-Bi System}

\subsubsection{Metallography}

The notion that $\mathrm{Sn}-\mathrm{Bi}$ eutectic is unusually resistant to coarsening $[7,30,57]$ is supported by metallographic observations in the current study. Sn-Bi eutectic joints were prepared using two cooling rates: $20^{\circ} \mathrm{C} / \mathrm{min}$. and a rapid ice water quench.

Microstructures from these two joint specimen are shown in Figures 4.5 and 4.6. The specimen cooled at $20^{\circ} \mathrm{C} / \mathrm{min}$. (Figure 4.5) shows a lamellar microstructure which is sometimes referred to as complex regular or quasi regular.[58] The colony size is estimated to be roughly $30-40 \mu \mathrm{m}$. Alternating "plates" of the Sn-rich and Bi phases are seen, although the plates are not flat. Rather, the alternating phases are bi-percolated or continuous throughout the joint. This type of microstructure is possible due to the equal volume fraction (51:49) of Sn-rich and Bi phases. Metallographic examination of the quenched joint (Figure 4.6) reveals a slightly finer microstructure, yet the morphology is generally the same as that seen in the more slowly cooled joint. In these optical micrographs, the Sn-rich phase appears dark while the Bi phase appears light.

For comparison, a bulk sample of $\mathrm{Sn}-\mathrm{Bi}$ eutectic was reduced by $50 \%$ and annealed at $95^{\circ} \mathrm{C}$ for one hour. The sample was then polished using the metallographic techniques described above. Figure 4.7 shows the resulting fine, equiaxed microstructure with a grain size of $3-5 \mu \mathrm{m}$. This microstructure could not be tested in joint form.

\subsubsection{Creep Behavior of Sn-Bi Solid Solution Joints}

Constant load creep tests were conducted for $\mathrm{Sn}-2 \mathrm{Bi}$ wt\% solid solution at room temperature $\left(25^{\circ} \mathrm{C}\right), 75^{\circ} \mathrm{C}$, and $90^{\circ} \mathrm{C}$. This composition was chosen because the solubility of the $\mathrm{Sn}$-rich phase at room temperature is approximately $2 \mathrm{wt} \% \mathrm{Bi}$. The 
loads used covered the range of shear stress between 3.0 and 25.0 MPa, producing steady-state strain rates that ranged from $\approx 10^{-8}$ to $\approx 10^{-2} / \mathrm{sec}$. The low-stress limit of these tests was determined by time constraints and the ability to measure low strain rates using the experimental apparatus described in section 3.2. The steady state creep rate is plotted as a function of the normalized $(\tau / \mathrm{G})$ shear stress in Figure 4.8. The values for $G$ were calculated from literature values of E.[59] Poison's ratio was assumed to be 0.33 . The values used for the shear modulus, $\mathrm{G}$, are shown in Table 4.1.

Table 4.1 Shear Modulus Values

ALLOY (wt. \%)

$\mathrm{Sn}-2 \mathrm{Bi}$

$\mathrm{Sn}-5 \mathrm{Bi}$

$\mathrm{Sn}-10 \mathrm{Bi}$

$\mathrm{Sn}-15 \mathrm{Bi}$

\section{Test Temperature $\left({ }^{\circ} \mathrm{C}\right)$}

20

75

90

20

90

20

20

\section{$\underline{\mathrm{G}(\mathrm{GPa})}$}

19.7

18.1

17.6

19.2

17.3

18.8

17.7

The Dorn equation has been chosen to represent the data. An equation of the form (1) applies to each independent creep mechanism.

\subsubsection{Stress Exponents}

Two parallel mechanisms are observed. Only the high-stress mechanism appears in the room temperature data. In addition, power-law breakdown (PLB) can be seen clearly for the data taken at room temperature. The low-stress mechanism is observed in the $75^{\circ} \mathrm{C}$ data and dominates over a slightly increasing stress range at $90^{\circ} \mathrm{C}$. The best fit to the data gives the stress exponents: 


$$
\begin{array}{ll}
\mathrm{n} \approx 5.9 & \text { (high stress) } \\
\mathrm{n} \approx 2.5 & \text { (low stress) }
\end{array}
$$

Again, the low-stress creep exponent is, hence, midway between that expected for a low-stress bulk mechanism and a grain boundary mechanism.

\subsubsection{Activation Energies}

The activation energies for the two creep mechanisms were obtained from the dependence of $\dot{\gamma}$ on $\mathrm{T}$ at a constant value of the normalized stress. The best fits are illustrated in Figure 4.9a (high stress mechanism) and Figure 4.9b (low stress mechanism). The measured activation energies are:

$$
\begin{aligned}
& \mathrm{Q} \approx 0.84 \mathrm{eV} \quad \text { (high stress) } \\
& \mathrm{Q} \approx 1.0 \mathrm{eV} \quad \text { (low stress) }
\end{aligned}
$$

The low-stress mechanism was not observed at room temperature due to the lower limit of measurable strain rates. These $Q$ values were confirmed by applying a multivariable linear regression analysis of the measured data fit to the Dorn equation (1). This confirmation is particularly important for the low-stress regime, since the value of the low-stress $Q$ is based on data at only two temperatures. It is reasonable to assume that activation energies for the low-stress mechanism and the high-stress mechanism are the same (within experimental error), since the range of the low-stress mechanism increases only slightly as the temperature increases. 


\subsubsection{Creep Mechanisms}

The measured activation energies for both the low stress and high stress regimes are in agreement with values published in the literature for the activation energy of creep in Sn.[44,45] As indicated above, the stress exponent for the low-stress regime is midway between that expected for a low-stress bulk mechanism and a grain boundary mechanism. In contrast to the In-Ag system however, it appears that both the highstress and low-stress creep mechanisms observed in the Sn-2Bi solid solution are dominated by dislocation motion in the bulk where the activation energy is associated with lattice diffusion. Observations from the creep tests show a steady-state strain of $\approx 10 \%$ for both the low-stress and high-stress regimes. Furthermore, the grain size of the $\mathrm{Sn}-2 \mathrm{Bi}$ solid solution joint specimens was $\sim 30 \mu \mathrm{m}$ which is greater than the grain size generally associated with grain-boundary sliding and superplastic creep $(1-10 \mu \mathrm{m})$.

\subsubsection{Constitutive Equations}

The remaining value to be determined in the constitutive equation for $\mathrm{Sn}-2 \mathrm{Bi}$ is the pre-exponential factor, A, which is measured from a plot of the temperaturecompensated strain rate $(\dot{j} \exp [\mathrm{Q} / \mathrm{kT}])$ against the shear $(\tau / \mathrm{G})$. The results are shown in Figures $4.10 \mathrm{a}$ and $4.10 \mathrm{~b}$. The best fit equations are shown in the figures. Truncating to two significant figures, behavior in the two creep regimes is well fit by the constitutive equations:

$$
\begin{array}{ll}
\dot{\gamma}=\left(2.6 \times 10^{26}\right)\left[\frac{\tau}{\mathrm{G}}\right]^{5.9} \exp \left[-\frac{0.84}{\mathrm{kT}}\right] & \text { (high stress) } \\
\dot{\gamma}=\left(4.3 \times 10^{17}\right)\left[\frac{\tau}{\mathrm{G}}\right]^{2.5} \exp \left[-\frac{1.0}{\mathrm{kT}}\right] & \text { (low stress) }
\end{array}
$$

where $\mathrm{T}$ is measured in degrees Kelvin, $\mathrm{k}$ is Boltzmann's constant and the $\mathrm{Q}$ values are given in $\mathrm{eV}$. The creep rate at given $\tau$ and $\mathrm{T}$ is the sum of these two creep rates which, 
for all practical purposes, turns out to be the larger of the two rates except in the very narrow range of $\tau$ where the two creep rates are nearly the same.

\subsubsection{Role of Bi Precipitates}

At the eutectic temperature $\left(139^{\circ} \mathrm{C}\right)$ the solubility of $\mathrm{Bi}$ in $\mathrm{Sn}$ is $21 \mathrm{wt} \%$, while at room temperature the solubility is about $2 \mathrm{wt} \%$. The Sn-rich eutectic phase, therefore contains Bi precipitates, which are illustrated in Figure 4.11. It is important to comment on the role of these Bi precipitates.

Steady-state creep rates were measured at $25^{\circ} \mathrm{C}$ and $90^{\circ} \mathrm{C}$ for $\mathrm{Sn}-5 \mathrm{Bi}$ joints. The data is shown in Figure 4.12. At room temperature, the Sn-rich phase contains a small amount of Bi precipitates. The room temperature data for $\mathrm{Sn}-2 \mathrm{Bi}$ and $\mathrm{Sn}-5 \mathrm{Bi}$ are shown together in Figure 4.13. Although additional temperature data are needed to determine the precise value of the activation energy, this initial data on $\mathrm{Sn}-5 \mathrm{Bi}$ suggests that $\mathrm{Sn}$ 2Bi and $\mathrm{Sn}-5 \mathrm{Bi}$ show similar creep behavior. The steady-state creep behavior of the high-stress mechanism for Sn-5Bi can also be represented by an equation in the form of Equ.(1). Using similar analysis methods described above, the resulting constitutive equation is:

$$
\dot{\gamma}=\left(2.8 \times 10^{26}\right)\left[\frac{\tau}{G}\right]^{6.0} \exp \left[-\frac{0.86}{k T}\right] \quad \text { (high stress) (28) }
$$

Only the high stress regime is represented here since the low stress mechanism was not observed at room temperature. The constitutive relations for the high-stress creep mechanisms of Sn-2Bi and Sn-5Bi (Eqs. 26 and 28) appear to be essentially the same. 
Bartels [63] measured the steady-state creep of $\mathrm{Sn}-10 \mathrm{Bi}$ and $\mathrm{Sn}-15 \mathrm{Bi}$ joints at room temperature. The presence of Bi precipitates does not appear to significantly change the creep behavior of the Sn-Bi solid solution as shown in Figure 4.14.

\subsubsection{Creep Behavior of Pure Bi Joints}

Constant load creep tests were conducted on pure $\mathrm{Bi}$ joint samples at $25^{\circ} \mathrm{C}$ and $90^{\circ} \mathrm{C}$.

The loads used covered the range of shear stress between 4.0 and $12.0 \mathrm{MPa}$, producing steady-state strain rates that ranged from $\approx 10^{-8}$ to $\approx 10^{-2} / \mathrm{sec}$. Only one creep mechanism was observed with a stress exponent of $n \approx 10$. Unfortunately the joints were of poor quality and the data should be evaluated with caution. Part of the problem stems from the fact that pure $\mathrm{Bi}$ is not a typical solder material. The no clean flux system contained in the solder paste was not originally designed for use with pure $\mathrm{Bi}$. Due to the poor quality of the pure Bi joint specimens, it was decided during the coarse of this work to abandon additional temperature testing on pure $\mathrm{Bi}$ joint specimens and refer to the literature for data regarding the creep behavior of bulk bismuth samples.

Activation energies reported for creep of $\mathrm{Bi}$ are fairly consistent and range from 0.49 $\mathrm{eV}$ to $0.6 \mathrm{eV}[43,46,47]$ These values are in agreement with the activation energy reported for self-diffusion of $\mathrm{Bi}\left(\mathrm{Q}_{S D} \approx 0.6 \mathrm{eV}\right)$. $[48,49]$ Literature values for the stress dependence(n) however, vary. Raeder et. al [43] report $n \approx 8.2$ while Goltsev et. al [47] report $n \approx 3.6$. Neither reference includes information about the microstructure. Singh and Merchant [46] report creep data measured using a spherical indentation method with a " $\alpha$ " $\geq 5$ but caution against comparing these results with those from other creep tests. Therefore, the thermal dependence of creep in pure $B \mathrm{i}\left(\mathrm{Q}_{\mathrm{Bi}} \approx 0.6 \mathrm{eV}\right)$ is known with some certainty, but the stress dependence $(\mathrm{n})$ is not clearly understood. 


\subsubsection{Creep Behavior of Sn-Bi Eutectic Joints}

The creep behavior of bulk Sn-Bi eutectic and Sn-Bi eutectic joints have been studied in some detail.[7-12] This material was included in the current study for completeness and comparison. The creep data for the $\mathrm{Sn}-\mathrm{Bi}$ eutectic specimen cooled at $20^{\circ} \mathrm{C} / \mathrm{min}$. have already been presented in Figure 2.5 from reference [8]. The steady-state strain was $\approx 10 \%$. The discussion in section 2.4 . 2 . is sufficient to describe the creep behavior of $\mathrm{Sn}-\mathrm{Bi}$ eutectic joints cooled at moderate rates and will not be repeated here.

The creep data for the quenched $\mathrm{Sn}-\mathrm{Bi}$ eutectic joints, however, have not yet been presented. The microstructure is somewhat finer, but still lamellar. Steady-state creep rates were measured at room temperature at intermediate shear stresses. The data are shown in Figure 4.15 along with room temperature creep data for lamellar $\mathrm{Sn}-\mathrm{Bi}$ eutectic joints cooled at moderate rates. The best fit to the data gives a stress exponent:

$$
\mathrm{n} \approx 2.4
$$

The steady-state strain was $\approx 9 \%$. Several data points were measured at higher temperatures $\left(40^{\circ} \mathrm{C}, 70^{\circ} \mathrm{C}\right.$, and $\left.90^{\circ} \mathrm{C}\right)$ in order to obtain an estimate value for the activation energy. Based on this data, $Q \approx 0.86 \mathrm{eV}$ which would suggest that, although the $\mathrm{n}$ value is midway between that expected for a low-stress bulk mechanism and a grain boundary mechanism, the rate controlling creep mechanism is not a grain boundary mechanism. Also shown in Figure 4.15 are two data points measured previously in this laboratory by Bartels [63] for Bi-Sn eutectic joints quenched in liquid nitrogen. While the exact geometry of these test specimens is unknown, the probable joint size is comparable to the size of solder joints tested in this work. Unfortunately, information about the microstructure is not available. The steady-state creep rates 
measured by Bartels were somewhat higher than the strain rates measured in this study and suggest the possibility of superplastic behavior. The data measured by Bartels, however, is insufficient to determine the nature of the creep behavior. Attempts were made to use liquid nitrogen as a quenching medium in the current study. The singleshear creep specimens, however, were unable to withstand the thermal shock and failed upon cooling. 


\section{DISCUSSION}

\subsection{Role of Constituent Phases in Controlling Eutectic Creep Behavior}

Experimental results of the current study provide a framework for discussion of the role of constituent phases in controlling the creep behavior of two-phase microstructures. The eutectic compositions of the In-Ag and $\mathrm{Sn}-\mathrm{Bi}$ alloy systems represent distinctly different microstructures. In the In-Ag eutectic the In-rich phase has a much greater volume fraction than the AgIn2 intermetallic. The In-rich phase is continuous throughout the joint while the AgIn2 intermetallic phase is discontinuous. The Sn-Bi eutectic, on the other hand, contains approximately equal volume fractions of the $\mathrm{Sn}$ rich and Bi phases. Each phase is continuous.

\subsubsection{In-Ag System}

The steady-state creep properties of In-Ag eutectic joints have been described in detail in section 4.1 above. To place the data in context, Figure 5.1 shows the $30^{\circ} \mathrm{C}$ data plotted along with steady-state creep data for pure In on a Cr-Ni-Pd substrate [60], InSn eutectic on a Ni substrate [61*], and Bi-Sn eutectic [7,8,9*]. The similarity of the In$\mathrm{Ag}$ creep rates to those of $\mathrm{In}$ is not surprising. The In-Ag microstructure is approximately $92 \%$ by volume In-rich phase (which is essentially pure In); it would be surprising if its creep behavior were not dominated by the In phase. Note that the eutectic is slightly stronger than pure In, as one would expect as a consequence of the reinforcement provided by the intermetallic constituent.

\subsubsection{Sn-Bi System}

The steady-state creep properties of $\mathrm{Sn-xBi}$ solid solutions have been described in detail in section 4.2 above. A comparison of the creep behavior of Sn-2Bi joints and Sn-Bi eutectic joints measured at $25^{\circ} \mathrm{C}$ and $75^{\circ} \mathrm{C}$ is shown in Figure 5.2. Both $\mathrm{Sn}-2 \mathrm{Bi}$ and $\mathrm{Sn}$ - 
Bi eutectic appear to exhibit two parallel mechanisms. The stress exponents and activation energies are similar. The $\mathrm{Sn}-2 \mathrm{Bi}$ solid solution is slightly more creep resistant than $\mathrm{Sn}-\mathrm{Bi}$ lamellar eutectic.

Due to the difficulties in preparing pure $\mathrm{Bi}$ joints, the creep data should be evaluated with caution. A precise constitutive relation could not be determined. Nevertheless, it is possible to get a rough idea as to how the creep behavior of pure $\mathrm{Bi}$ compares to the creep behavior of $\mathrm{Sn}-\mathrm{Bi}$ eutectic and $\mathrm{Sn}-2 \mathrm{Bi}$ solid solution. Figure 5.3 compares the room temperature data for all three materials. It is also helpful to refer to literature data reported for bulk Bi specimens. Activation energies for creep of $\mathrm{Bi}$ reported in the literature are fairly consistent and range from $0.49 \mathrm{eV}$ to $0.6 \mathrm{eV}[43,46,47]$ These values are significantly less than the $Q$ values calculated here for the low-stress and high-stress regimes of both the $\mathrm{Sn}-2 \mathrm{Bi}$ solid solution and the Sn-Bi eutectic. Unfortunately, values for the stress exponent (n) of creep in pure Bi vary significantly (n ranges from 3 to 10 ) $[43,46,47$, current study], thus the stress dependence is not clearly understood. See section 4.2.3.

Bi has a rhombohedral crystal structure with partially covalent bonding. The directionality of the bonding would imply that plastic deformation is difficult. The

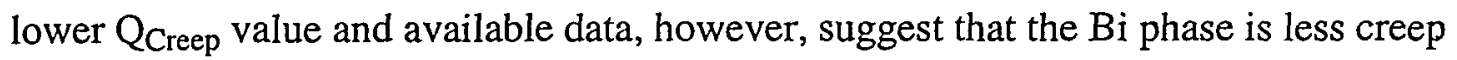
resistant than the Sn-rich phase over the given range of applied shear stress. The creep behavior of Sn-Bi eutectic, with a lamellar microstructure, appears to be dominated by the creep behavior of the Sn-rich phase.

\subsubsection{Continuous vs. Discontinuous Phases}

For the purposes of this study, only two-phase microstructures, with a significant difference in creep behavior of the individual phases, were considered. The 
experimental data suggest that, when each phase of a two-phase microstructure, exhibits significantly different creep behavior, the harder or more creep resistant phase will dominate the creep behavior in a lamellar microstructure, if both phases are continuous. If a microstructure contains a hard, discontinuous phase, the creep behavior of this phase is not important.

\subsection{Application of Two-Phase Creep Models from Literature}

The unit cell model [37] assumes that the creep rate of the composite "primarily manifests from the deformation of matrix" while the second phase is rigid and nondeformable in the given temperature range. The model predicts the steady-state creep behavior of composites based on the creep behavior of the matrix and the volume fraction of the second phase. (See section 2.4.1.) This model has been applied to both the Sn-Bi and In-Ag systems. Figure 5.4 shows the predicted creep rates along with the measured creep rates for the In-Ag eutectic joints. Good agreement is observed for data measured in the high stress regime where the bulk creep mechanism dominates the behavior. Here the steady-state creep rate is not dependent on the microstructure. In the low-stress regime however, the predicted creep rates are lower than the measured values. This is not surprising, in light of the fact, that the dominating creep mechanism in the low-stress regime is a grain boundary mechanism which is strongly dependent on the microstructure.

In the case of Sn-Bi eutectic (volume fraction 51:49), the model was applied using $\mathrm{Sn}-2 \mathrm{Bi}$ as the matrix. The experimental results from section 4.2.2. were used as input for the model. Figure 5.5 illustrates that the stress dependence and thermal dependence predicted by the model for the high stress regime are in reasonable agreement, although the thermal dependence of the low stress regime is not well predicted by the model. 
The predicted steady-state creep rates are underestimated by at least an order magnitude for the high stress and low stress regimes. Unfortunately, the unit cell model could not be applied using the Bi phase as the matrix (which would be more consistent with the theoretical assumptions outlined above) due to uncertainty of the experimental data. (See section 4.2.3.)

In general, the application of the unit cell model to the In-Ag system, supports the hypothesis that the creep behavior of a two-phase microstructure is dominated by the creep behavior of the continuous phase. The unit cell model assumes a particular microstructure which does not apply in the case of the $\mathrm{Sn}-\mathrm{Bi}$ eutectic, therefore, the model proposed by Ravichandran and Seetharaman is less useful in predicting the creep behavior of Sn-Bi eutectic.

Another continuum mechanics model proposed by Tanaka et al.[42] predicts the creep deformation of ductile two-phase alloys . This model has been applied to $\mathrm{Sn}-\mathrm{Bi}$ eutectic, but the predicted steady-state creep rates are significantly lower than the experimental values.[43] Raeder et. al [43] use input data from bulk specimens. The model proposed by Tanaka et al. [42] could not be applied to the data measured in the current study due to the uncertainty of the creep data for pure Bi joints. (Furthermore, stress exponent values reported in the literature for creep of pure Bi do not agree; $\mathrm{n}$. varies from 3 to 10.) To the best of my knowledge, theoretical models have not yet accurately predicted the steady-state creep behavior of $\mathrm{Sn}-\mathrm{Bi}$ eutectic from the creep properties of the constituent phases. 


\subsection{Attainability of Superplastic Microstructures in Solder Joints}

It is well documented in the literature $[18,62]$ that a superplastic microstructure (described in section 2.3.4. above) can contribute to improved fatigue resistance, especially if the fatigue loading occurs at relatively low strain rates. Research on $\mathrm{Pb}-\mathrm{Sn}$ eutectic joints $[50,64-66]$ demonstrates that it is possible obtain a superplastic microstructure by: 1) quenching joint specimen, or 2) adding chemical species to inhibit the formation of the classic eutectic microstructure. It is useful at this point, to comment on attainability of superplastic microstructures in In-Ag and Sn-Bi eutectic solder joints.

\subsubsection{In-Ag System}

Metallographic observations and creep test results show that it is relatively easy to obtain a superplastic microstructure with In-Ag eutectic solder joints. The cooling rate of the test specimens was approximately $35^{\circ} \mathrm{C} / \mathrm{min}$., which is well within practical manufacturing limits. (In industry, the maximum practical limit for the cooling rate of printed circuit boards is $\sim 240^{\circ} \mathrm{C} / \mathrm{min}$.[67]) Even with a "slow" cooling rate of $35^{\circ} \mathrm{C} / \mathrm{min}$, the In-Ag eutectic test specimens exhibited some degree of superplasticity. The microstructure appeared to be fine-grained $(\sim 5 \mu \mathrm{m})$ and the measured activation energy $(Q)$ and stress exponent (n) in the low stress regime were indicative of a grain boundary creep mechanism. Furthermore, tests conducted in the low-stress regime exhibited extensive steady-state strain.

\subsubsection{Sn-Bi System}

$\mathrm{Sn}$-Bi eutectic, however, seems to preserve a lamellar microstructure over a wide range of cooling rates as previously mentioned and illustrated in Figure 2.7. The current study employed an even faster cooling rate than those used in refs. [7,8,9*]: Sn-Bi eutectic joints were quenched in ice water from a reflow temperature of $170^{\circ} \mathrm{C}$. The 
cooling rate could only be estimated, but was $\sim 70^{\circ} \mathrm{C} / \mathrm{sec}$. This cooling rate is much greater than the practical manufacturing limits. The quenched microstructure however, although somewhat finer, was still lamellar in nature. Creep test results from these quenched specimen did not exhibit superplastic characteristics. Although the stress exponent was $<3(n \approx 2.4)$ and the steady-state creep rates were slightly higher (Figure 4.15), the measured activation energy, $Q$, was indicative of a bulk creep mechanism. Furthermore, extensive strain in the steady-state regime was not observed.

It is difficult, therefore, to obtain a superplastic microstructure for $\mathrm{Sn}-\mathrm{Bi}$ eutectic joints by varying the cooling rate. As illustrated in Figure 4.7, a fine, equiaxed microstructure of $\mathrm{Sn}-\mathrm{Bi}$ eutectic is easily produced by cold-working and annealing of a bulk sample. This, however, is obviously not useful in terms of microelectronic manufacturing. A promising approach seems to be to inhibit the formation of the "classic" lamellar eutectic microstructure by adding chemical species to Sn-Bi eutectic solder. Interesting research in this area is being conducted by McCormack et. al [68] on bulk specimen. This task, however, is beyond the scope of the current study.

\subsection{Alternative Constitutive Equations}

Another equation which is often used to relate steady-state creep rate to stress and temperature was first proposed by Garofalo [69] and later adopted by others[23,70,71]. Frost and Ashby [23] modified this sinh law relation by taking into account the temperature-dependence of the shear modulus. The empirical equation can be expressed as:

$$
\dot{\gamma}=\mathrm{A}\left(\sinh \left[\frac{\alpha \tau}{\mathrm{G}}\right]^{\mathrm{n}} \exp \left[-\frac{\mathrm{Q}}{\mathrm{kT}}\right]\right.
$$


Eq. 30 reduces to a power law equation, such as that proposed by Dorn[22], at low stresses and to an exponential law at high stresses. Although the Garofalo equation is useful for describing power-law creep (one mechanism only) and power-law breakdown with one equation, it is less useful for describing power-law creep where there are two independent creep mechanisms as discussed in this work. Unsuccessful attempts were made to fit one sinh law equation to the In-Ag eutectic data measured in this study, since the two independent creep mechanisms observed in In-Ag eutectic exhibited two distinctly different activation energies.

It is the author's opinion that the creep behavior of $\mathrm{Sn}-\mathrm{xBi}$ solid solution and $\mathrm{Sn}-\mathrm{Bi}$ eutectic reflect two independent creep mechanisms operating in parallel, as well as power-law breakdown at high stresses (approximately $\tau / \mathrm{G}>10^{-3}$ ). Figure 4.8 clearly shows two power-law creep mechanisms $(n \approx 3$ and $n \approx 6)$ in addition to power-law breakdown $(\mathrm{n} \approx 11)$. Nevertheless, the $\mathrm{Sn}-\mathrm{xBi}$ solid solution and Sn-Bi eutectic joint data can be fit to a sinh equation because the two independent creep mechanisms have similar activation energies (but different $\mathrm{n}$ values). The Garofalo equation has been used to represent creep data measured from Sn-based alloy specimens.[16,72,73] There are, however, inherent problems with this sinh equation as pointed out by Frost and Ashby.[23] Equation (30) uses only two parameters, $\mathrm{n}$ and $\alpha$, to describe three quantities: $n$ describes the power-law; $\alpha$ designates the stress at which the power-law. breaks down; and n $\alpha$ describes the strength of the exponential stress-dependence. Frost and Ashby point out that, without a physical model, "it must be fortuitous that any set of $\mathrm{n}$ and $\alpha$ can correctly describe the behavior over a wide range of stresses". Therefore, for the purposes of this study, the Dorn [22] equation (Eq. 1) was chosen to represent the data in order to clearly convey information regarding the creep mechanisms. 


\section{SUMMARY and CONCLUSIONS}

The mechanical properties of low melting temperature solders are highly influenced by their creep properties. This study has provided insight regarding the dominant mechanisms which control creep behavior of two-phase, low-melting temperature alloys. For continuous, two-phase microstructures, where each phase exhibits significantly different creep behavior, the harder or more creep resistant phase will dominate the creep behavior in a lamellar microstructure. If a microstructure contains a hard, discontinuous phase, the creep behavior of this phase is not important. These conclusions are supported by creep data measured using joint specimen on two alloy systems: In-Ag and $\mathrm{Sn}-\mathrm{Bi}$.

The Sn-Bi eutectic microstructure consists of two bi-percolated, continuous phases. This type of microstructure is possible because the volume fraction of the Sn-rich and $\mathrm{Bi}$ phases (51:49) is approximately equal. The creep behavior of $\mathrm{Sn}-\mathrm{Bi}$ eutectic, with a lamellar microstructure, is dominated by the creep behavior of the Sn-rich phase, which is the harder phase over the given range of applied shear stress.

The In-Ag eutectic microstructure consists of an In-rich matrix with a discontinuous AgIn2 intermetallic phase. The creep behavior of In-Ag eutectic is dominated by the creep behavior of the softer phase (In-rich matrix), which is essentially pure In. The creep behavior of the second phase (AgIn2) is not important.

Constitutive equations, generated from creep tests on joint specimen, have been presented. These equations are particularly useful because the creep properties were measured from microstructures simulating those in industry. Furthermore, a superplastic microstructure is easily obtained for In-Ag eutectic joints using cooling 
rates that are well within practical manufacturing limits. It is difficult, however, to obtain a superplastic microstructure for $\mathrm{Sn}-\mathrm{Bi}$ joints by varying the cooling rate within practical manufacturing limits.

\section{FUTURE RESEARCH}

Knowledge regarding creep mechanisms of eutectic solders is critical in determining the creep-fatigue interaction leading to joint failure. This work has investigated the creep mechanisms in two-phase microstructures. In both In-Ag eutectic and $\mathrm{Sn}-\mathrm{Bi}$ eutectic it appears that two creep mechanisms operate in parallel. Different creep mechanisms imply that there is a different response to fatigue. It would be both interesting and valuable to explore the correlation between load under fatigue at a constant strain rate and the steady-state creep data measured in this work. A reasonable approach would be to conduct fatigue tests on $\mathrm{In}-\mathrm{Ag}$ and $\mathrm{Sn}-\mathrm{Bi}$ eutectic joint specimens in the regimes where different creep mechanisms are observed. 


\section{REFERENCES}

[1]

[2]

[3]

[4]

[5]

$\left[9^{*}\right]$

[10]

[20]

E. R. Bangs and R. E. Beal, Welding Research Supplement, Welding Journal, 54, 377s (1978).

W. M. Wolverton, Brazing and Soldering, 13, 33 (1987).

D. R. Frear, D. Grivas and J. W. Morris, Jr., Journal of Metals, 40,18 (1988).

T. S. E. Summers and J. W. Morris, Jr., ASME Journal of Electronic Packaging, 112, 94 (1990).

D. Tribula and J. W. Morris, Jr., ASME Journal of Electronic Packaging, 112, 87 (1990)

H. L. Reynolds, S. H. Kang, and J. W. Morris, Jr., to be published in J. Electronic Mater. , January 1999.

Z. Mei and J. W. Morris, Jr., J. Electronic Mater., 21, 599 (1992).

F. Bartels, H. L. Reynolds, and J. W. Morris, Jr., unpublished work.

J.L.F. Goldstein, Ph.D. Thesis, University of California at Berkeley, Nov. 1993; and J. W. Morris, Jr., J. L. Freer Goldstein, and Z. Mei, J. Metals, 45, 25 (1993). See Appendix B.

C. H. Raeder, L. E. Felton, D. B. Knorr, G. B. Schmeelk, and D. Lee, Proc. IEEE-CHMT int. electronics manufacturing technology symp., Santa Clara, CA, 119 (1993).

W. J. Tomlinson and I. Collier, Mater. Sci. Eng., 22, 1835 (1987).

S. Pattanaik and V. Raman, Proc. Mater. Dev. in Microelectronic Packaging, Montreal, ASM International, 251 (1991).

J. Glazer, International Materials Reviews, 40, 65 (1995).

T. H. Alden, Acta Met, 15, 469 (1967).

M. A. Clark and T. H. Alden, Acta Met, 21, 1195 (1973).

D. Mitlin, C. H. Raeder and R. W. Messler, Jr.,Met. Trans., In press.

M. C. Flemings, Solidification Processing, McGraw-Hill, Inc. (1974).

Z. Mei and J. W. Morris, Jr., ASME Journal of Electronic Packaging, 114, 104 (1992)

J. P. Chilton and W. C. Winegard, J. Inst. Met., 89, 162 (1960)

D. Tribula, Ph.D. Thesis, University of California, Berkeley, CA, 1990. 
T. B. Massalski, Cheif Ed., Binary Alloy Phase Diagrams, American Society of Metals, Metals Park, Ohio, Vols. 1 and 2 (1986). Between Properties and Microstructure, 255 (Israel University Press, 1969).

[23] H. J. Frost and M. F. Ashby, Deformation-Mechanism Maps: The Plasticity and Creep of Metals and Ceramics, Pergamon Press, New York (1982)

J. W. Edington, K. N. Melton, and C. P. Cutler, Prog. Mater. Sci., 21, 61 (1976). Sci., 9, 151 (1979).

O. D. Sherby, and J. Wadsworth., Prog. Mater. Sci., 33, 169 (1989).

C. E. Pearson, J. Inst. Met., 54, 111 (1934).

H. E. Cline and T. H. Alden, Trans. AIME, 239, 710 (1967)

J.W. Morris, Jr., J. L. Freer Goldstein and Z. Mei, in " The Mechanics of Solder Alloy Interconnects, eds. S. N. Burchett, D.R. Frear, H. S. Morgan and J. H. Lau, Van Nostrand Reinhold, New York, 1993

J. W. Morris, Jr. and H. L. Reynolds, in Experimental/Numerical Mechanics in Electronic Packaging, Vol. I,ed. R. Mahajan, Society for Experimental Mechanics, Inc., Bethel, CT (1997).

M. R. Pinnel and A. Lawley, Metall. Trans., 2, 1415 (1971)

G. F. Lucas and T. R. McNelley, Metall. Trans., 7A, 1317 (1976)

D. L. McDanels, R. A. Signorelli, and J. W. Weeton:, NASA-TN-D4173 (1967)

T. Arai, T. Kobayashi, T. Itagaki, K. Koike and N. Sakuma, Trans. Natn. Res. Inst. Metalls, 32, 1 (1990)

I. D. Choi, D. K. Matlock and D. L. Olsen, Metall. Trans., 21A, 2513 (1990)

F. W. Crossman, F. R. Karlak and D. M. Barnett, Failure Modes in Composites II, eds. J. N. Fleck and R. L. Mehan, p.8, TMS, Warrandale, PA (1974)

K. S. Ravichandran and V. Seetharaman, Acta metall. mater., 41, 3351 (1993) 
[38] L. C. Davis and J. E. Allison, Metall. and Mater.Trans., 26A, 3081 (1995)

[39] P. E. Krajewski, J. W. Jones, and J. E. Allison, Metall. and Mater.Trans., 26A, 3081 (1995)

[40] G. Bao, J. W. Hutchinson and R. M. McMeeking, Acta metall. mater., 39, 1871 (1991).

T. L. Dragone, J. J. Schlautmann and W. D. Nix, Metall. Trans., 22A, 1029 (1991).

[44]

M. Tanaka, T. Sakaki and H. Iizuka, Acta metall. mater., 39, 1549 (1991)

C. H. Raeder, D. Mitlin and R. W. Messler, Jr., J.of Mat.Sci., In press.

R. E. Frenkel, M.S. Thesis, University of California, Berkeley, 1954

F. A. Mohamed, K. L. Murty and J. W. Morris, Jr., Metall. Trans, 4, 935 (1973).

U. P. Singh and H. D. Merchant, Met. Trans., 4, 2621 (1973).

V. P. Goltsev, S. I. Zhukova and V. M. Anishchik, phys. stat. sol. (a), 96, 135 (1986).

S. Otake, Y. Ishii and N. Matsuno, Jpn. J. Appl. Phys., 20, 1037 (1981).

N. J. Matsuno, Phys. Soc. Japan, 42, 1675, (1977).

Z. Mei, D. Grivas, M. C. Shine, and J. W. Morris, Jr., J. Electronic Mater., 19, 1273 (1990).

J. C. Wei, Ph.D Thesis, Stanford University, 1981.

J. E. Dorn, in Creep and Recovery, ASM, 1957, p. 255

J. Weertman, Trans. AIME, 218, 207 (1960)

R. Darveaux, E. Yung, I. Turlik, and K. L. Murty, Mater. Res. Soc. Symp. Proc., 203, 443 (1991).

Z. Mei, R. Hansen, M. C. Shine and J.W. Morris, Jr., J. Electronic Packaging, 113, 109 (1991)

Z. Mei and J.W. Morris, Jr., J. Electronic Materials , 21, 401 (1992).

J. Seyyedi, Solder. Surf. Mt Technol., Feb. 1993, 26-32.

M. N. Crocker, R. S. Fidler, and R. W. Smith, Proc. R. Soc., A335, 15 (1973). 
[59] B. M. Drapkin and V. K. Kononenko, Izvestiya Akademii Nauk SSSR, Meetally, 2, 162 (1987).

[60] R. Darveaux, and I. Turlick, IEEE Trans. on Components, Hybrids and Manuf. Tech., 13, 929, December 1990.

[61*] J. L. Freer Goldstein, and J. W. Morris, Jr., Metall. Trans. A, 25A, 2715 (1994). See Appendix B.

[62] Z. Mei, J. W. Morris, Jr., M. C. Shine and T. S. E. Summers, J. Electronic Mater., 20, 599 (1991).

F. Bartels and J. W. Morris, Jr., unpublished work. L.K. Quan, M.S. Thesis University of California at Berkeley, Aug. 1988.

D. Tribula and J. W. Morris, Jr., ASME Journal of Electronic Packaging, 112, 87 (1990).

T.S.E. Summers, Ph.D. Thesis, University of California at Berkeley, May 1991; and ASME Journal of Electronic Packaging, 112, 94 (1992).

J. Glazer, private communication.

M. McCormack, H. S. Chen, G. W. Kammlott and S. Jin, J. Electronic Materials , 26, 954 (1997).

[70] C. M. Sellars and W. J. McG. Tegart, Mem. Sci. Rev. Met., 63, 731 (1966)

[71] W. A. Wong and J. J. Jonas, Trans. AIME, 242, 2271 (1968)

[72] K. L. Murty, H. Yang, P. Deane, and P. Magill, ASME, Adv. in Electron. Packaging, 19-1, 1221 (1997)

[73] H. Conrad, Z. Guo, and Y. H. Pao, ASME, Adv. in Electron. Packaging, 19-2, 1551 (1997)

[74] E. P. Unksov, An Engineering Theory of Plasticity, p. 157, Butterworths, London (1961). 


\section{FIGURES}

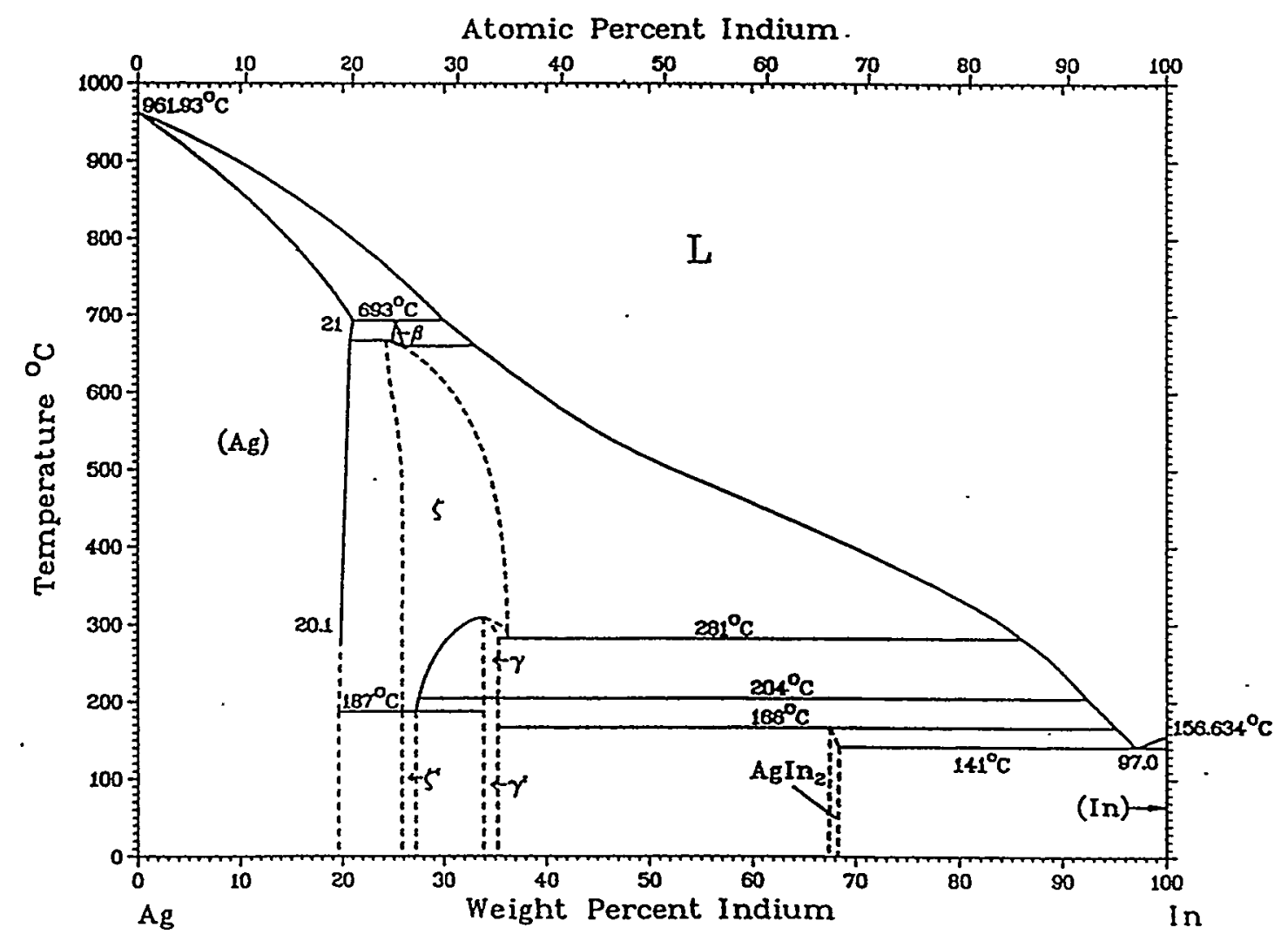

rigure 1.1. In-Ag phase diagram. [21] 


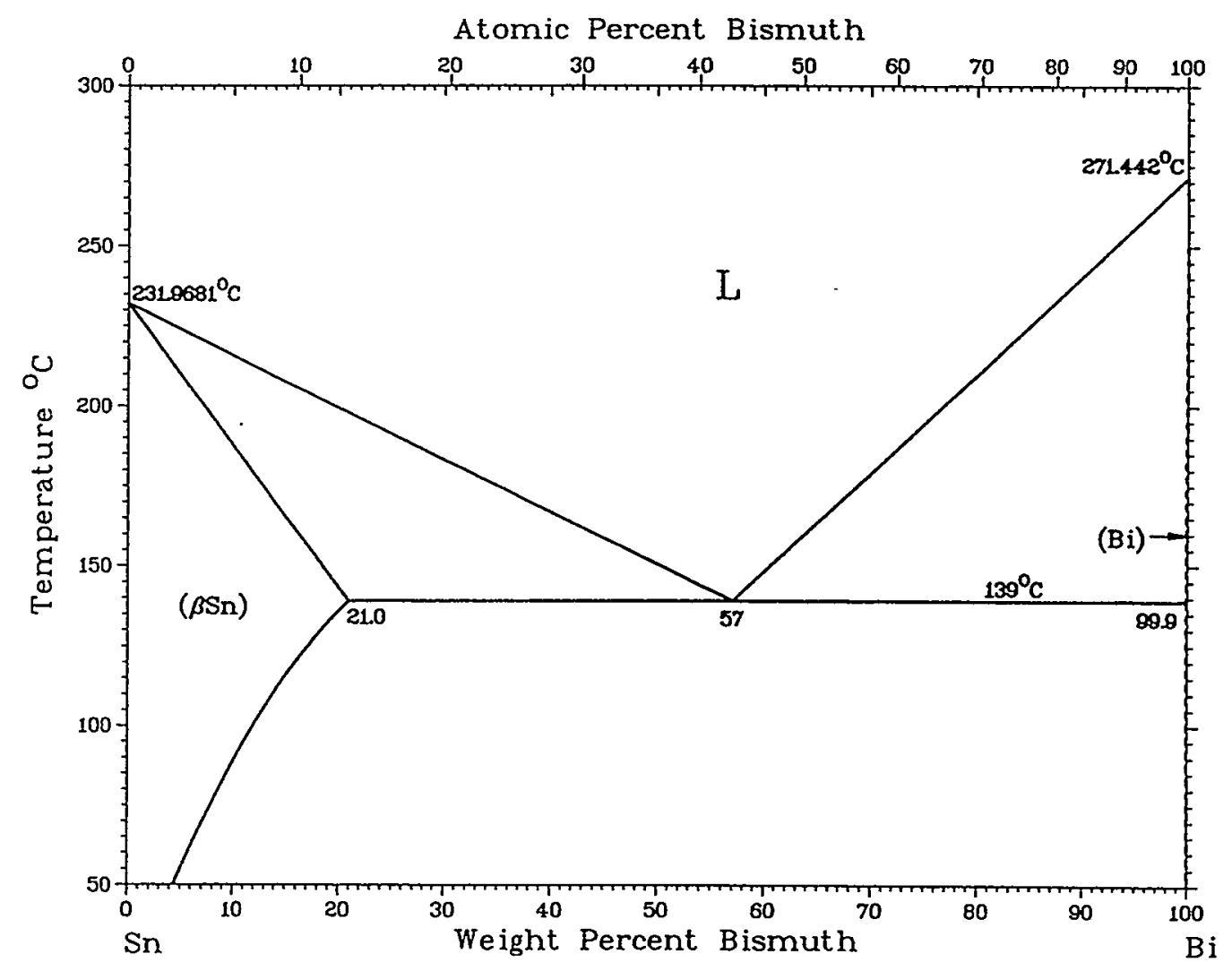

Figure 2.2. Sn-Bi phase diagram. [21] 


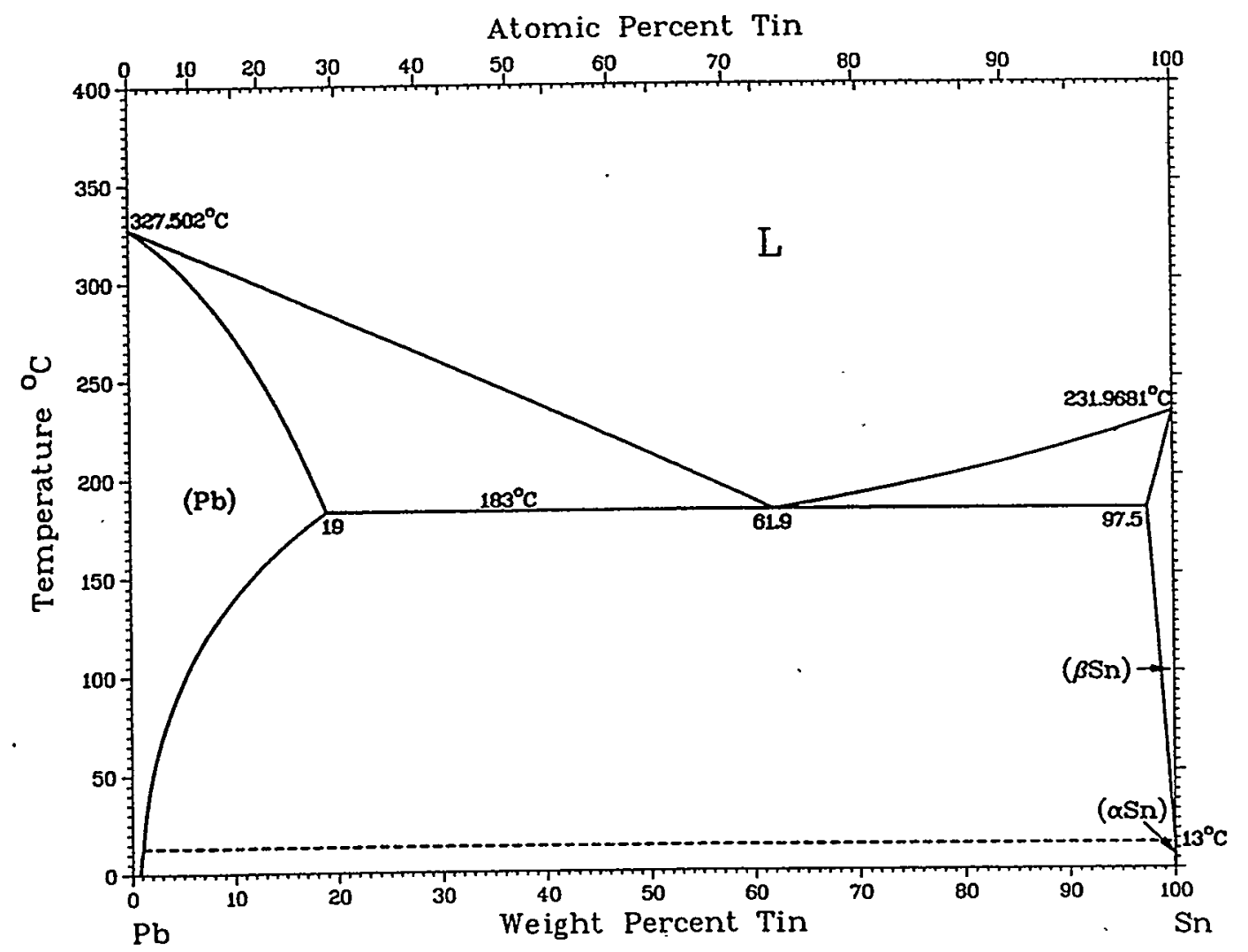

Figure 2.3. $\mathrm{Pb}-\mathrm{Sn}$ phase diagram. [21] 


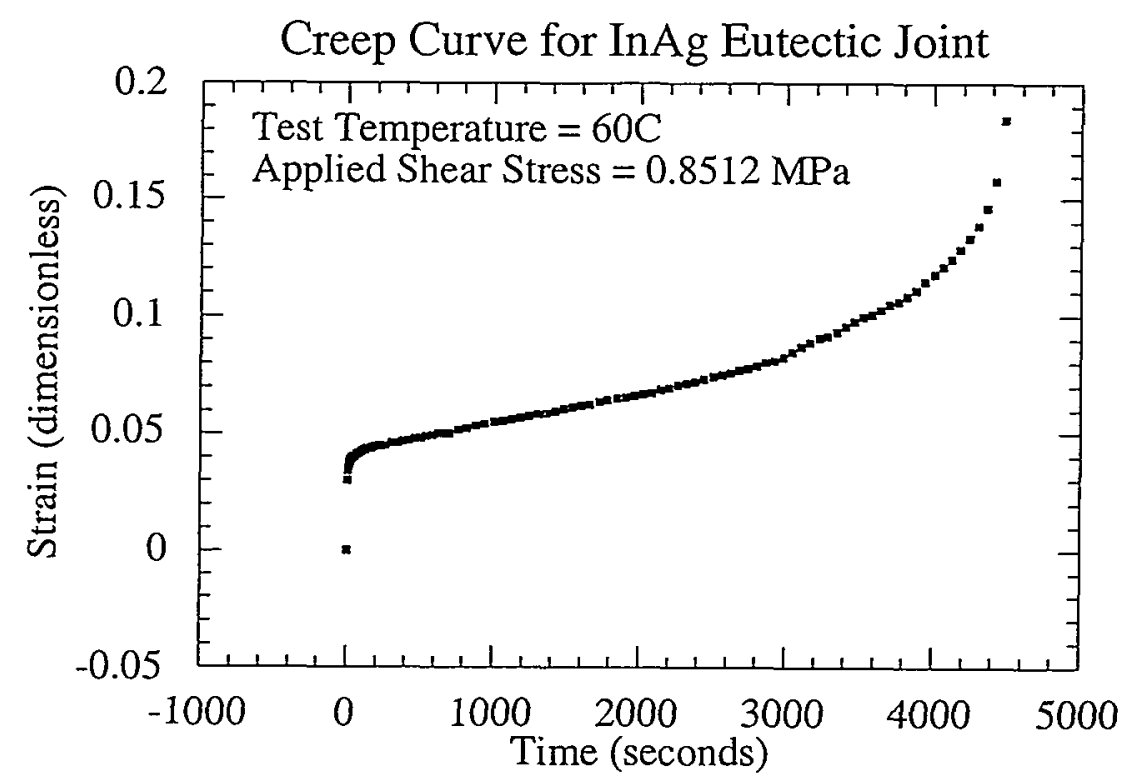

Figure 2.4. Typical creep curve showing primary, steady-state, and tertiary creep regions.[6] 


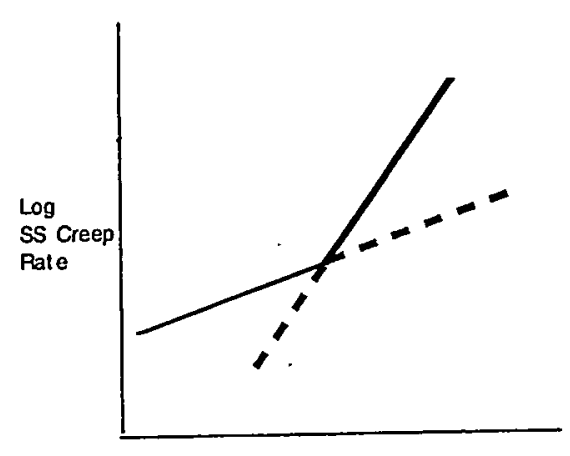

Log Stress

Parallel

Faster Mechanism Dominates

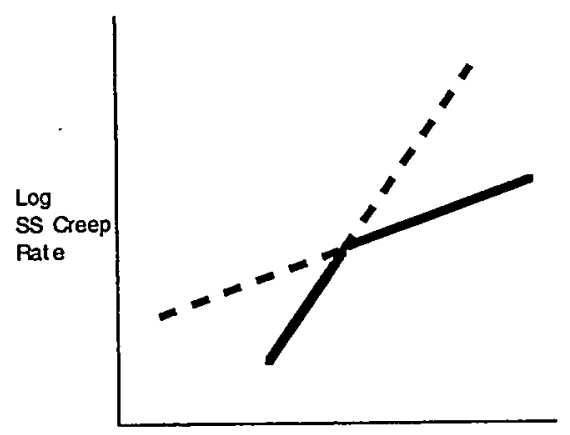

Log Stress

Series

Slower Mechanism Dominates

Figure 2.5. Schematic illustrating the behavior of multiple creep mechanisms. 


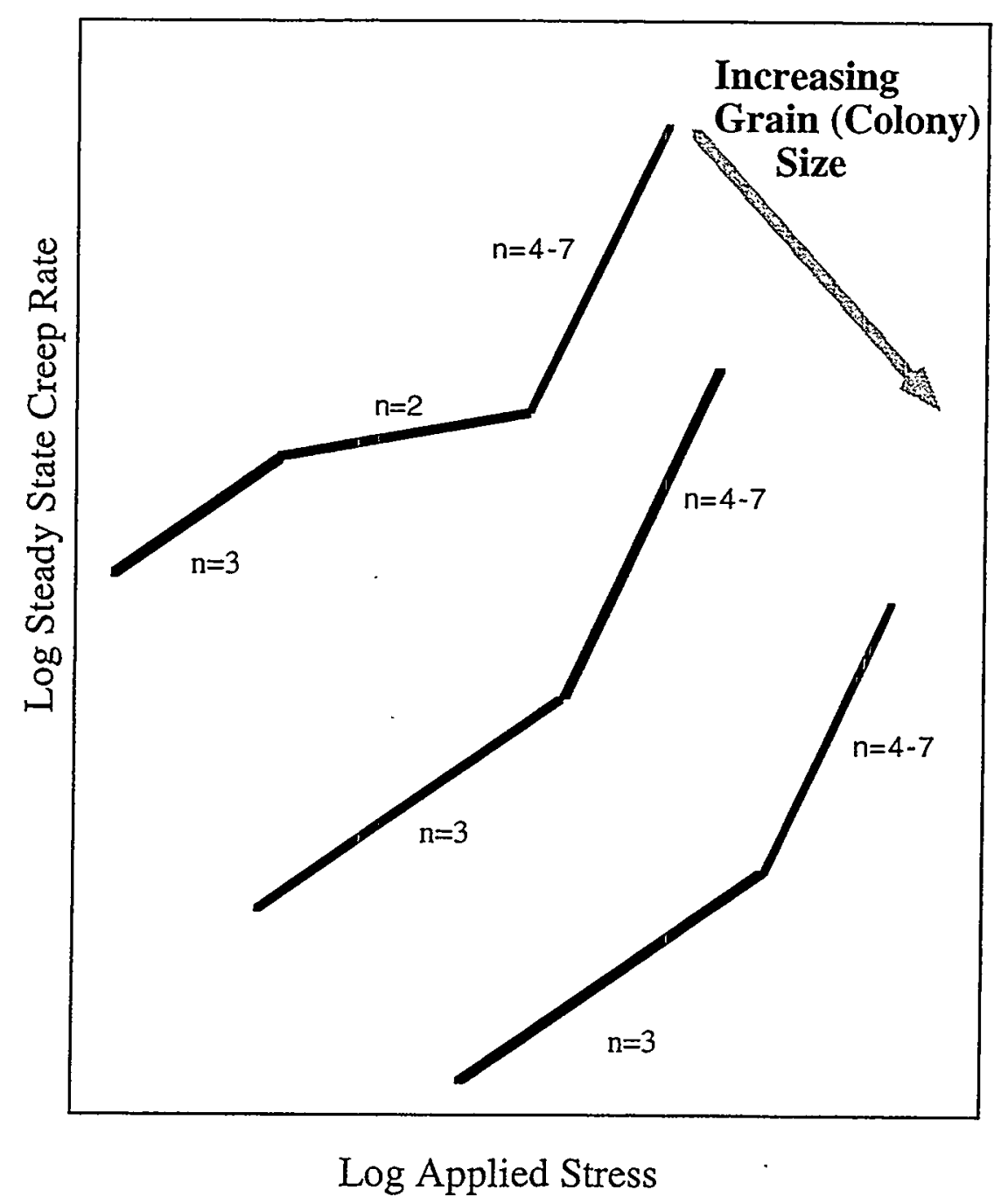

Figure 2.6. Schematic illustrating the effect of grain (colony) size on the creep rate of a typical eutectic material. [30] 
Bi-Sn Eutectic/Room Temperature Data

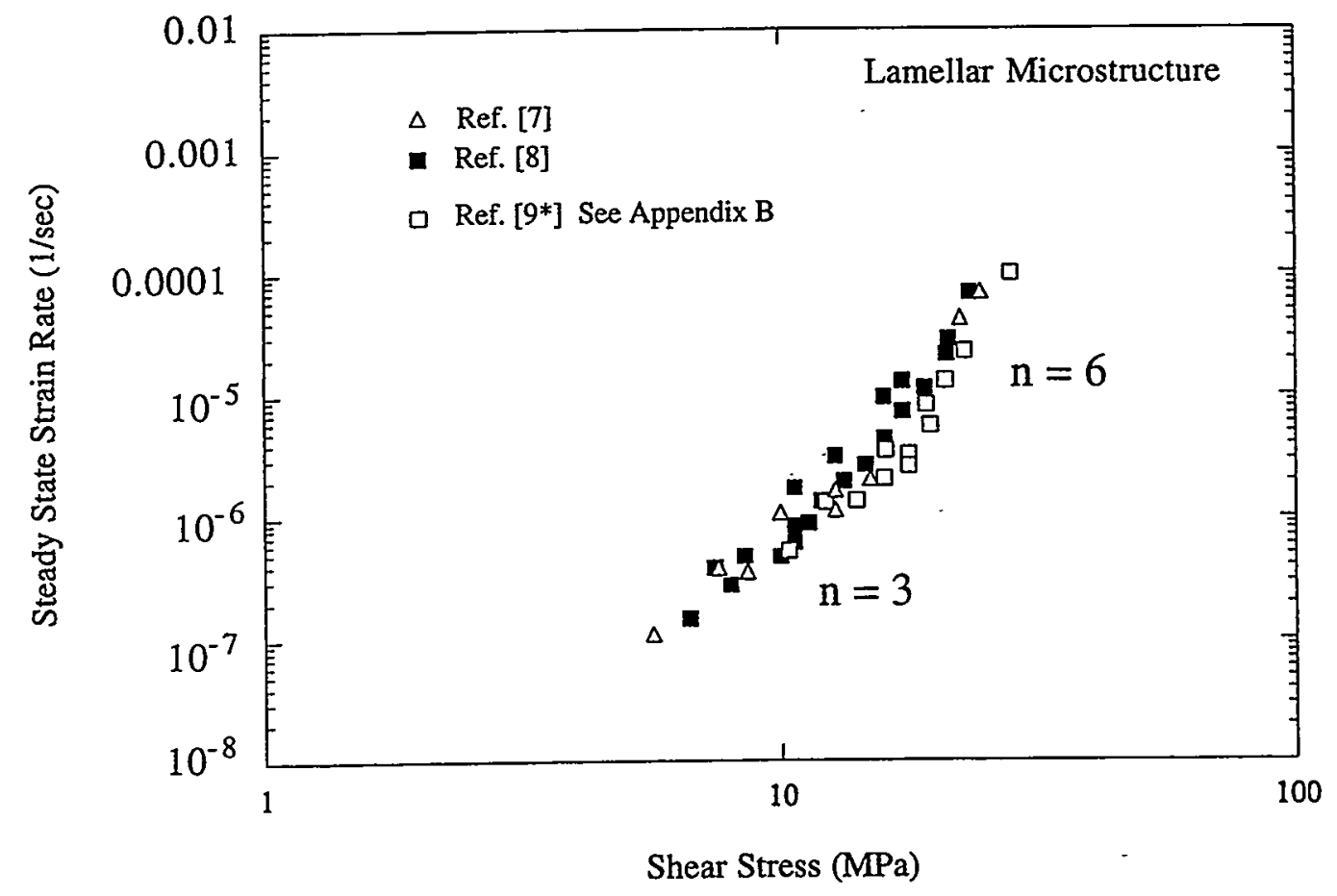

Figure 2.7. Creep behavior of Sn-Bi eutectic with "classic" (lamellar) microstructure. Different specimen geometries result in a range of cooling rates yet the microstructure and creep rate are nearly the same. 


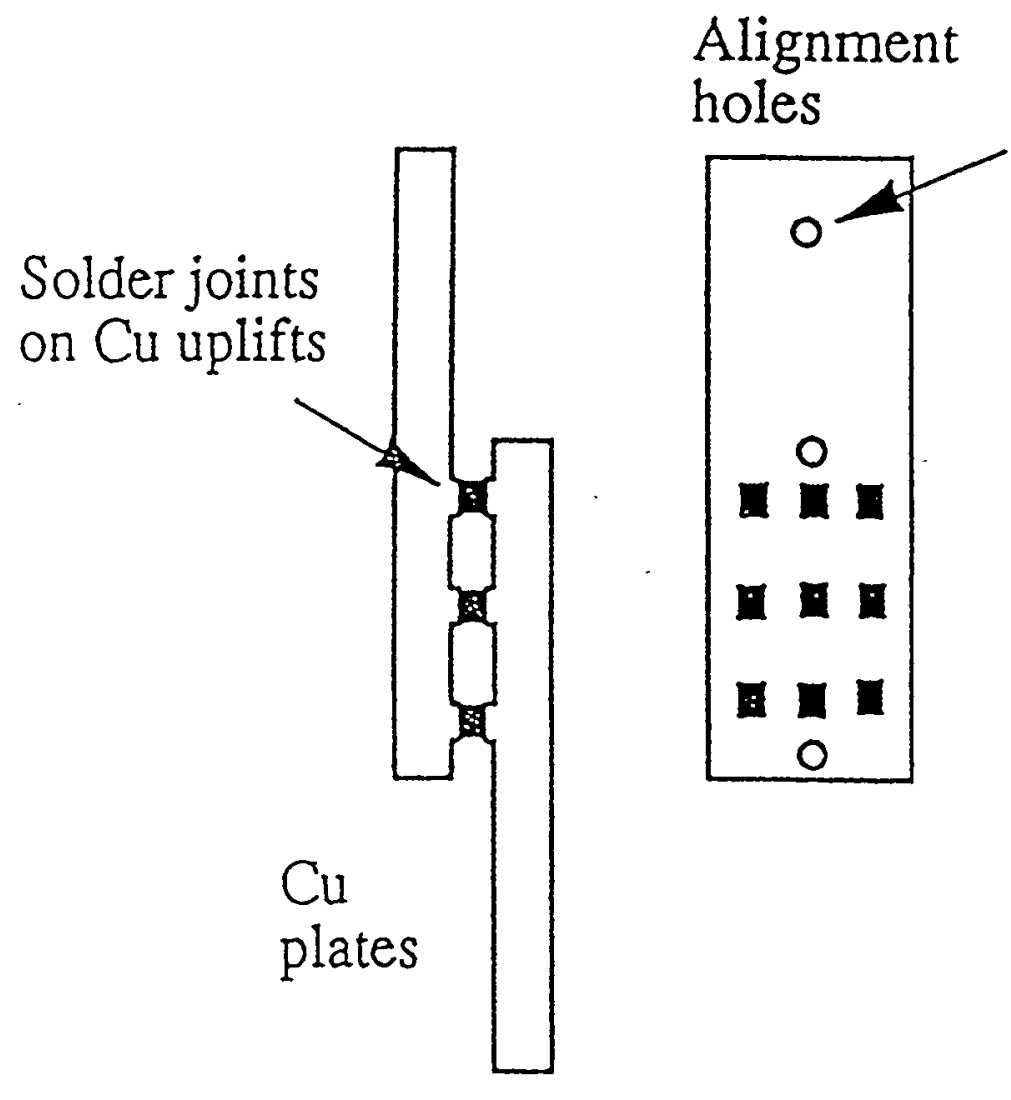

Figure 3.1. Geometry of single shear joint specimen used for creep tests.[62] Solder Pad Dimensions: Area - 80 mils x 45mils (2.03mm x $1.14 \mathrm{~mm})$ Thickness - 10 to $12 \mathrm{mils}(0.25$ to $0.30 \mathrm{~mm})$ 


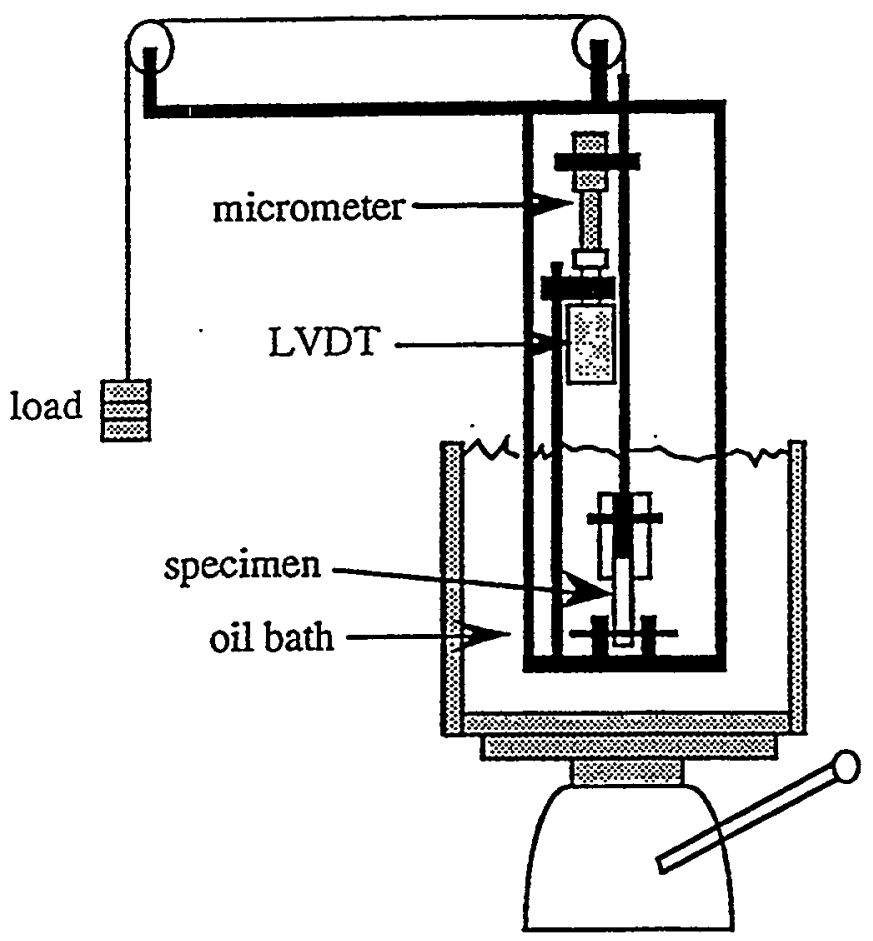

Figure 3.2. Schematic of apparatus used for constant load creep testing. 


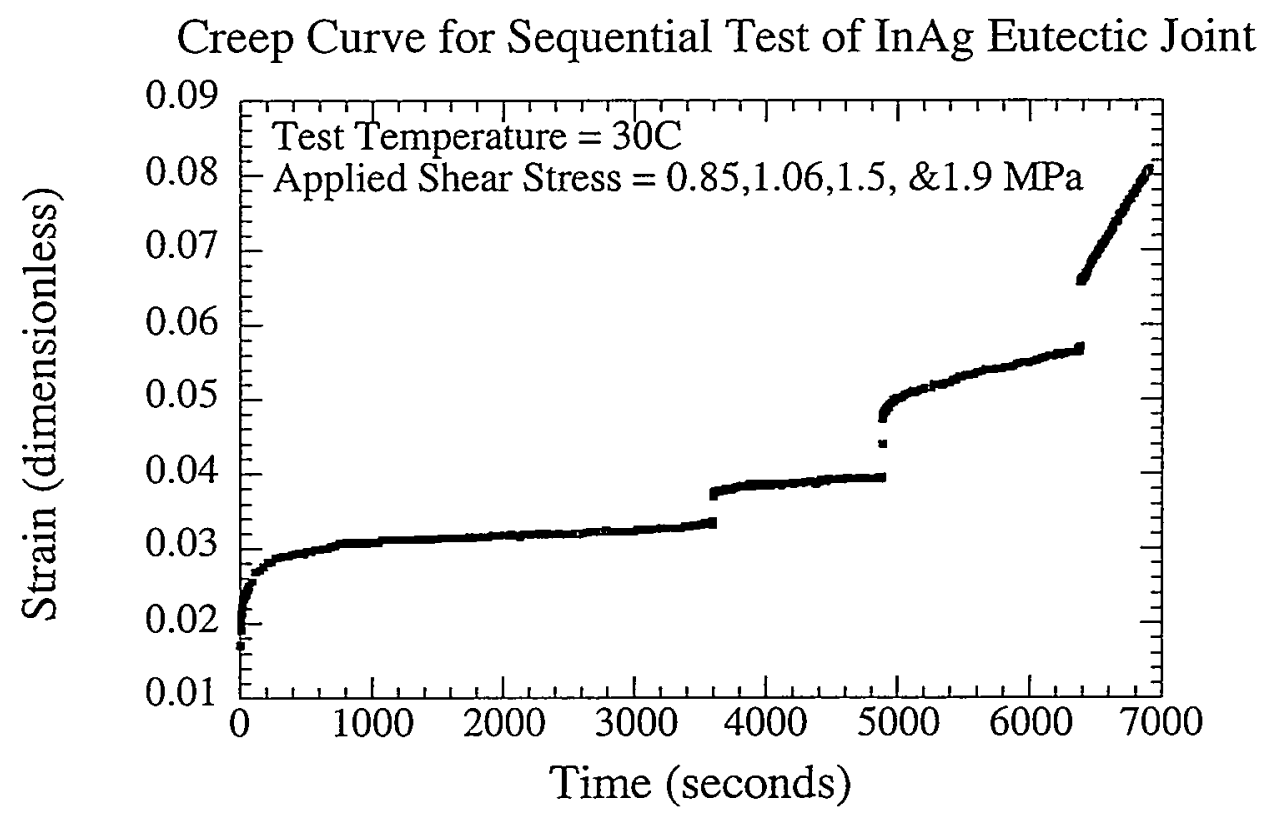

Figure 3.3(a). Typical curves obtained for a sequential creep test.[6] (a) strain vs. time 


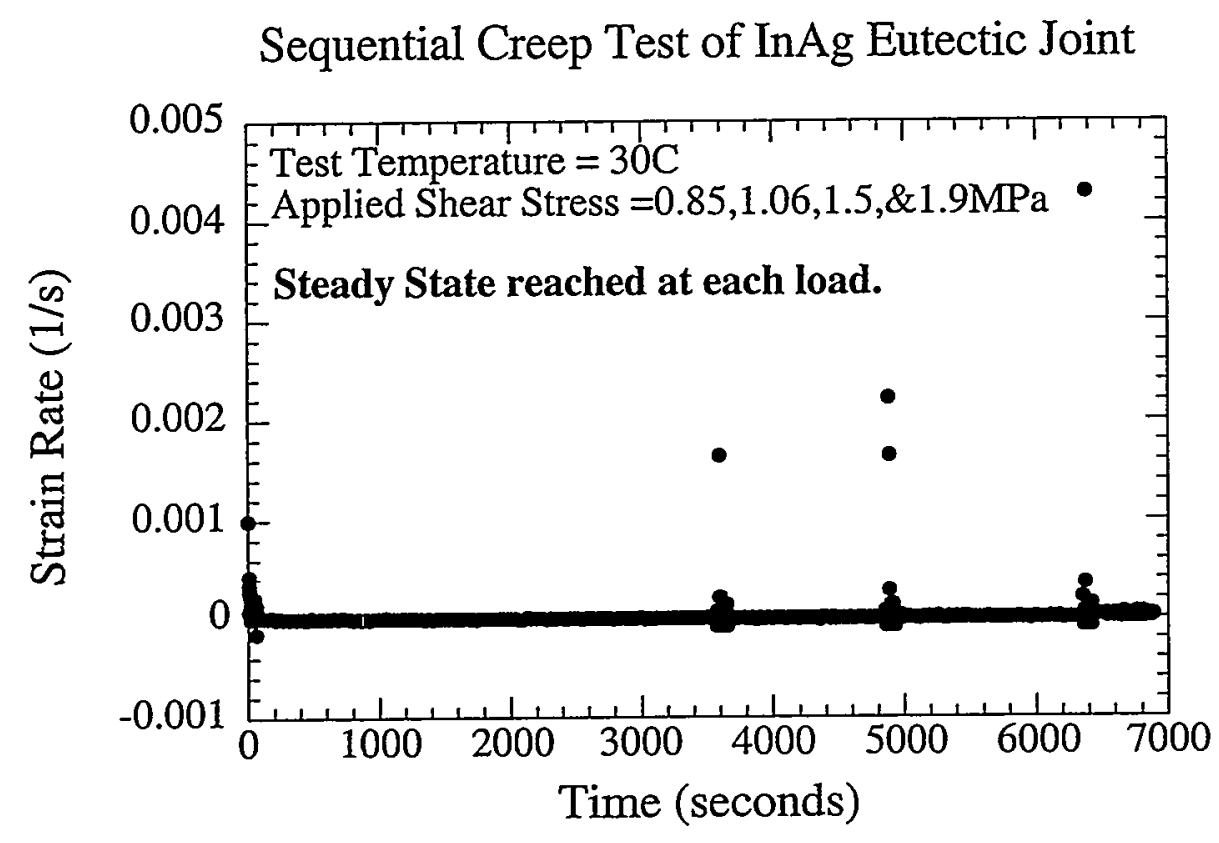

Figure 3.3(b). Typical curves obtained for a sequential creep test.[6]

(b) strain rate vs. time 


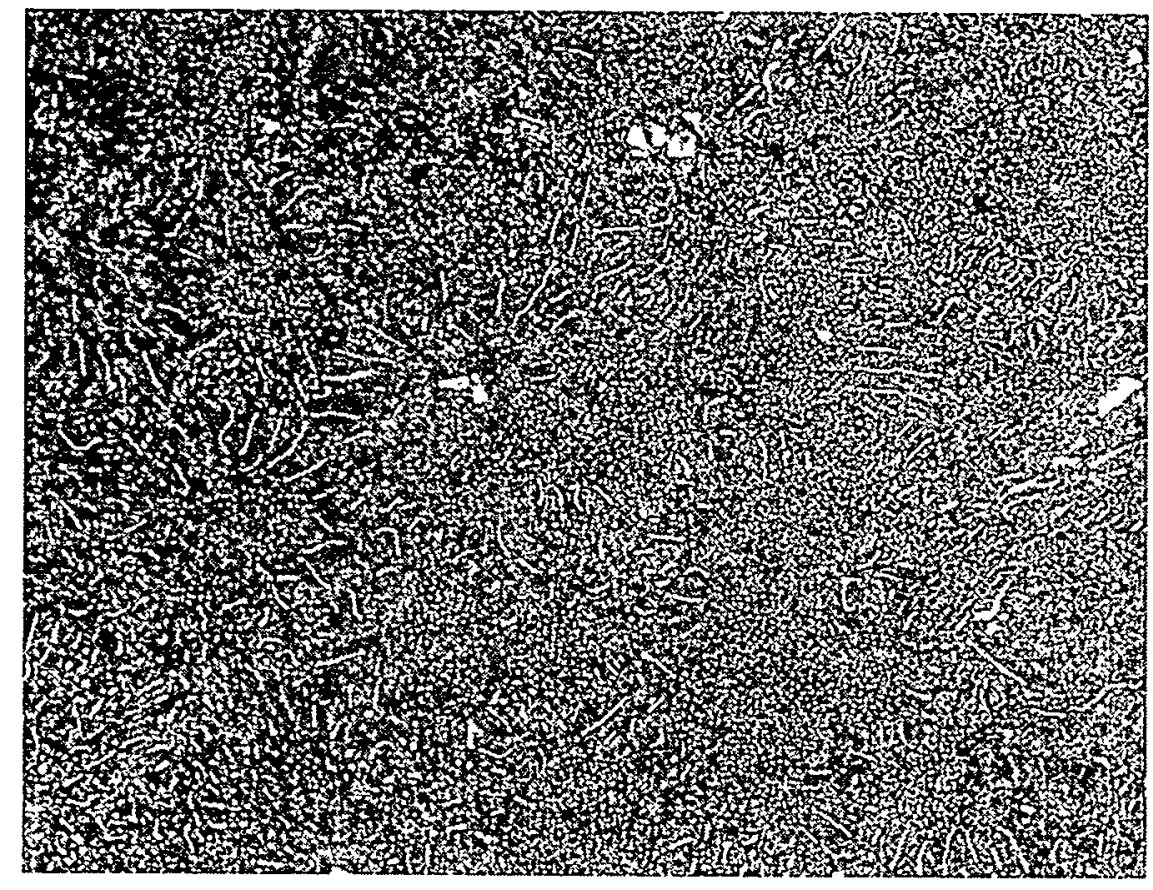

$25 \mu \mathrm{m}$

Figure 4.1(a). Optical micrographs of In-Ag eutectic solder joint. Etchant is $15 \% \mathrm{HNO}_{3}, 5 \% \mathrm{HCl}$, and $80 \% \mathrm{H}_{2} \mathrm{O}$.

The dark phase is In-rich matrix and the light phase is AgIn2 intermetallic. (a) Low Magnification 


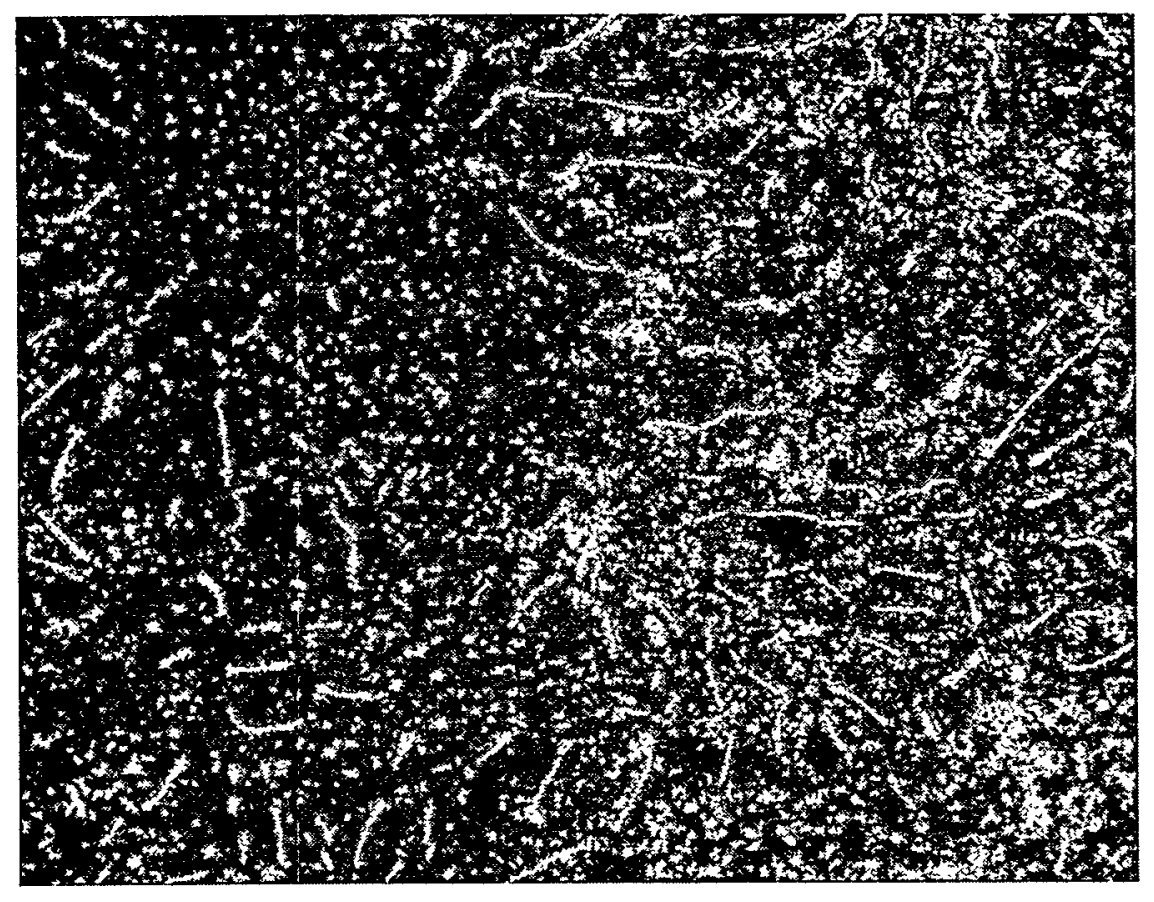

$\overline{10 \mu \mathrm{m}}$

Figure 4.1(b). Optical micrographs of In-Ag eutectic solder joint. Etchant is $15 \% \mathrm{HNO}_{3}, 5 \% \mathrm{HCl}$, and $80 \% \mathrm{H}_{2} \mathrm{O}$.

The dark phase is In-rich matrix and the light phase is AgIn2 intermetallic. (b) High Magnification 


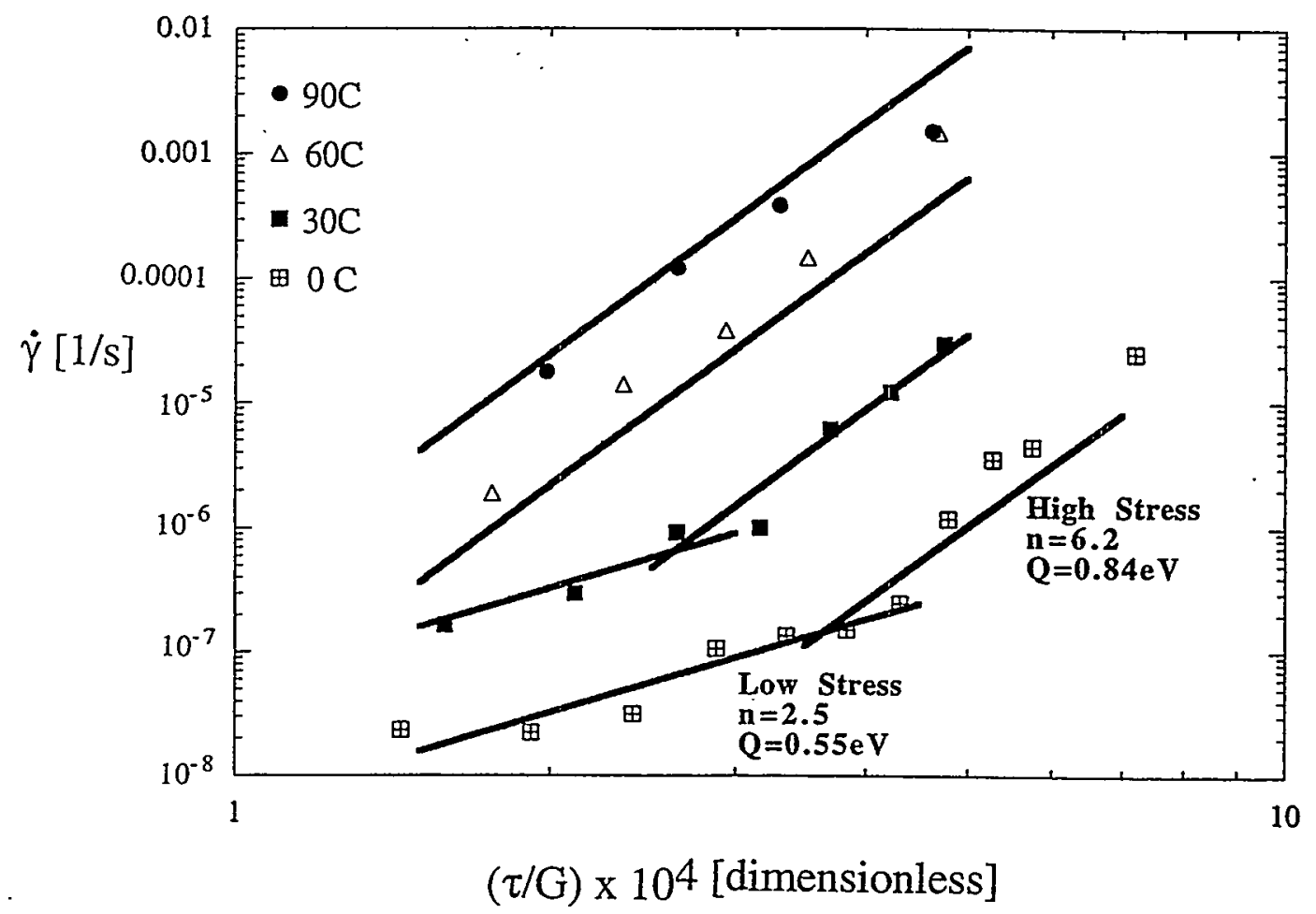

Figure 4.2. Creep behavior of In- $\mathrm{Ag}$ eutectic joints. Data shown are average values. [6] 


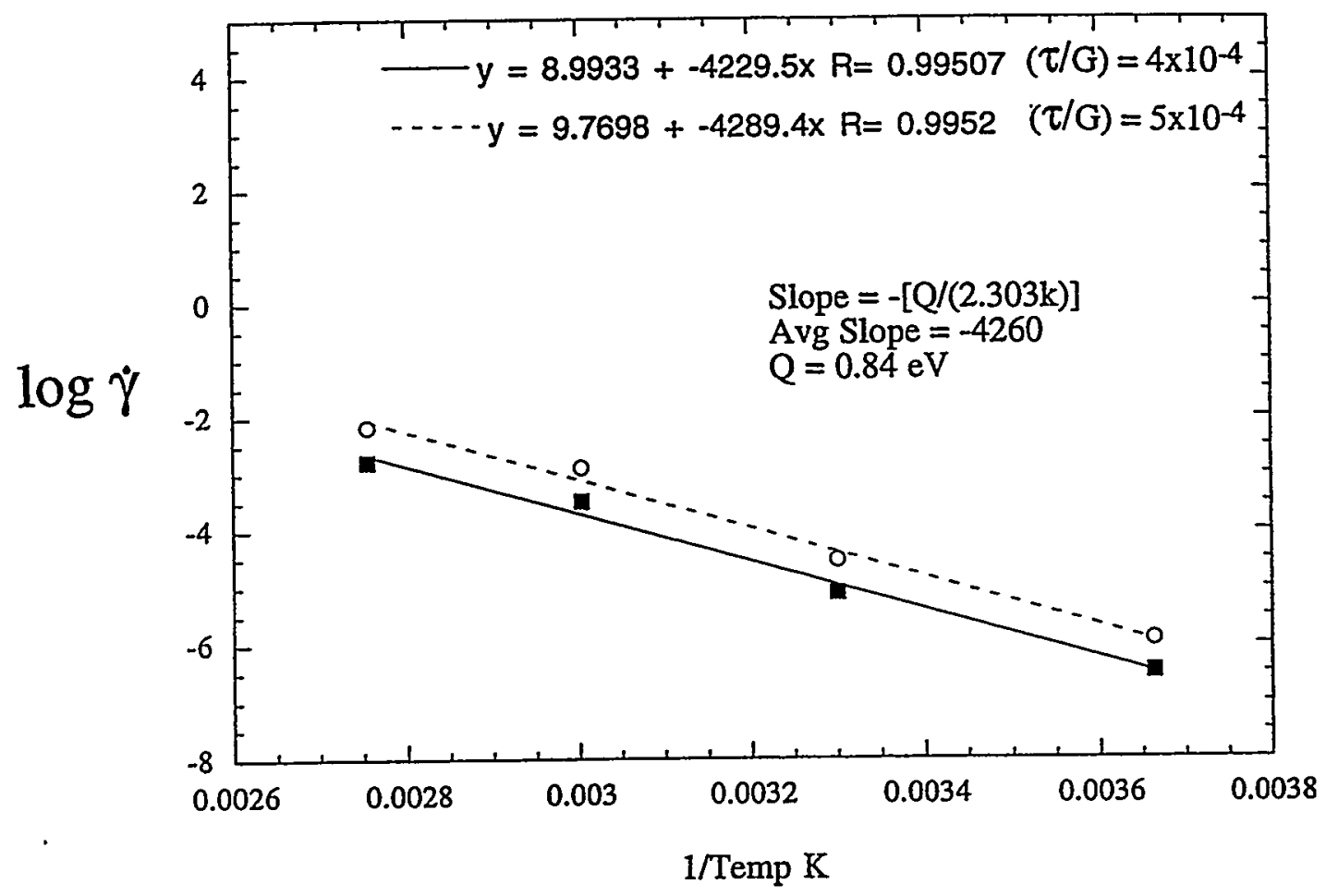

Figure 4.3(a). Plot illustrating the determination of creep activation energy for In-Ag eutectic joints in the (a) high stress regime 


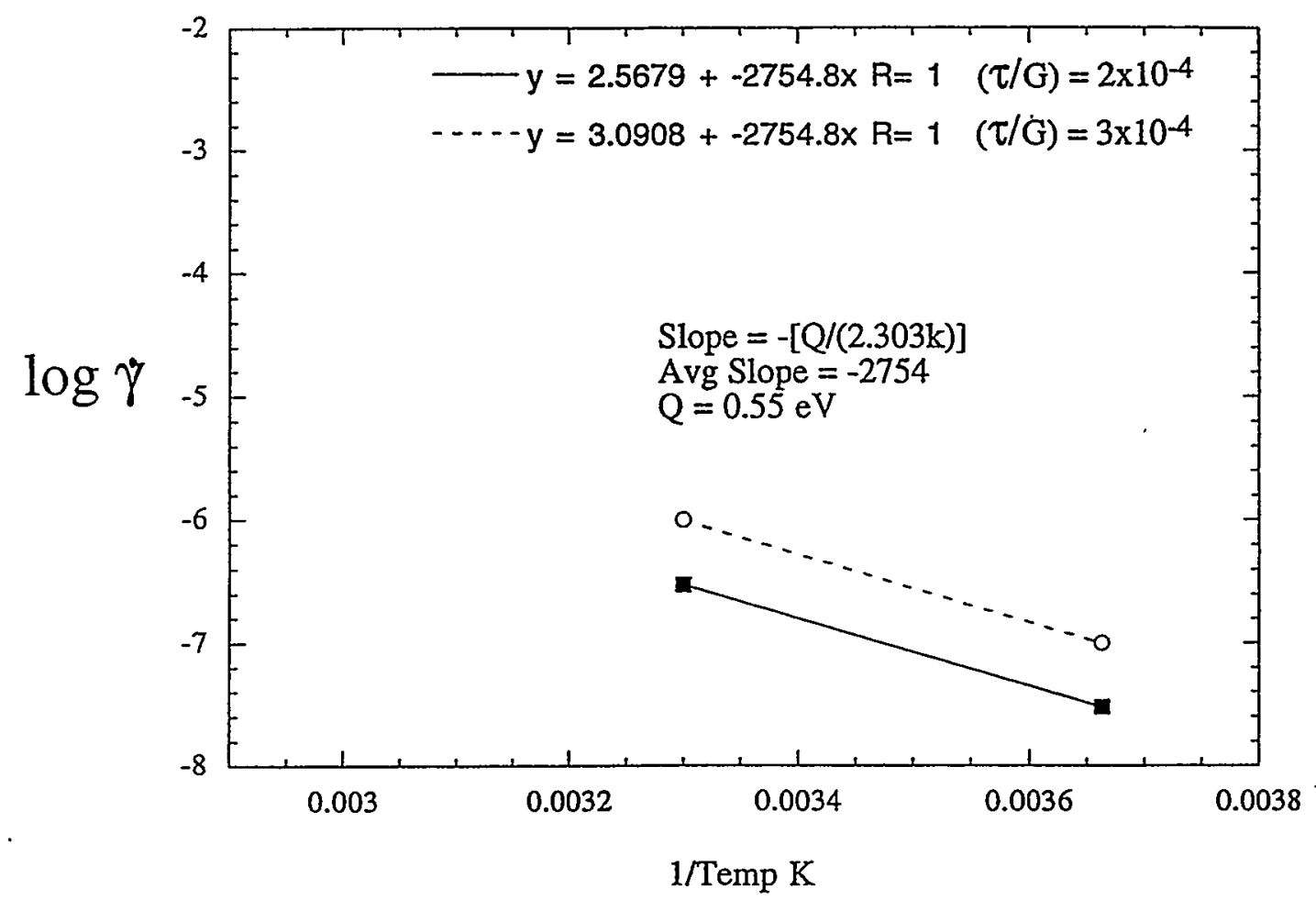

Figure 4.3(b). Plot illustrating the determination of creep activation energy for In- $\mathrm{Ag}$ eutectic joints in the (b) low stress regime.[6] 


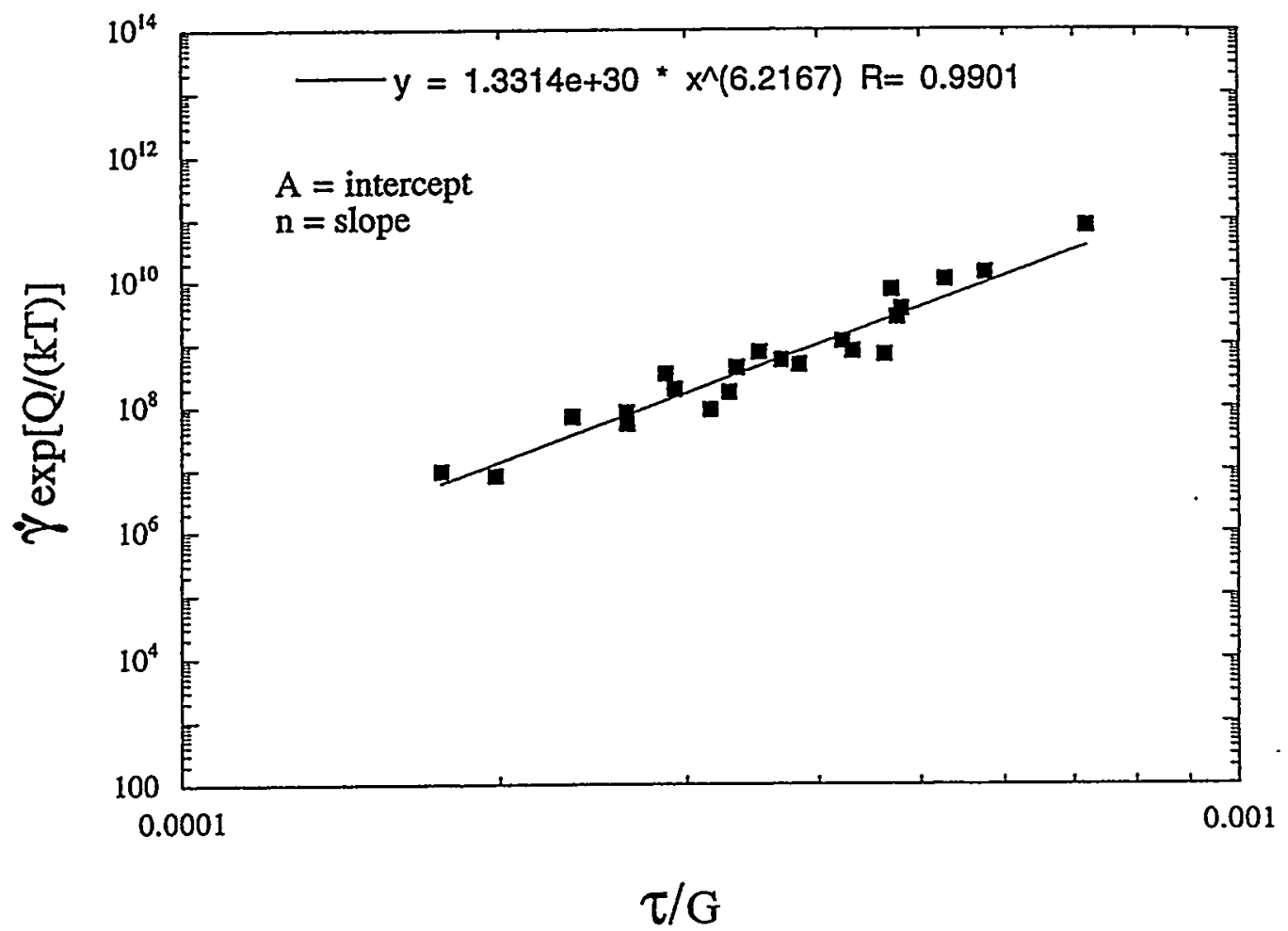

Figure 4.4(a). Plot showing the temperature-compensated creep rate as a function of reduced stress for In-Ag eutectic joints. Assuming the following values for $Q$, constitutive parameters $A$ and $n$ can be obtained.[6]

(a) high stress regime, $\mathrm{Q}=0.84 \mathrm{eV}$ 


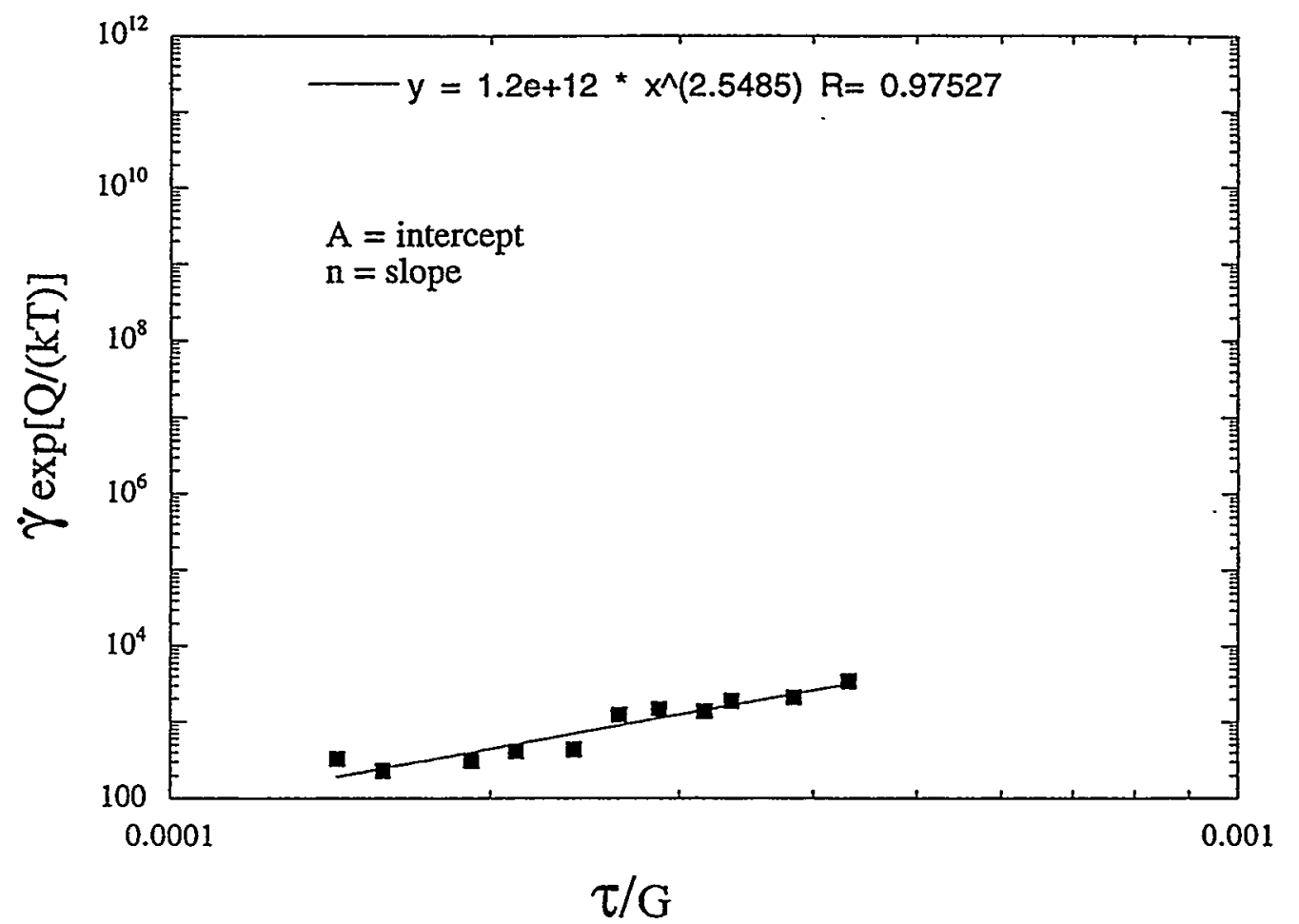

Figure 4.4(b). Plot showing the temperature-compensated creep rate as a function of reduced stress for $\mathrm{In}-\mathrm{Ag}$ eutectic joints. Assuming the following values for $\mathrm{Q}$, constitutive parameters $\mathrm{A}$ and $\mathrm{n}$ can be obtained.[6]

(b) low stress regime, $\mathrm{Q}=0.55 \mathrm{eV}$ 

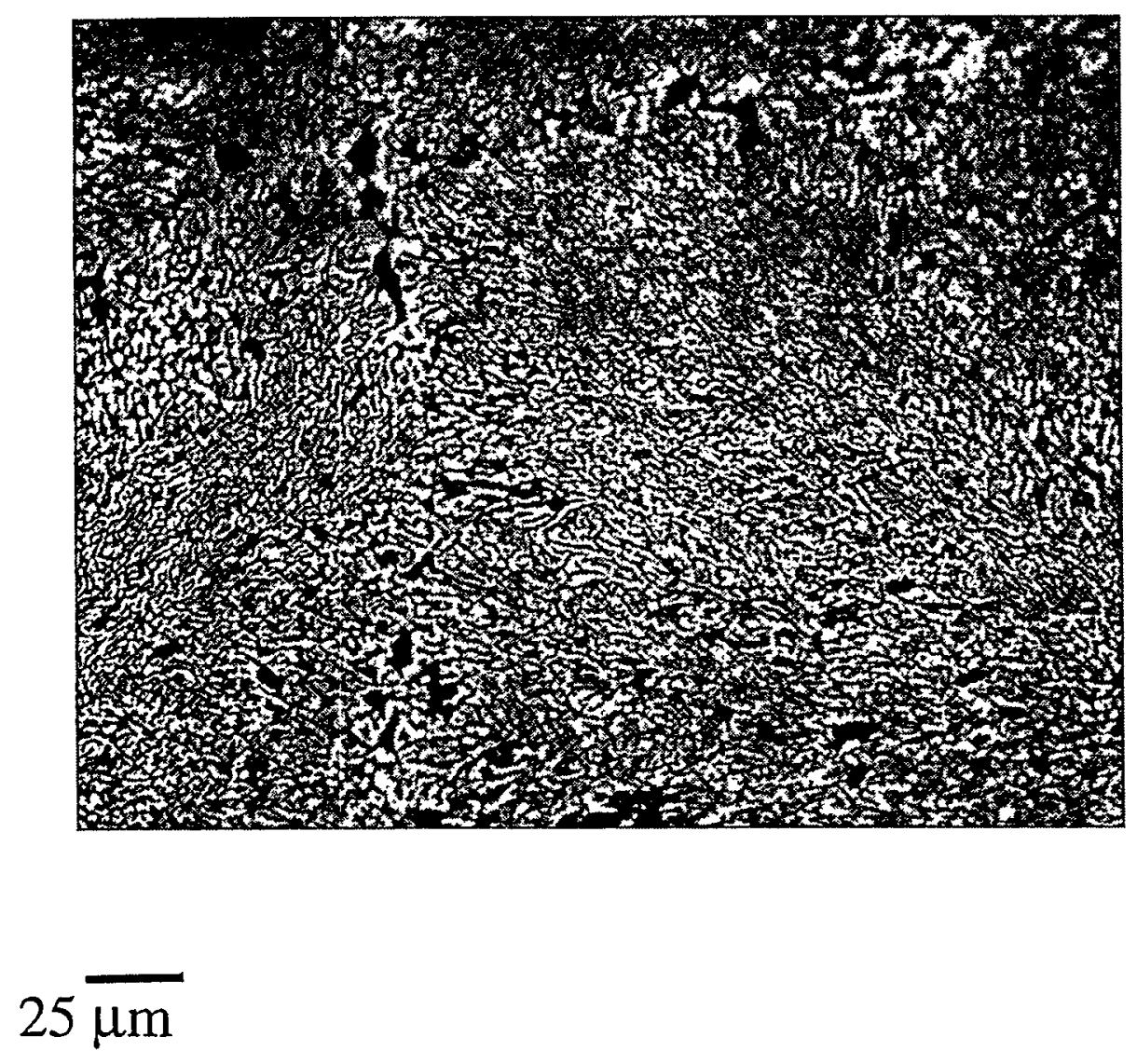

Figure 4.5(a). Optical micrograph of Sn-Bi eutectic joint showing lamellar microstructure. Cooling Rate $-20^{\circ} \mathrm{C} / \mathrm{min}$.

(a) Low Magnification 


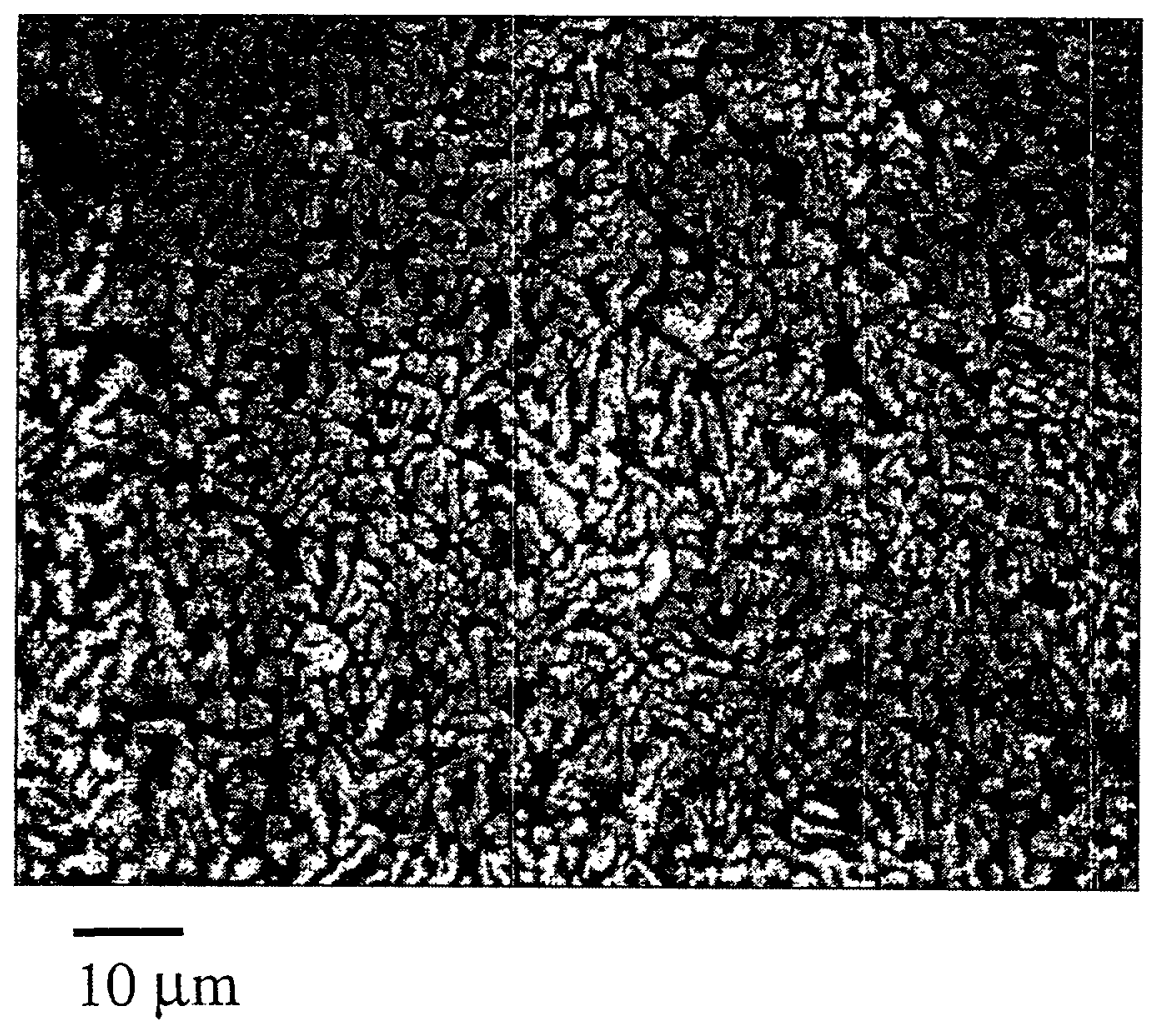

Figure 4.5(b). Optical micrograph of Sn-Bi eutectic joint showing lamellar microstructure. Cooling Rate $-20^{\circ} \mathrm{C} / \mathrm{min}$.

(b) High Magnification 


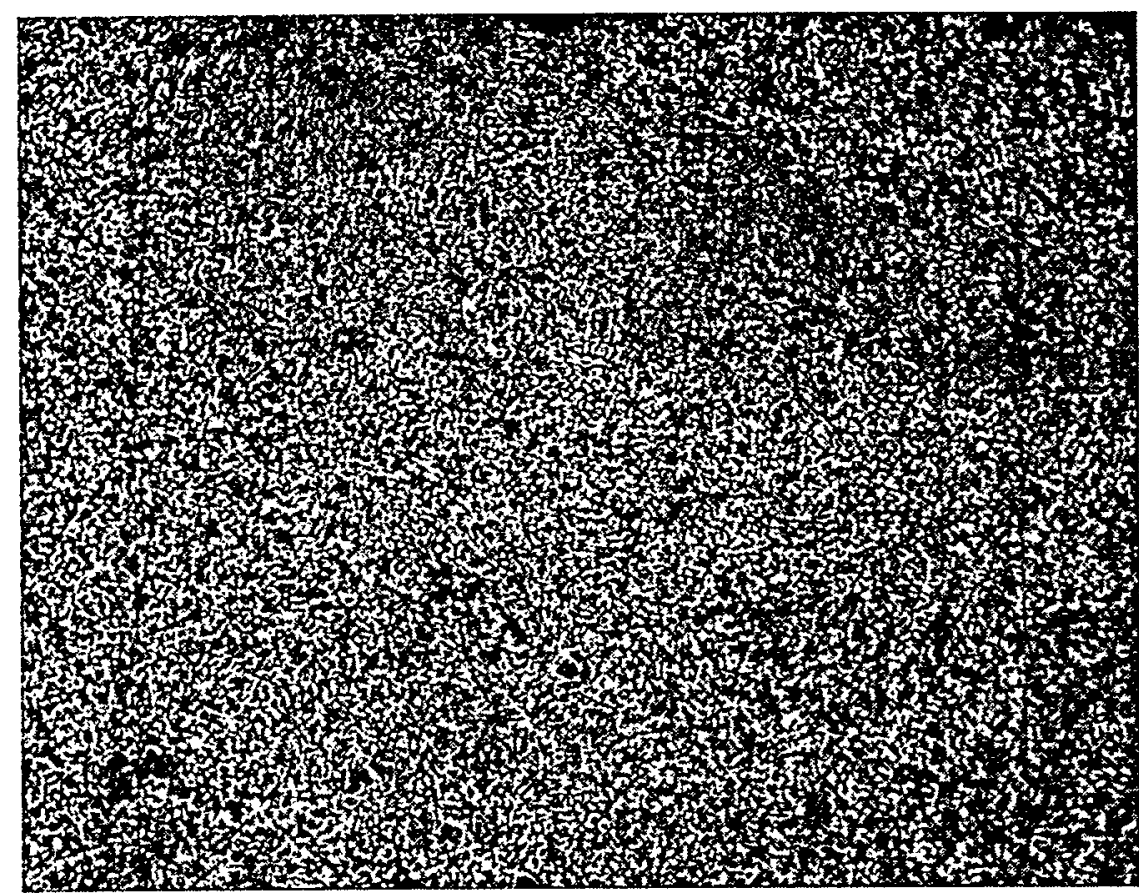

$25 \mu \mathrm{m}$

Figure 4.6(a). Optical micrograph of Sn-Bi eutectic joint quenched in ice water, showing a finer, yet still lamellar microstructure.

(a) Low Magnification 


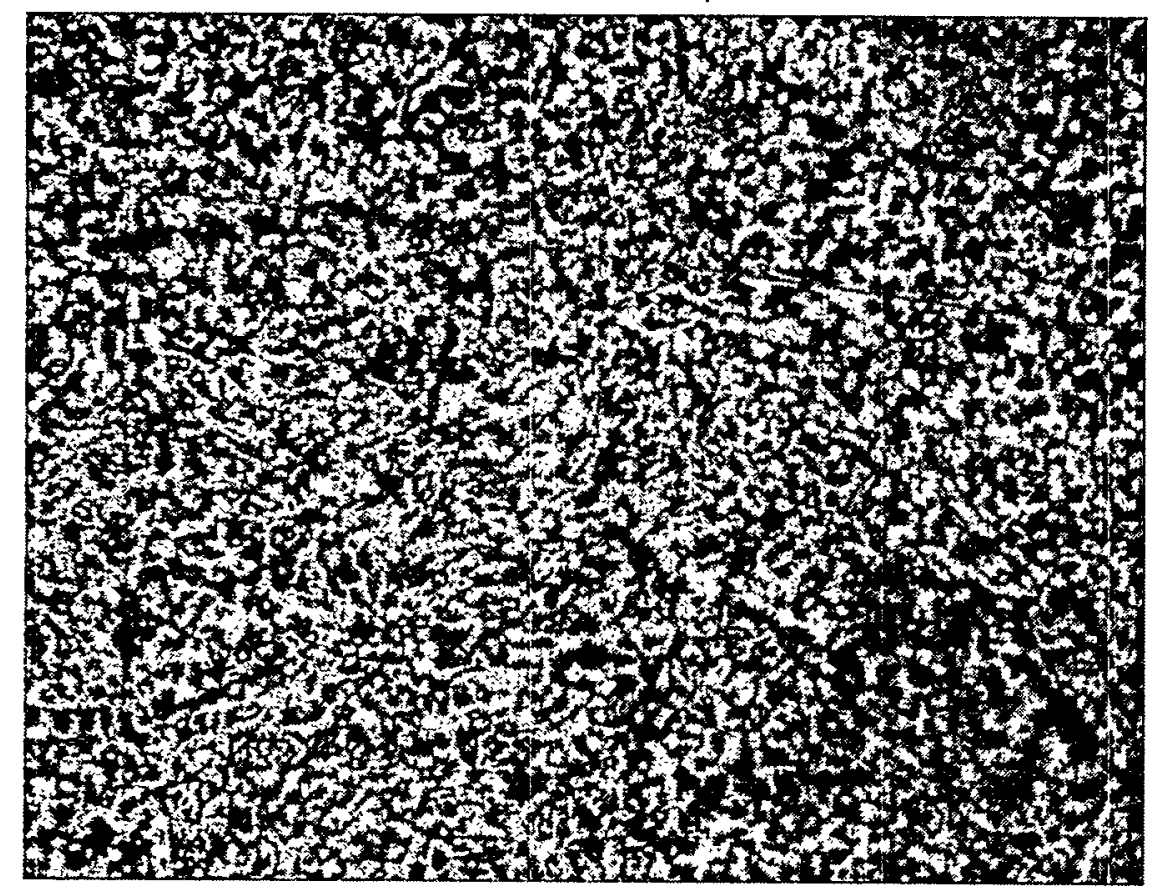

$10 \overline{\mu \mathrm{m}}$

Figure 4.6(b). Optical micrograph of Sn-Bi eutectic joint quenched in ice water, showing a finer, yet still lamellar microstructure.

(b) High Magnification 


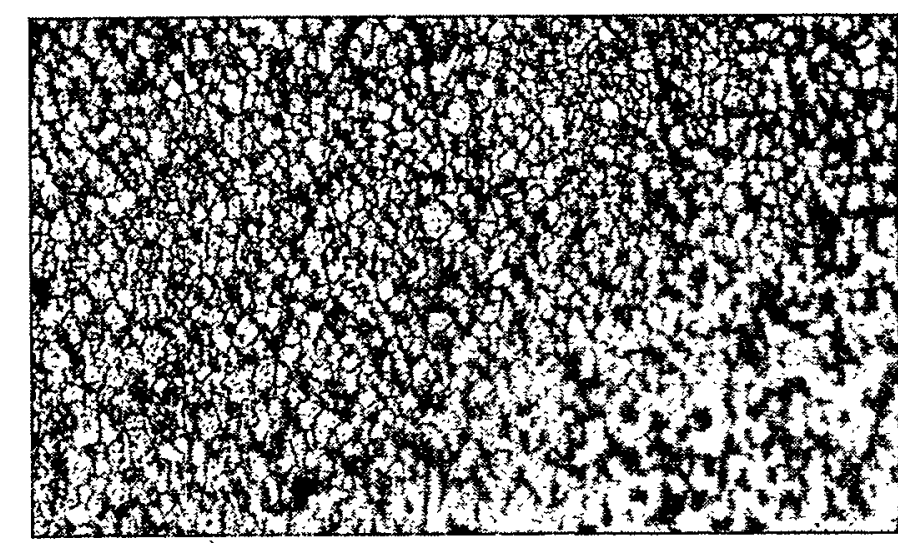

$25 \overline{\mu \mathrm{m}}$

Figure 4.7. Optical micrograph of Sn-Bi eutectic bulk specimen after $50 \%$ reduction and annealing at $95^{\circ} \mathrm{C}$ for 1 hour. Microstructure is fine and equiaxed. 


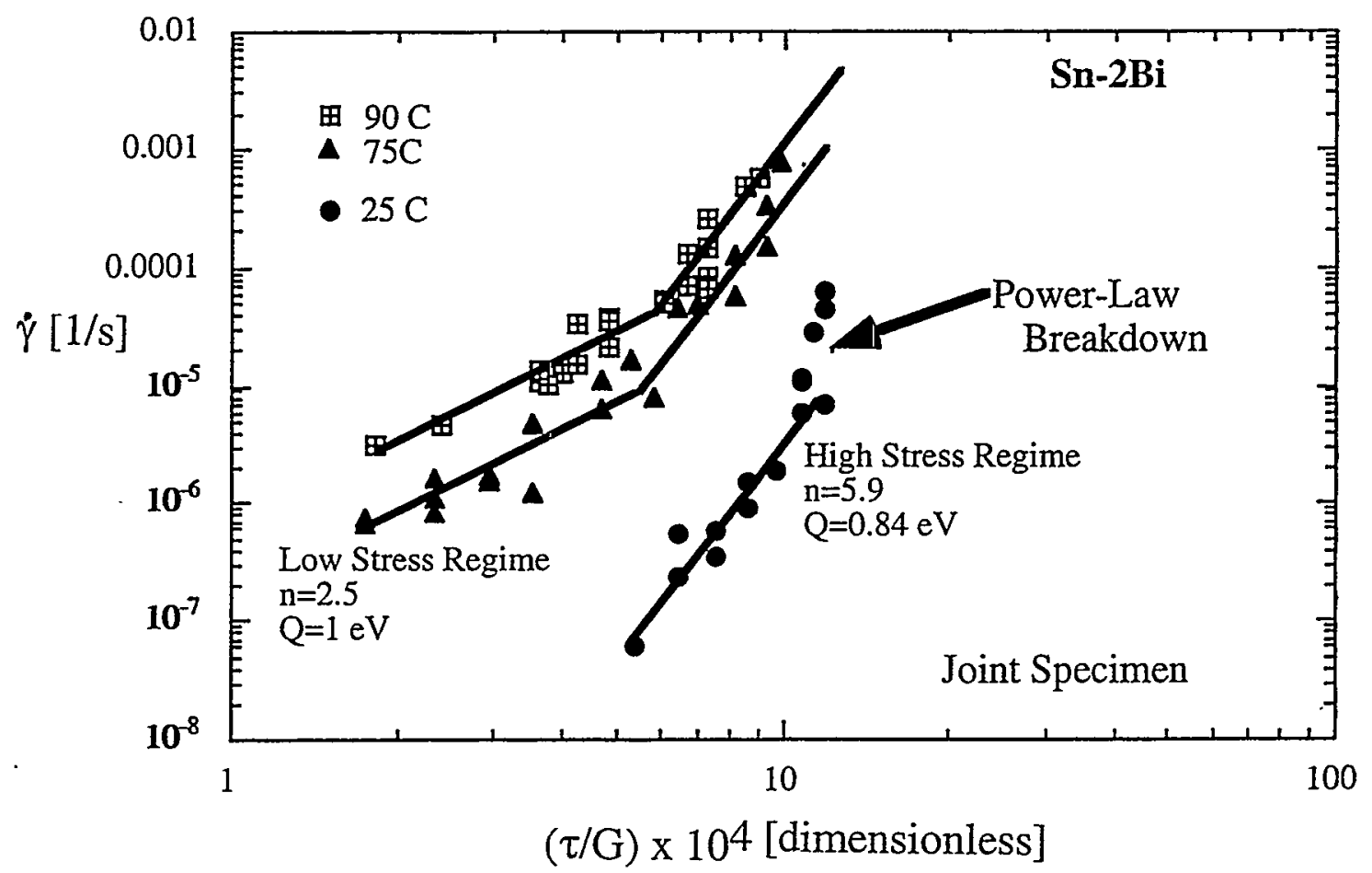

Figure 4.8. Creep behavior of Sn-2Bi solid solution joints. 


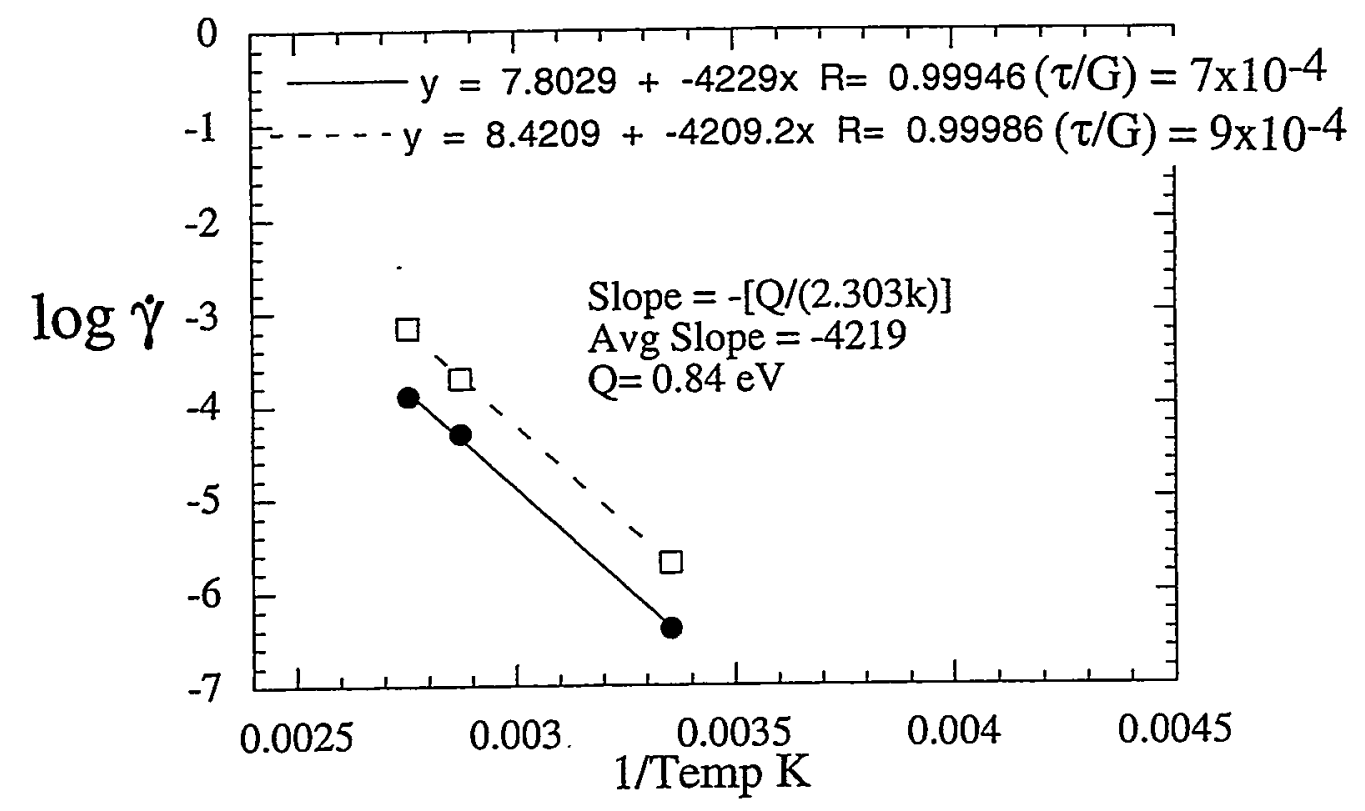

Figure 4.9(a). Plot illustrating the determination of creep activation energy for $\mathrm{Sn}-2 \mathrm{Bi}$ solid solution joints in the(a)high stress regime. 


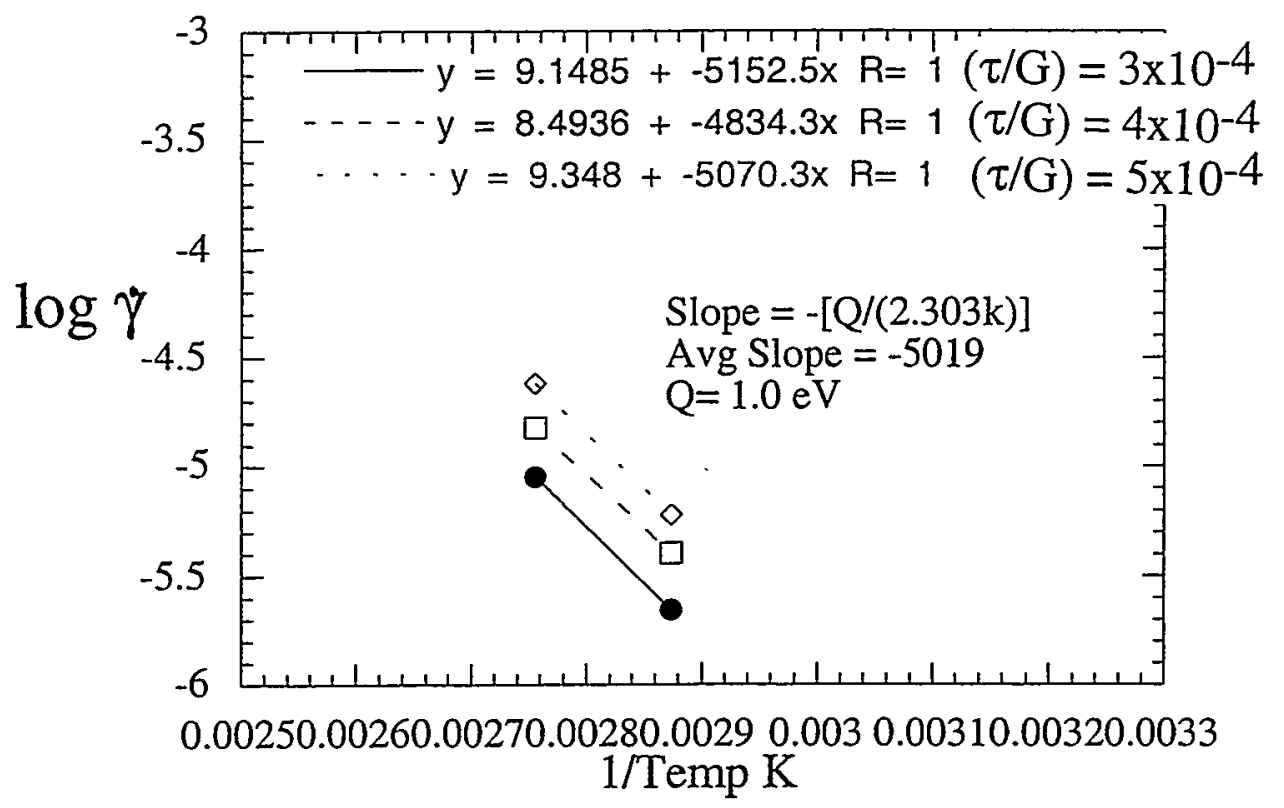

Figure 4.9(b). Plot illustrating the determination of creep activation energy for $\mathrm{Sn}-2 \mathrm{Bi}$ solid solution joints in the (b)low stress regime. 


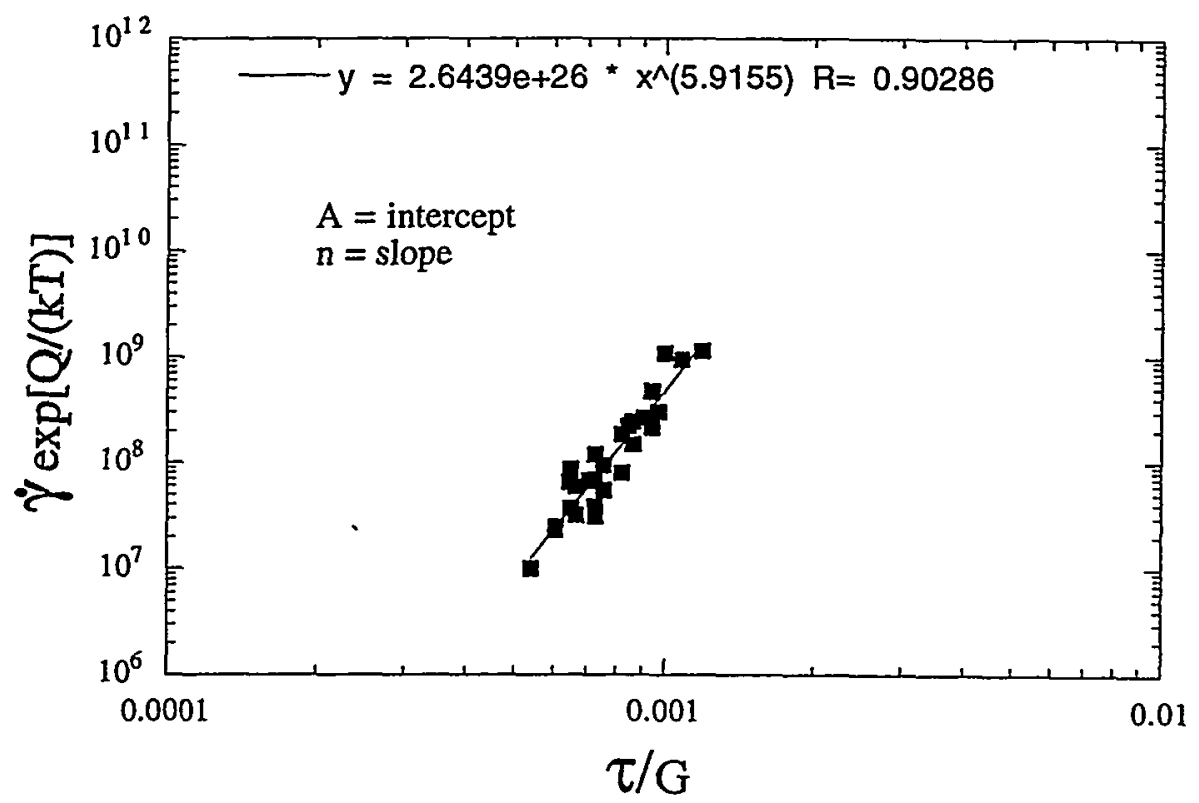

Figure 4.10(a). Plot showing the temperature-compensated creep rate as a function of reduced stress for $\mathrm{Sn}-2 \mathrm{Bi}$ solid solution joints. Assuming the following values for $\mathrm{Q}$, constitutive parameters $\mathrm{A}$ and $\mathrm{n}$ can be obtained.

(a) high stress regime, $\mathrm{Q}=0.84 \mathrm{eV}$ 


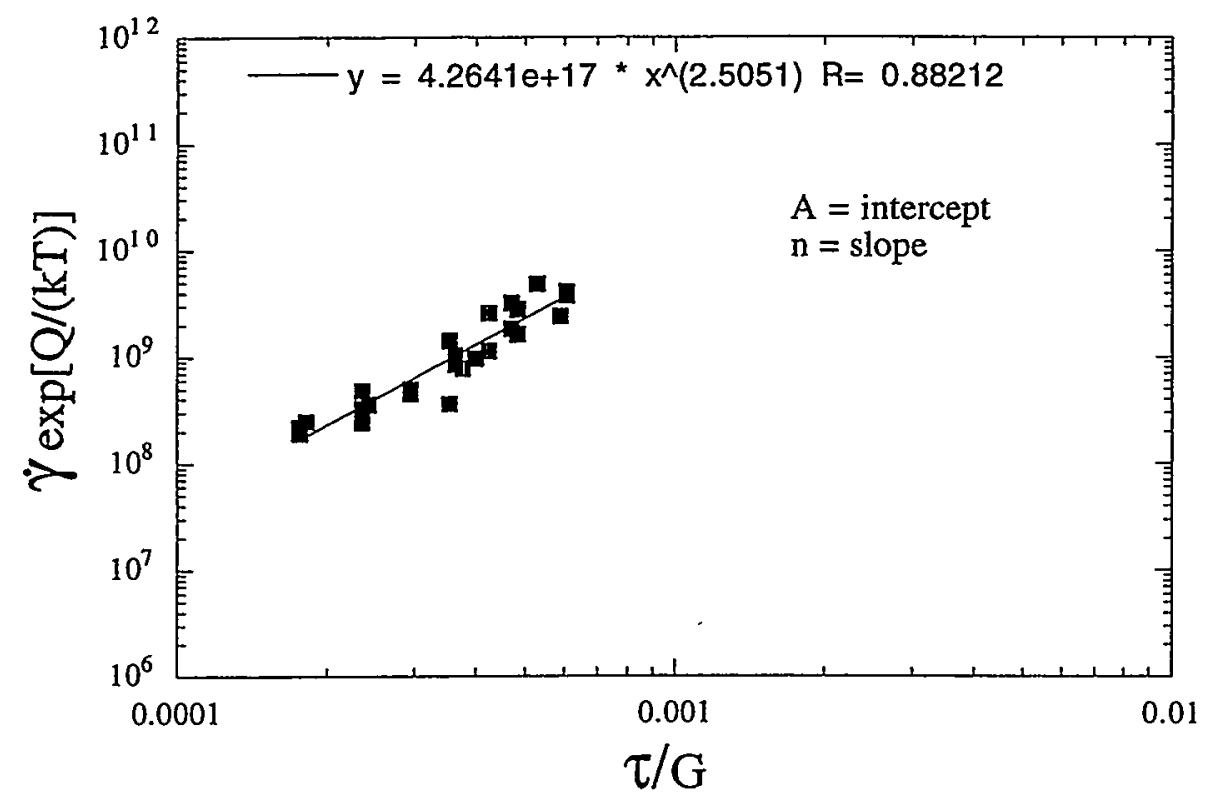

Figure 4.10(b) Plot showing the temperature-compensated creep rate as a function of reduced stress for Sn-2Bi solid solution joints. Assuming the following values for $\mathrm{Q}$, constitutive parameters $\mathrm{A}$ and $\mathrm{n}$ can be obtained.

(b) low stress regime, $\mathrm{Q}=1.0 \mathrm{eV}$ 


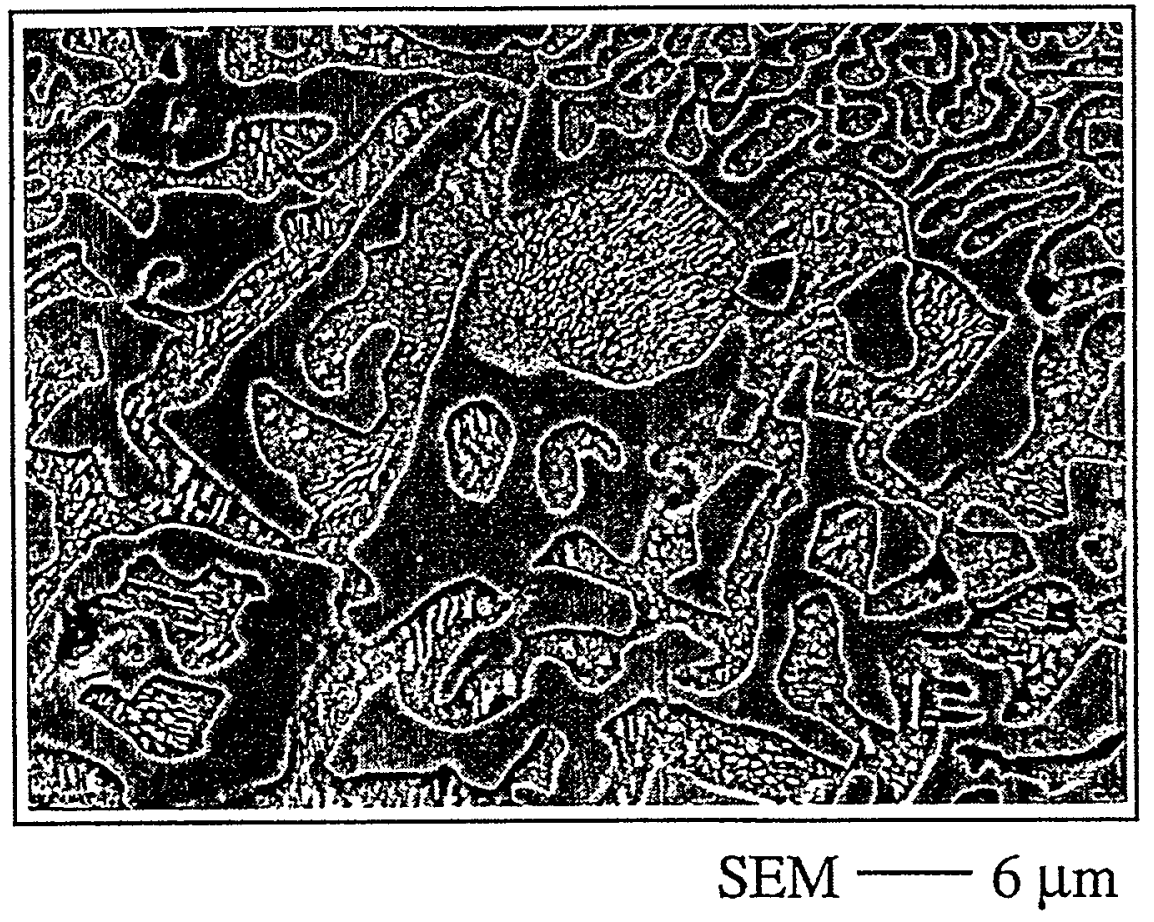

Figure 4.11. SEM micrograph of Sn-Bi eutectic. Bi precipitates can be seen within the Sn-rich phase. [63] 


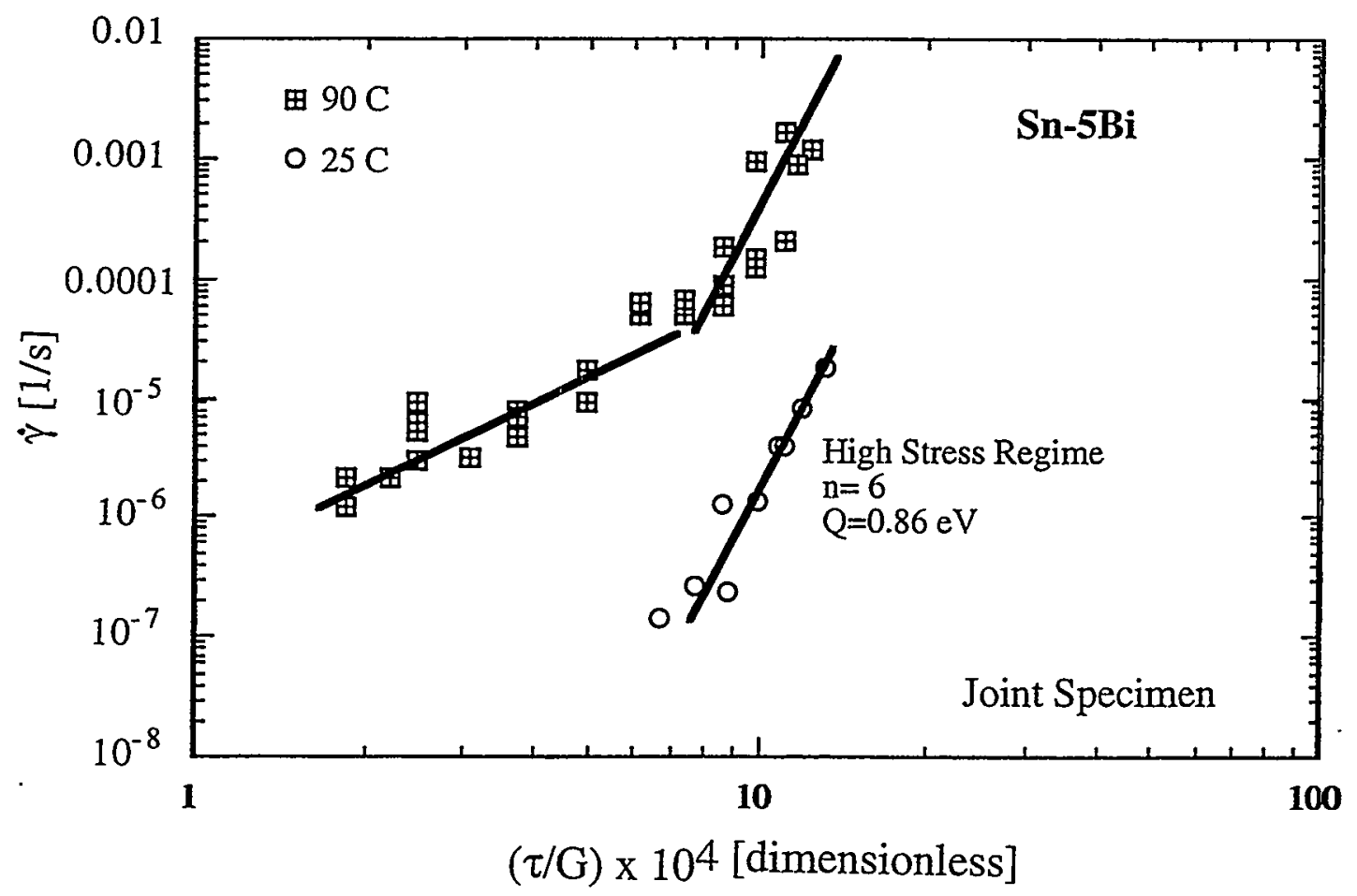

Figure 4.12 Creep behavior of Sn-5Bi joints. 


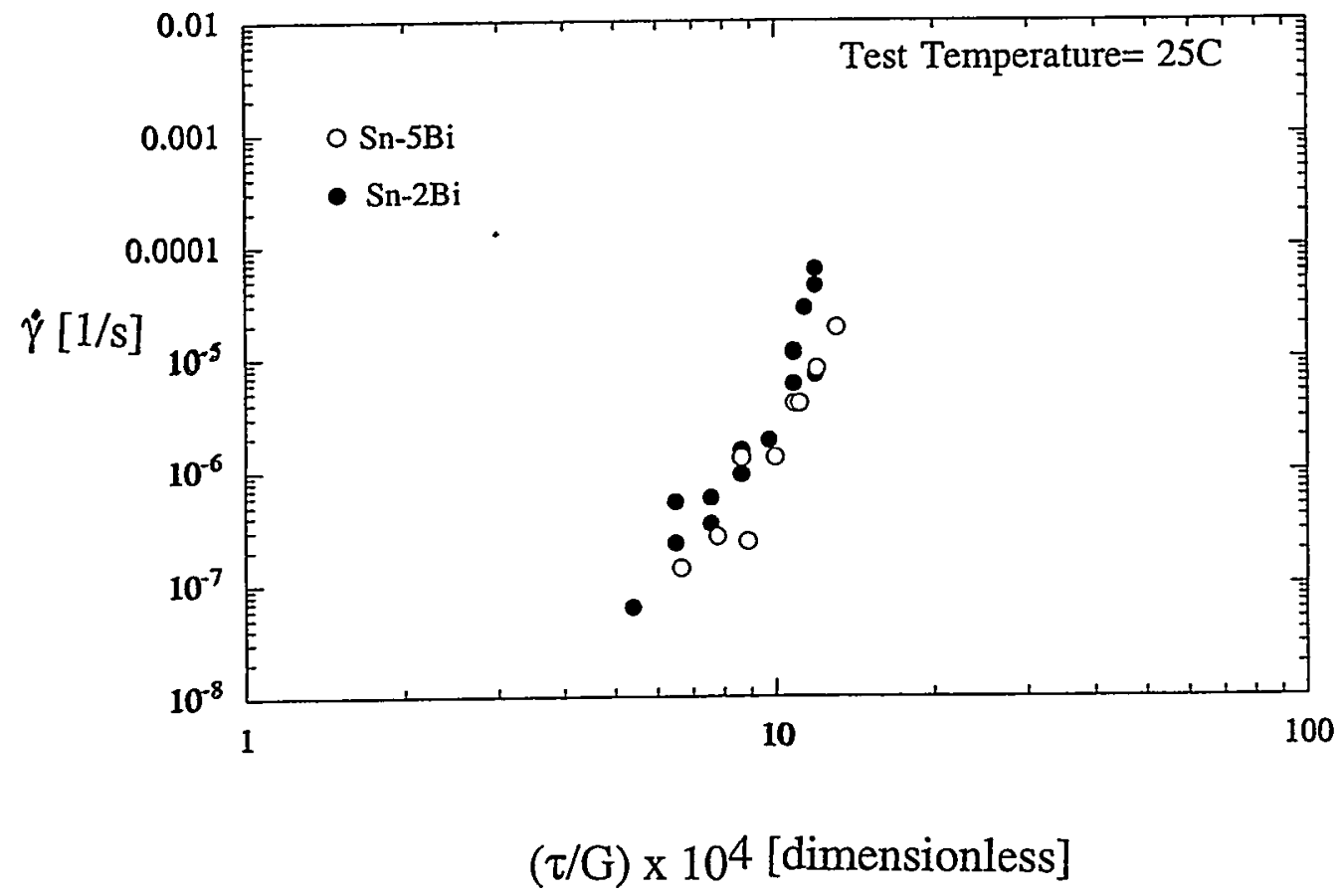

Figure 4.13 Comparison of creep behavior of $\mathrm{Sn}-2 \mathrm{Bi}$ and $\mathrm{Sn}-5 \mathrm{Bi}$ joints at $25^{\circ} \mathrm{C}$. 


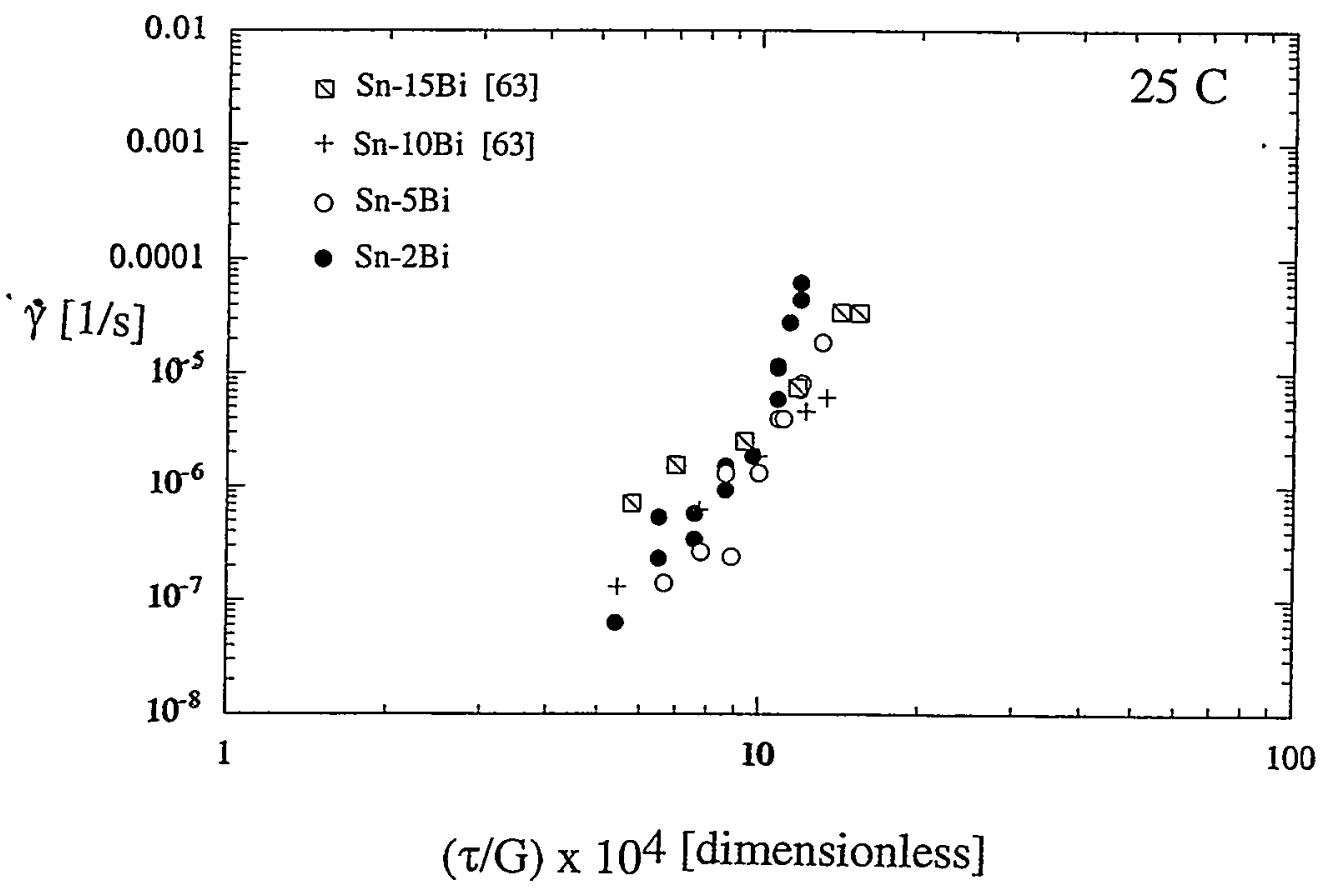

Figure 4.14. Comparison of creep behavior of $\mathrm{Sn}-2 \mathrm{Bi}, \mathrm{Sn}-5 \mathrm{Bi}, \mathrm{Sn}-10 \mathrm{Bi}$, and $\mathrm{Sn}-15 \mathrm{Bi}$ joints at $25^{\circ} \mathrm{C}$. 


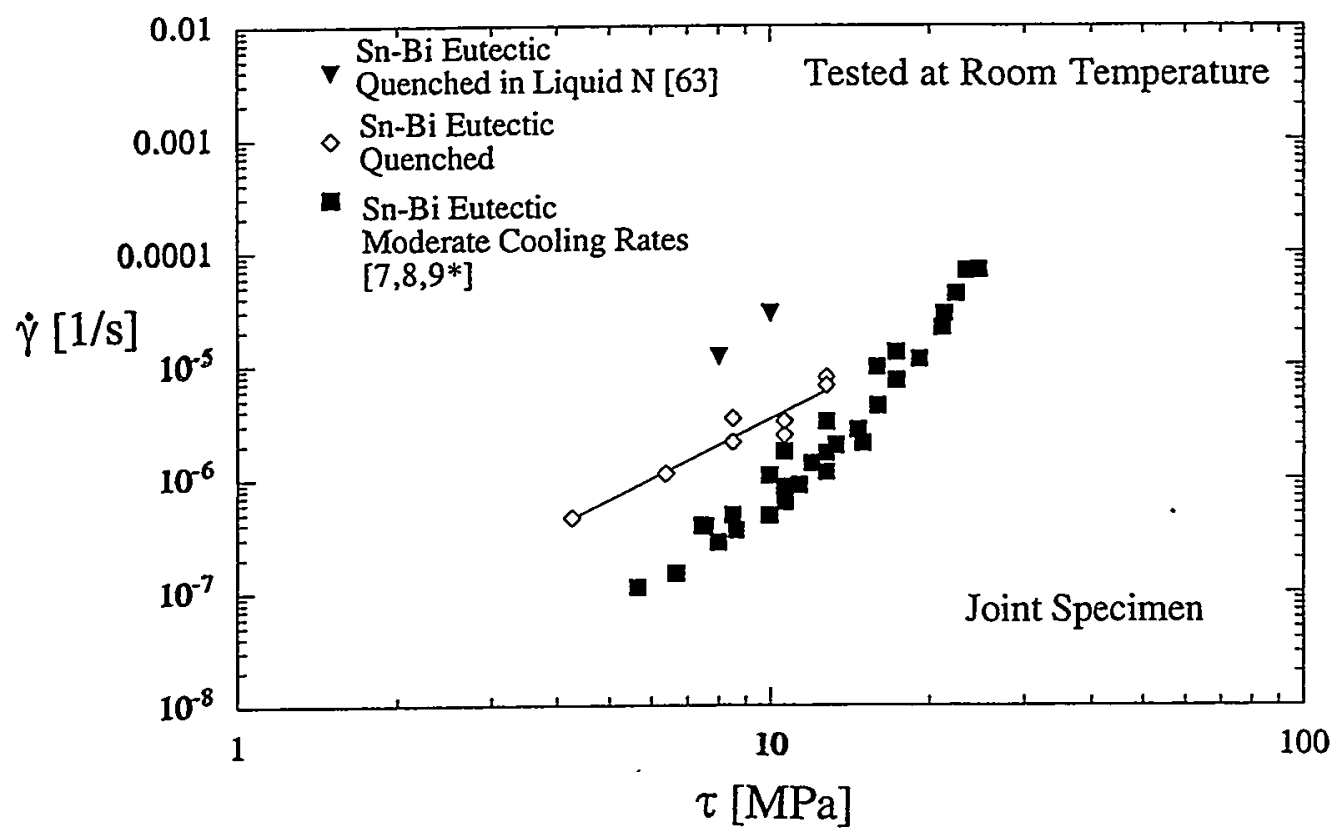

Figure 4.15. Creep behavior of quenched Sn-Bi eutectic joints compared with creep behavior of Sn-Bi eutectic joints cooled at moderate rates.

Creep tests were conducted at room temperature. 


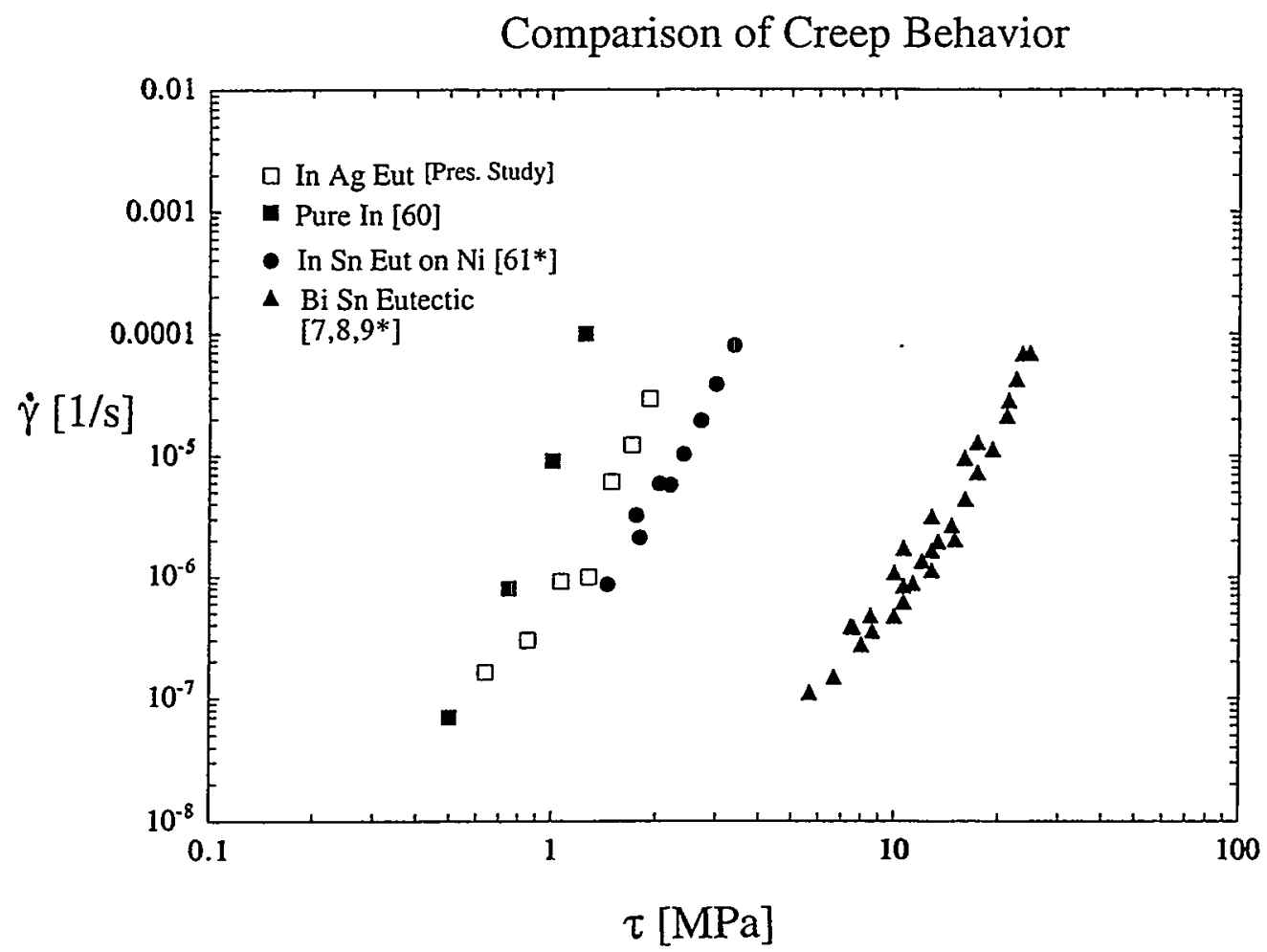

Figure 5.1. Comparison of joint creep behavior for pure In and In-Ag, In-Sn, and Bi-Sn eutectics.[6] (See Appendix B.) 


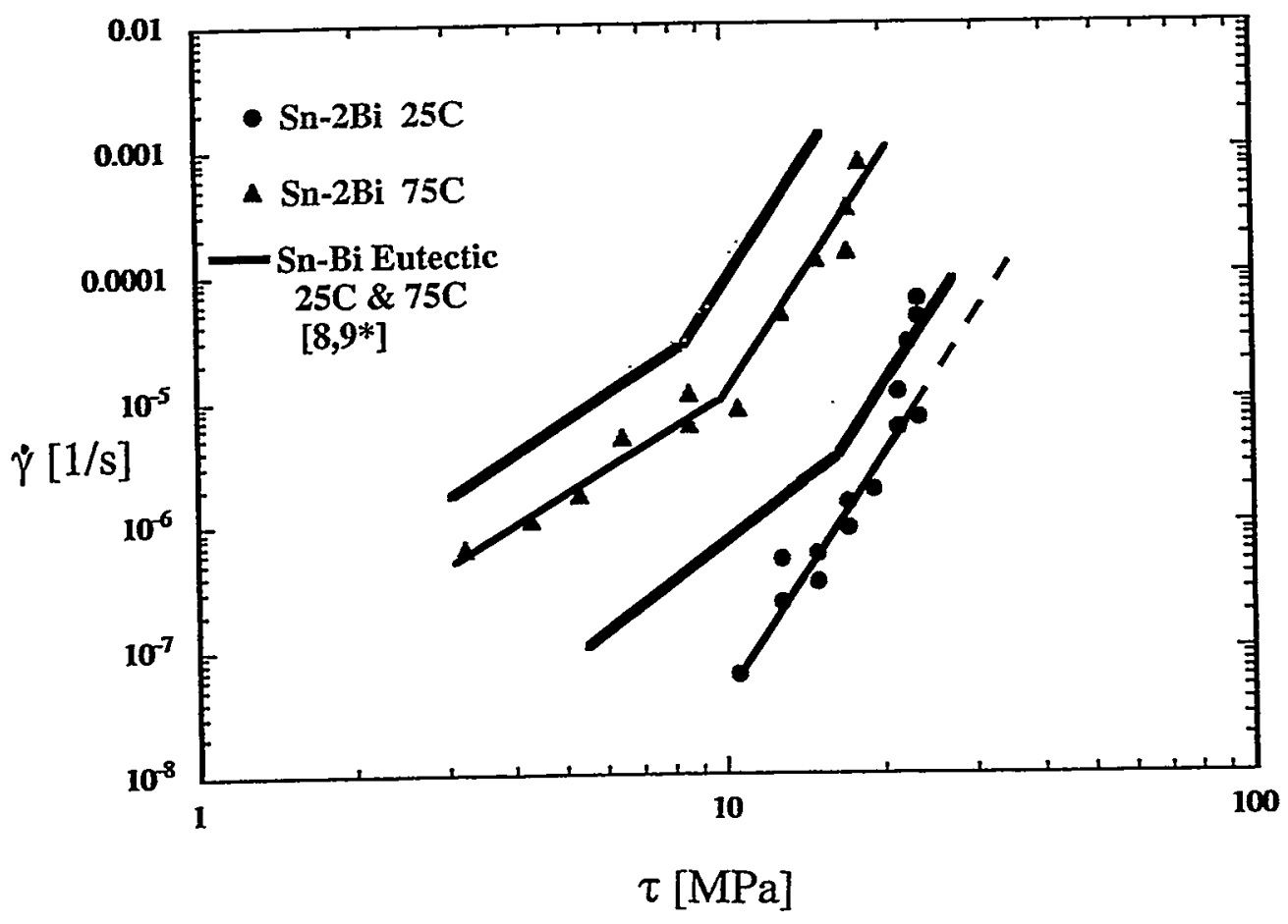

Figure 5.2. Comparison of joint creep behavior for $\mathrm{Sn}-2 \mathrm{Bi}$ solid solution and $\mathrm{Sn}-\mathrm{Bi}$ eutectic at $25^{\circ} \mathrm{C}$ and $75^{\circ} \mathrm{C}$. 


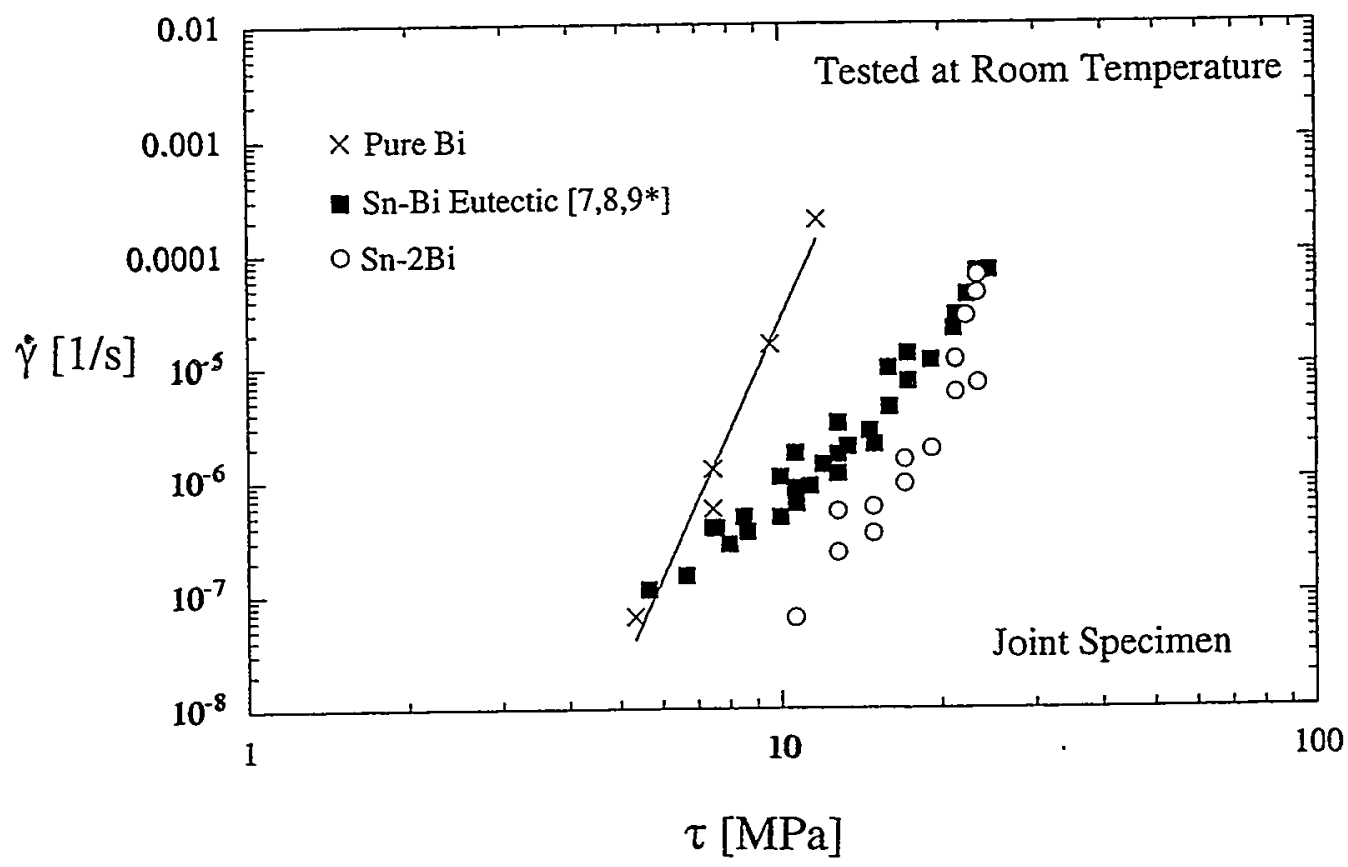

Figure 5.3. Comparison of joint creep behavior for $\mathrm{Sn}-2 \mathrm{Bi}$ solid solution, $\mathrm{Sn}-\mathrm{Bi}$ eutectic and pure $\mathrm{Bi}$ at room temperature. 


\section{In-Ag Eutectic Joint Data}

(Creep behavior predicted by model is shown by lines.)

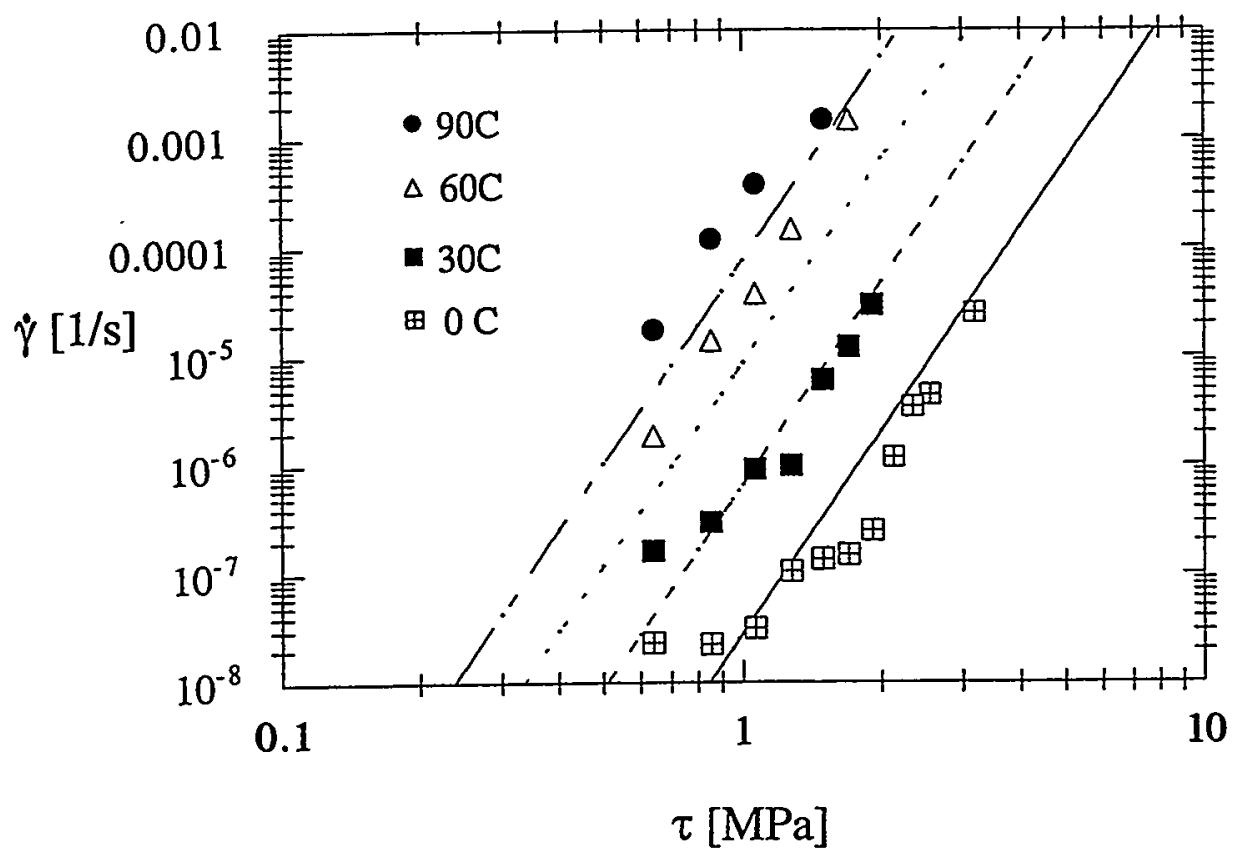

Figure 5.4. Steady-state creep rates of In-Ag eutectic joints compared with steady-state creep rates predicted from the continuum mechanics model proposed by Ravichandran and Seetharaman [37]. 


\section{Sn-Bi Eutectic Joint Data $25 \mathrm{C}$ and $75 \mathrm{C}\left[8,9^{*}\right]$}

(Creep behavior predicted by model is shown by lines.)

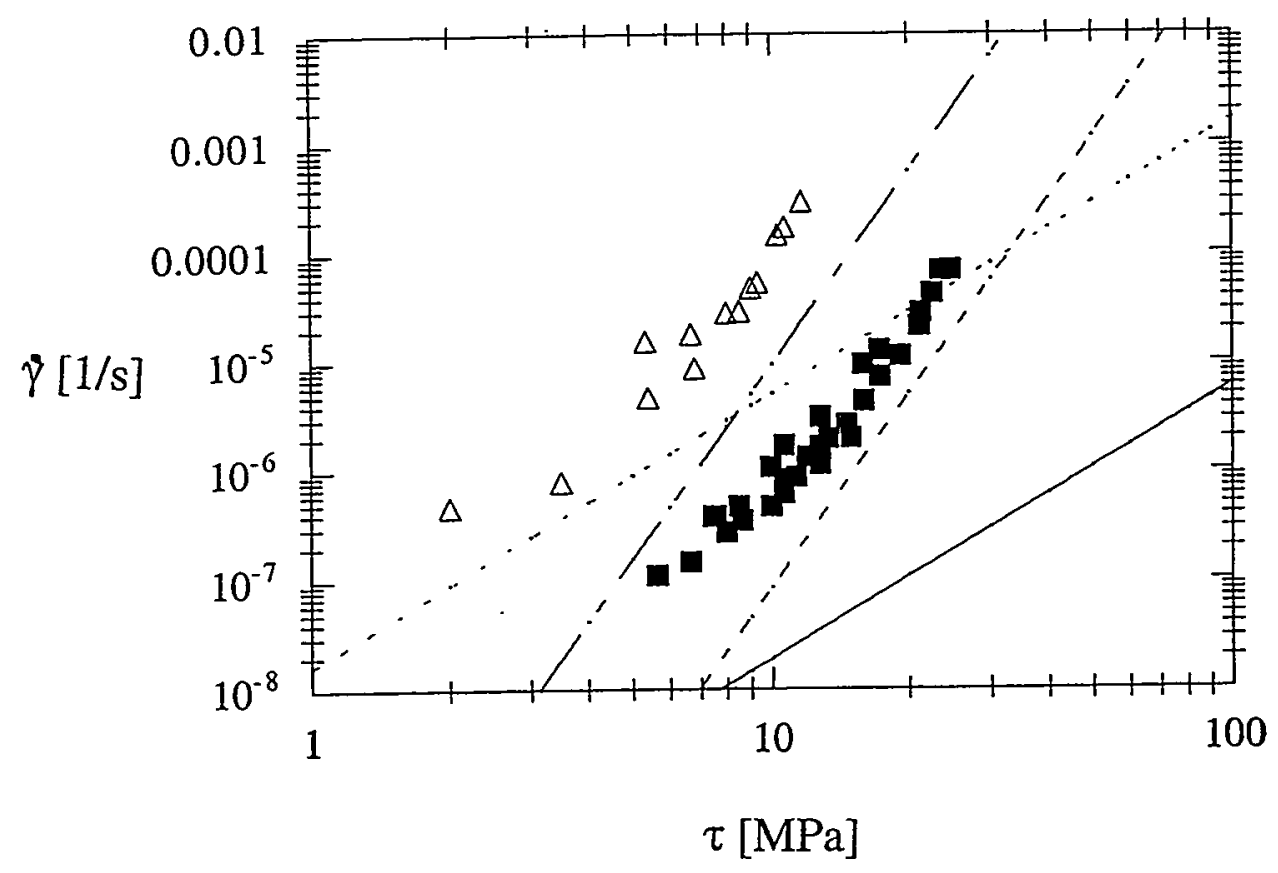

Figure 5.5. Steady-state creep rates of Sn-Bi eutectic joints compared with steady-state creep rates predicted from the continuum mechanics model proposed by Ravichandran and Seetharaman [37]. 


\section{APPENDICES}

\section{Appendix A}

Two-Phase Creep Model - Ravichandran and Seetharaman (1993)

Refer to Section 2.4.1.3.

Ravichandran and Seetharaman [37] use a continuum mechanics-based model to predict the steady-state behavior of particulate composites containing coarse, rigid reinforcements based on the creep behavior of the matrix and volume fraction of the constituents. This model derives expressions for the steady-state creep behavior of two phase systems, using a unit cell representative of the microstructure. This idealized microstructure is illustrated in Figure A.1. Cubic inclusions of the second phase are distributed uniformly in a continuous matrix. The approach used by Ravichandran and Seetharaman [37] involves dividing the unit cell into parallel and series elements shown in Figure A.2. The elements in Figure A.2 are loaded uniaxially and assumed to undergo creep deformation under isostrain and isostress conditions. The two series elements add up to form an element in the parallel configuration as illustrated in Figure A.3 where the elemental volume fractions are shown. The second phase has a volume fraction, $V_{p}$, and given the dimensions in Figure A.1, is related to the non-dimensional quantity $\mathrm{c}=\mathrm{h} / \mathrm{a}$ as:

$$
c=\left[\frac{1}{V_{p}}\right]^{\frac{1}{3}}-1 \quad \text { where } V_{p}+V_{m}=1
$$


The elemental volume fractions shown in Figure A.3 can all be expressed in terms of c:

$$
\begin{aligned}
& \mathrm{V}_{1}=\frac{\text { volume of element } 1}{\text { volume of unit cell }}=\frac{1}{(1+\mathrm{c})^{2}} \\
& \mathrm{~V}_{2}=\frac{\text { volume of element } 2}{\text { volume of unit cell }}=1-\frac{1}{(1+\mathrm{c})^{2}} \\
& \mathrm{~V}_{3}=\frac{\text { volume of element } 3}{\text { volume of element } 1}=\frac{1}{(1+\mathrm{c})} \\
& \mathrm{V}_{4}=\frac{\text { volume of element } 4}{\text { volume of element } 1}=\frac{\mathrm{c}}{(1+\mathrm{c})}
\end{aligned}
$$

Assuming the creep behavior of the matrix and particle reinforment are known and have the following form:

$$
\begin{aligned}
& \dot{\varepsilon}_{\mathrm{m}}=\mathrm{K}_{\mathrm{m}} \sigma^{\mathrm{n}_{\mathrm{m}}} \\
& \dot{\varepsilon}_{\mathrm{p}}=\mathrm{K}_{\mathrm{p}} \sigma^{\mathrm{n}_{\mathrm{p}}}
\end{aligned}
$$

the creep rate of the composite can be determined by calculating the creep rates of the elemental volume fractions, $\mathrm{V}_{1}, \mathrm{~V}_{2}, \mathrm{~V}_{3}$, and $\mathrm{V}_{4}$. The total creep rate of element 1 in Figure A.3a is the sum of the creep rates of series elements 3 and 4 in Figure A.3b. Therefore:

$$
\dot{\varepsilon}_{1}=\dot{\varepsilon}_{3} \mathrm{~V}_{3}+\dot{\varepsilon}_{4} \mathrm{~V}_{4}
$$

The particles $\left(V_{p}\right)$ are considered non-deformable, so $\varepsilon_{3}=0$ and substituting for $V_{4}$, Eq. (A8) becomes:

$$
\dot{\varepsilon}_{1}=\dot{\varepsilon}_{4} \frac{c}{(1+c)}
$$


From Eq. (A6), it follows that the creep rates of elements 1 and 2 are:

$$
\begin{gathered}
\dot{\varepsilon}_{1}=\left[\frac{\mathrm{c}}{(1+\mathrm{c})}\right] \mathrm{K}_{\mathrm{m}} \sigma_{1}^{\mathrm{n}_{\mathrm{m}}} \\
\text { and } \\
\dot{\varepsilon}_{2}=\mathrm{K}_{\mathrm{m}} \sigma_{2}^{{ }^{\mathrm{n}_{\mathrm{m}}}}
\end{gathered}
$$

The strain rates of elements 1 and 2 are equal, therefore, combining Eqs. (A10) and (A11) gives a relationship between the stresses in elements 1 and 2:

$$
\sigma_{1}=\sigma_{2}\left(\frac{1+c}{c}\right)^{\frac{1}{n_{m}}}
$$

The stress applied to the composite is:

$$
\sigma_{\mathrm{c}}=\sigma_{1} \mathrm{~V}_{1}+\sigma_{2} \mathrm{~V}_{2}
$$

or, substituting for $\mathrm{V}_{1}$ and $\mathrm{V}_{2}$ :

$$
\sigma_{c}=\frac{\sigma_{1}}{(1+c)^{2}}+\sigma_{2}\left(1-\frac{1}{(1+c)^{2}}\right)
$$

From Eqs. (A12) and (A14)

$$
\sigma_{2}=\left[\frac{\sigma_{c}(1+c)^{2}}{\left(\frac{1+c}{c}\right)^{\frac{1}{n_{m}}}+(1+c)^{2}-1}\right]
$$

Recall that $\dot{\varepsilon}_{c}=\dot{\varepsilon}_{1}=\dot{\varepsilon}_{2}$. Applying Eq. (A11) gives the composite creep rate in terms of the matrix parameters:

$$
\dot{\varepsilon}_{c}=K_{m}\left[\frac{\sigma_{c}(1+c)^{2}}{\left(\frac{(1+c)}{c}\right)^{\frac{1}{n_{m}}}+(1+c)^{2}-1}\right]^{n_{m}}
$$


The geometrical characteristics of the microstructure must also be considered. If the matrix phase is constrained between two rigid second phase particles, illustrated schematically in Figure A.4, then this microstructural constraint would influence the creep of element 4 in Figure A.3b. The stress in Eq. (A10) should be replaced by an effective stress, $\sigma_{1} / \phi$, where $\phi$ is the constraint factor given by [74]

$$
\phi=\left[1.0184+0.295\left(\frac{d}{h}\right)\right] .
$$

As a first approximation, the parameters $\mathrm{d}$ and $\mathrm{h}$ can be considered to represent the mean particle diameter, a, and the thickness of the matrix, respectively. Therefore, incorporating the microstructural constraint factor, and substituting $(1 / \mathrm{c})$ for $(\mathrm{d} / \mathrm{h})$ the steady-state creep rate of the composite is given by:

$$
\dot{\varepsilon}_{\mathrm{c}}=\mathrm{K}_{\mathrm{m}}\left[\frac{\sigma_{c}(1+\mathrm{c})^{2}}{\left(1+\frac{0.3}{\mathrm{c}}\right)\left(\frac{(1+\mathrm{c})}{\mathrm{c}}\right)^{\frac{1}{n_{\mathrm{m}}}}+(1+\mathrm{c})^{2}-1}\right]^{\mathrm{n}_{\mathrm{m}}}
$$




\section{Appendix A}

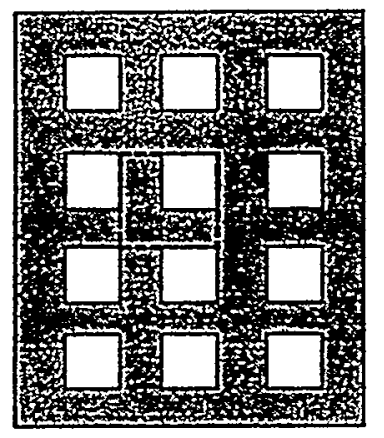

(a)

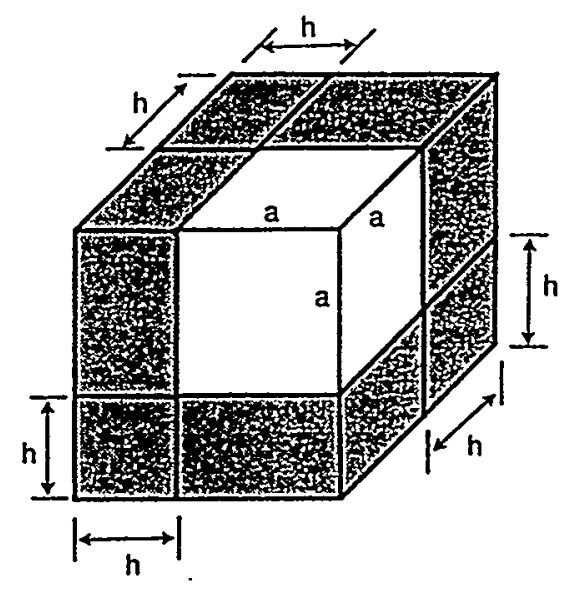

(b)

Figure A.1. Schematics of the idealized microstructure of the composite (a) in two dimensions and (b) the unit cell.[37] 
Appendix A

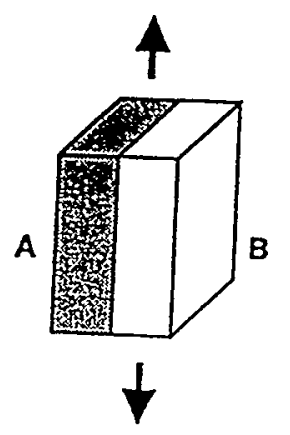

(a)

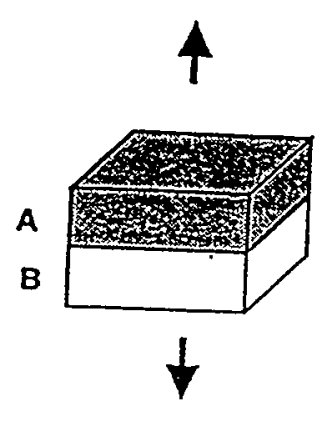

(b)

Figure A.2. Schematics of a bimaterial loaded in (a) parallel and (b) series.[37] 


\section{Appendix A}

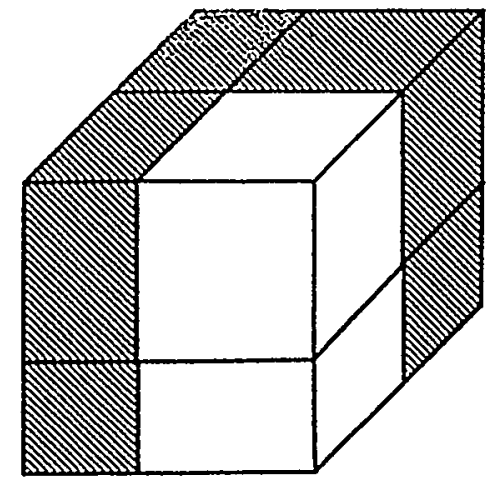

(a)

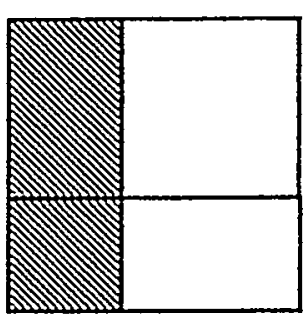

(c)

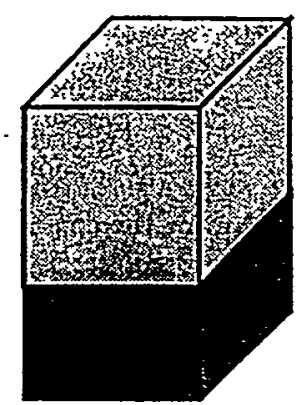

(b)

Element

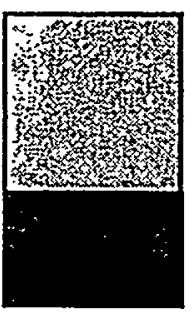

1<smiles>[Al]C1CCC1</smiles>

2

$v_{2}$

3

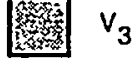

4

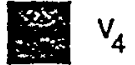

(d)

Figure A.3. Schematics of divisions of the unit cell into several elements, (a) and (b) representing the 3D model for particulate composites and (c) and (d) representing the $2 \mathrm{D}$ model for the transverse orientation of reinforced composites.[37] 


\section{Appendix A}

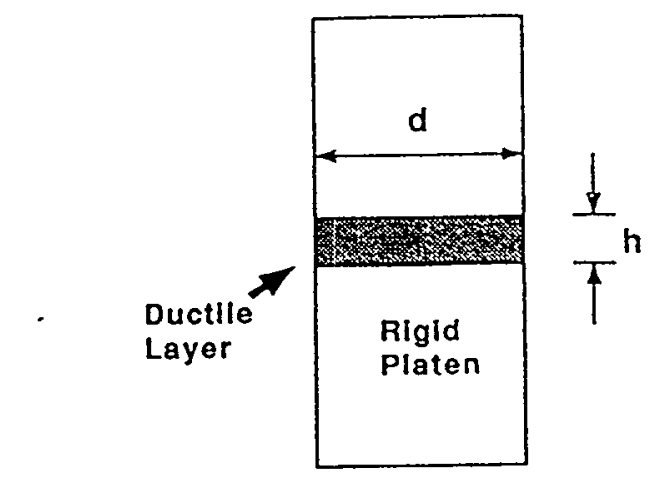

Figure A.4. A schematic of a ductile layer between two rigid platens.[37] 


\section{Appendix B}

Creep data from references $\left[9^{*}\right]$ and $\left[61^{*}\right]$ have been corrected. The sample geometry used in these studies is shown below in Figure B.1. The applied shear stress $(\tau)$ should be calculated as

$$
\tau=\mathrm{P} /(2 * \mathrm{x} * \mathrm{~h})
$$

rather than

$$
\tau=\mathrm{P} /(\mathrm{x} * \mathrm{~h})
$$

where $\mathrm{P}$ is the load, $\mathrm{x}$ is the length of the joint (central gage section length), and $\mathrm{h}$ is the sample thickness. Therefore, the applied shear stresses $(\tau)$ from references $9 *$ and $61^{*}$ have been reduced by a factor of two and are now consistant with other literature references.

\section{Corrected References}

[9*] J. L. F. Goldstein, Ph.D. Thesis, University of California at Berkeley, November 1993; and J. W. Morris, Jr., J. L. Freer Goldstein and Z. Mei, J. Metals, 45, 25 (1993).

[61*] J. L. Freer Goldstein and J. W. Morris, Jr., Metall. Mater. Trans., 25A, 2715 (1994). 


\section{Appendix B}

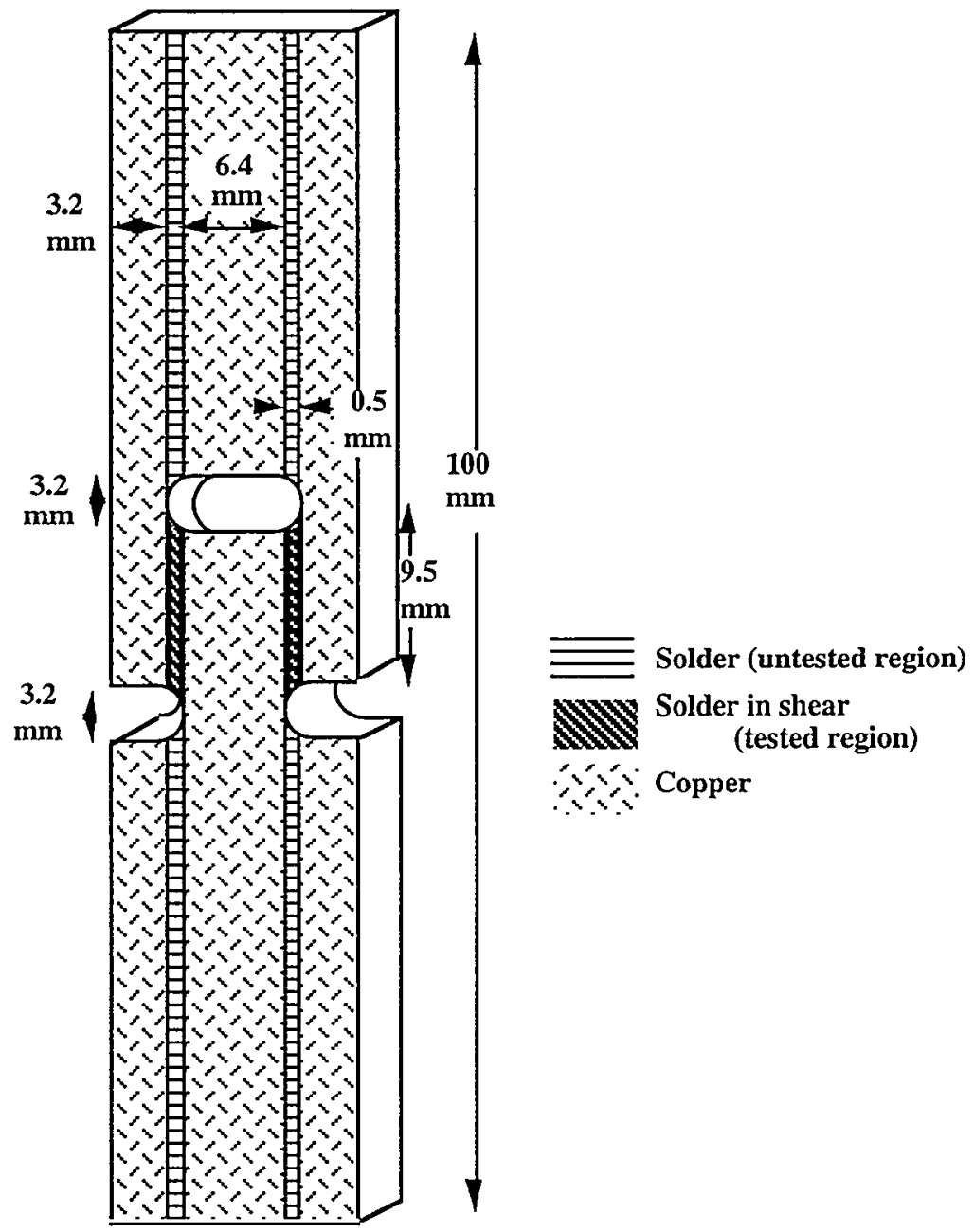

Figure B.1: Double-lap shear specimen. $[9 *, 61 *]$ 